Portland State University

PDXScholar

\title{
An Assessment of the Adequacy of the Services of an Urban Public University for International and U.S. Students: a Comparative Study
}

Alfonso Hernandez Pioquinto

Portland State University

Follow this and additional works at: https://pdxscholar.library.pdx.edu/open_access_etds

Part of the Higher Education Administration Commons

Let us know how access to this document benefits you.

\section{Recommended Citation}

Pioquinto, Alfonso Hernandez, "An Assessment of the Adequacy of the Services of an Urban Public University for International and U.S. Students: a Comparative Study" (1995). Dissertations and Theses. Paper 1279.

https://doi.org/10.15760/etd.1278

This Dissertation is brought to you for free and open access. It has been accepted for inclusion in Dissertations and Theses by an authorized administrator of PDXScholar. Please contact us if we can make this document more accessible: pdxscholar@pdx.edu. 


\section{DISSERTATION APPROVAL}

The abstract and dissertation of Alfonso Hernandez Pioquinto, Jr. for the Doctor of Education in Educational Leadership: Postsecondary were presented April 14, 1995, and accepted by the dissertation committee and the doctoral program.

COMMITTEE APPROVALS:
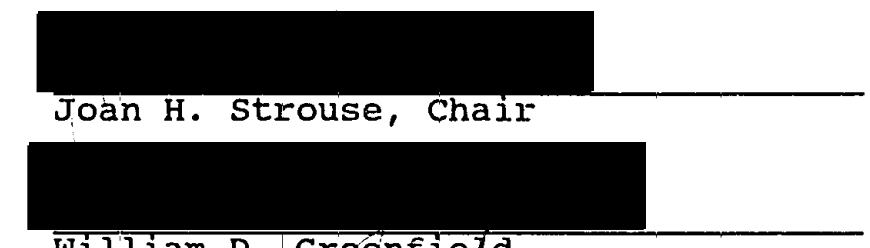
William D. Greenfield

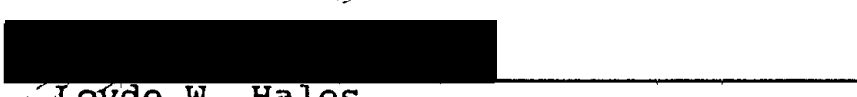
Coyde W. Hales

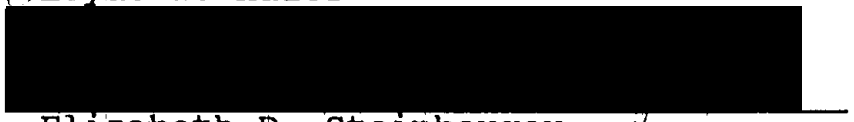

Elizabeth D. Steinberger

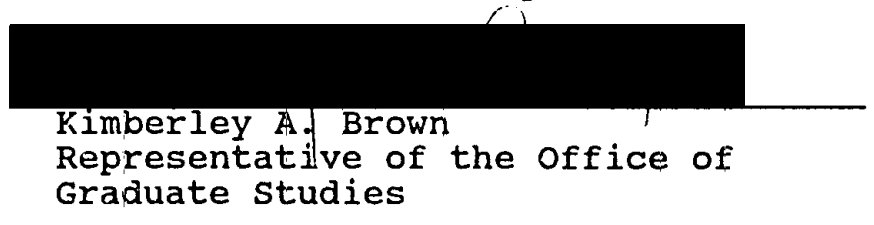

DOCTORAL PROGRAM APPROVAL:

Robert B. Everhart, Dean School of Education

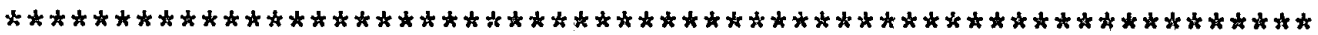
ACCEPTED FOR PORTLAND STATE UNIVERSITY BY THE LIBRARY by on

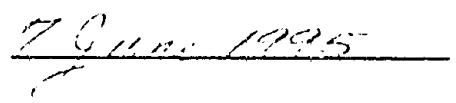


An abstract of the dissertation of Alfonso Hernandez Pioquinto, Jr. for the degree of Doctor of Education in Educational Leadership: Postsecondary presented April 14, 1995.

Title: An Assessment of the Adequacy of the Services of an Urban Public University for International and U.S. Students: A Comparative Study

This study compares the instructional, academic support, and student services needs of international and American students at Portland State University (PSU), Portland, oregon. Variables measured include the perceived importance of university-related services, and the level of satisfaction with services received.

A questionnaire with 26 background questions and 41 service-related items for ranking and discussion was mailed to 225 undergraduate international students and 225 undergraduate American students, with a response rate of 528 .

Responses were tabulated to ascertain demographic profile of PSU students, importance of university services to international students at PSU, current level of 
satisfaction of international students in regards to university services received, importance of the various university services to U.S. students at PSU, current level of satisfaction of U.S. students in regards to these university services, if U.S. and international students at PSU differ in the importance they assign to university services, if U.S. and international students differ in their level of satisfaction with services at PSU, relationship between perceived importance and level of satisfaction for U.S. and international students, relationship between perceived importance and level of satisfaction for international students, perceived reasons for dissatisfaction concerning service quality for U.S. and international students, and any suggestions these students have for improving the quality of services. Respondents' descriptive characteristics were reported and tabulated as background information. Frequency distribution, the chi-square rest of significance, and means were calculated using responses to queries about the service-quality items, and responses of international and American students were compared.

Major findings included that there are many areas of agreement between international and American students. However, significant differences were found: 2 "need" items under instruction, 5 "need" items under academic support, and 13 "need" items under student services. 
Focus group interviews were also conducted.

Researchers can use this additional data to develop theories about answers given; university administrators could use this information to develop programs to ameliorate perceived problems, or make changes in the quality or delivery of existing student services. 
AN ASSESSMENT OF THE ADEQUACY OF THE SERVICES OF

AN URBAN PUBLIC UNIVERSITY FOR INTERNATIONAL

AND U.S. STUDENTS: A COMPARP.TIVE STUDY

by

ALFONSO HERNANDEZ PIOQUINTO, JR.

A dissertation submitted in partial fulfillment of the requirements for the degree of

\author{
DOCTOR OF EDUCATION \\ in \\ EDUCATIONAL LEADERSHIP: \\ POSTSECONDARY \\ Portland State University \\ 01995
}


UMI Number: 9532758

Copyright 1995 by Pioquinto, Alfonso Hernandez, Jr. All rights reserved.

UMI Microform 9532758

Copyright 1995, by UMI Company. All rights reserved:

This microform edition is protected against unauthorized copying under qitle 17, United States Code.

\section{UMI}

300 North Zeeb Road

Ann Arbor, MI 48103 


\section{DEDICATION}

This study is dedicated to my parents, Alfonso, Sr. and Serafina H. Pioquinto and to my three children Selina (5), Serafina (5), and Leizl (4) 


\section{ACKNOWLEDGMENTS}

I would like to express my sincerest thanks and appreciation to the members of my Dissertation Committee, particularly Dr. Joan H. Strouse, Chairperson; Dr. Loyde Hales; Dr. William Greenfield; Dr. Kim Brown; and Dr. Betsy Steinberger.

I would like to thank the staff of the office of Institutional Research and Planning, particularly Belen Tapang who provided me with the list of respondents.

Appreciation is extended as well to the questionnaire respondents and to those who participated in the focus groups for this research.

My final thanks goes to the many people, including my colleagues, friends and relatives, who in one way or another gave me needed encouragement to make this work a reality. 
TABLE OF CONTENTS

PAGE

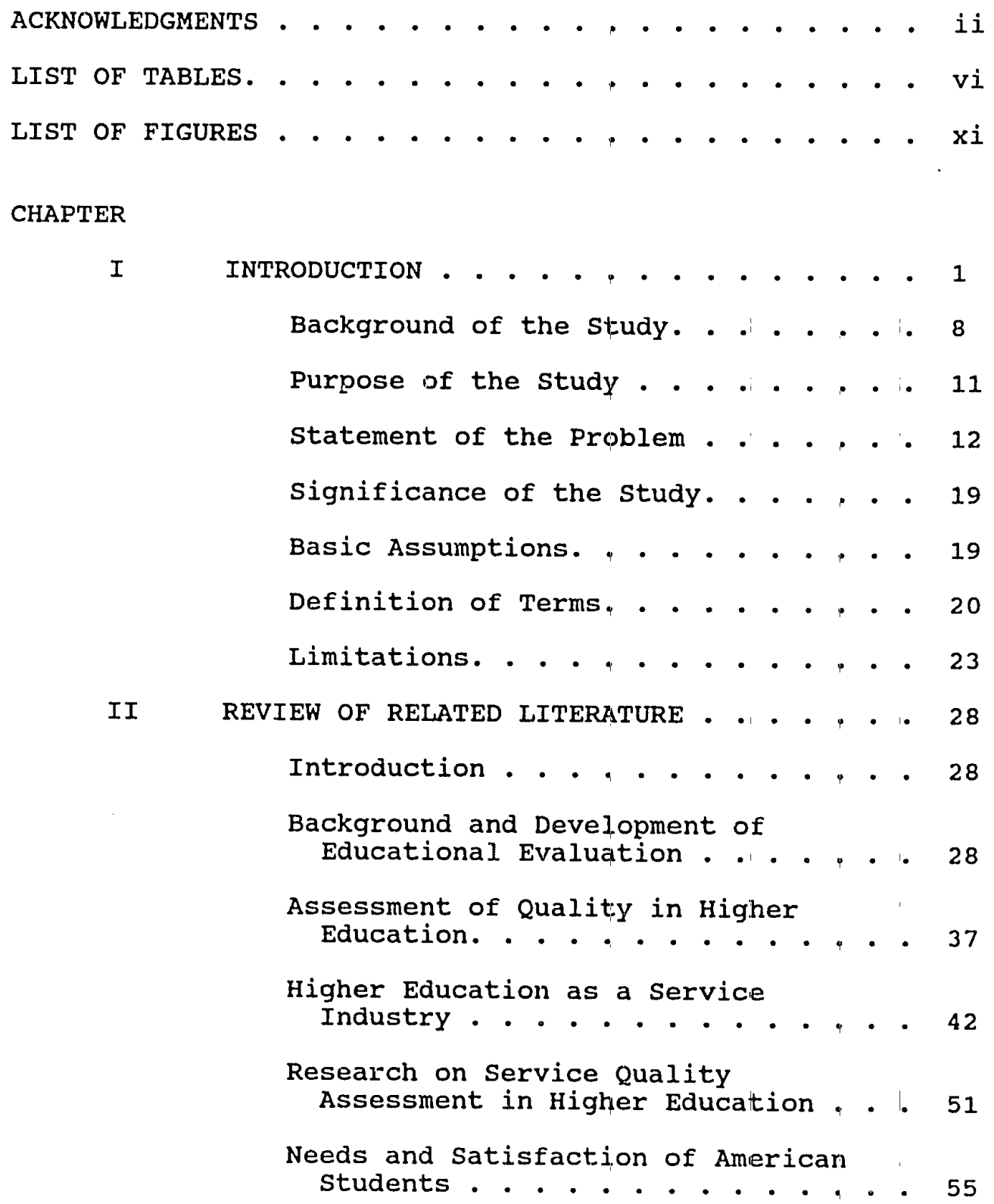


Problems and Needs of International Students in U.S. Higher Education. - 59

Implications and Conclusion. . . . . 66 III METHODS AND PROCEDURES . . . . . . . 70

Introduction . . . . . . . . 70

Research Design. . . . . . . 70

Conceptual Framework . . . . . . 71

Research Questions........ . 72

Variables. . . . . . . . 73

Instrumentation. . . . . . . 73

Procedures and Analyses. . . . . . 79

Assessment Survey

Focus Group study

summary. . . . . . . . . . 88

IV SURVEY RESULTS . . . . . . . . . . 91

Description of Participants. . . . . 92

Results for Research Question \#2 . . 107

Instruction

Academic Support

Student services

Results for Research Question \#3 . . 112

Instruction

Academic Support

student services

Results for Research Question \#4 . . 117

Results for Research Question \#5 . . 132

Conclusion . . . . . . . . . 138

$\mathrm{V}$ RESULTS OF THE FOCUS GROUP INTERVIEWS. • . 140

Protocol of the Focus Group

Interviews ............ 140 
Interviewees

Summary of Findings in the Focus Group Interviews: American Students. . . 142

Instruction

Academic Support Services

Student support Services

Summary of Findings in the Focus Group

Interviews: International students . 151

Instruction

Academic Support Services

Student Support Services

Conclusion . . . . . . . . . 165

VI DISCUSSIONS, CONCLUSIONS AND

RECOMMENDATIONS. . . . . . . . . . 167

Responses to Open-Ended Survey

Questions Compared with Survey

Results. . . . . . . . . . 167

Focus Froup Responses Compares with

Survey Responses... . . . . . 171

Discussion . . . . . . . . . 172

Conclusion and Recommendations . . . 191

REFERENCES. . . . . . . . . . . . . . 196

APPENDICES

A SURVEY INSTRUMENTS. . . . . . . . . 204

B LETTERS . . . . . . . . . . . 209

C COMMENTS TO OPEN-ENDED QUESTIONS. . . . . 212 
1. Basic Paradigms of Educational Evaluation. . . . . . . . . . 33

2. [Need] Service Quality Items and Open-Ended Questions . . . . . . . 79

3. Distribution and Return Rate of the Questionnaires. . . . . . . . . 93

4. Marital status of Participants . . . . . 96

5. Living situation, Living Quarters, and Perception of Economic/class Background, Aultomobile Ownership, and Method of Going to School. . . . . . . . . 99

6. Understanding Level for written English/Average Hours Spent studying/ Week . . . . . . . . . . . . . 100

7. Percentage of Respondents' Average Hours Spent Working/Week . . . . . . 101

8. Percentage of Respondents' Religion at Home, Changed Religious Beliefs/ practices at School. . . . . . . . 102

9. Percentage of Respondents Who Attended PSU student orientation and Attended other . . . . . . . . 102

10. Percentage of Respondents Who Plan to Stay permanently in U.S. HE Institution in U.S... . . . . . . . . 103

11. Percentage of Respondents' Reasons Why They chose PSU, and How students Learned about PSU. . . . . . . . 105

12. Percentage of Importance and Satisfaction Responses of International students for Instruction $(\underline{N}=106)$ 
vii

13. Percentage of Importance and Satisfaction Responses of International students for Academic Support $(\underline{N}=106)$. . . . . . . . . 110

14. Percentage of Importance and Satisfaction Responses of International students for Student Services $(\underline{N}=106)$. . . . . . 111

15. Percentage of Importance and Satisfaction Responses of American students for Instruction $(\underline{N}=124) . . . . . . . . . . .113$

16. Percentage of Importance and Satisfaction Responses of American Students for Academic support $(\underline{\mathrm{N}}=124) . . . . . .115$

17. Percentage of Importance and Satisfaction Responses of American Students for student Services $(\underline{\mathrm{N}}=124)$. . . . . . . . . . . 117

18. Distribution of Responses and Chi-Square Analyses of Significance Between American and International Students Pertaining to Satisfaction of Fairness of Faculty Treatment

of Students. ..... 120

19. Distribution of Responses and Chi-Square Analyses of Significance Between American and International students Pertaining to Satisfaction of Fairness of Testing and Grading . . . 120

20. Distribution of Responses and Chi-Square Analyses of Significance Between American and International students Pertaining to Importance of Library collections. . . . . . . . 121

21. Distribution of Responses and Chi-Square Analyses of Significance Between American and International students Pertaining to Importance of Library Services..... . . . . . 121 
22. Distribution of Responses and Chi-Square Analyses of Significance Between American and International students Pertaining to Importance of Laboratory Facilities. . . . . . . . 122

23. Distribution of Responses and Chi-Square Analyses of Significance Between American and International Students Pertaining to Importance of Computer Facilities. . . . . . . . . 122

24. Distribution of Responses and Chi-Square Analyses of Significance Between American and International Students Pertaining to Importance of Tutoring Facilities. . . . . . . . . 123

25. Distribution of Responses and Chi-Square Analyses of Significance Between American and International students Pertaining to Importance of Admissions office. . . . . . . . . 123

26. Distribution of Responses and Chi-Square Analyses of Significance Between American and International students Pertaining to Satisfaction of Admission Office. . . . . . . . . . 124

27. Distribution of Responses and Chi-Square Analyses of Significance Between American and International Students Pertaining to Importance of Campus Housing. . . . . . . . . . 124

28. Distribution of Responses and Chi-Square Analyses of Significance Between American and International Students Pertaining to Importance of Recreation Programs/Activities. . . . 125

29. Distribution of Responses and Chi-Square Analyses of Significance Between American and International Students Pertaining to Importance of Student organizations . . . . . . 125 
30. Distribution of Responses and Chi-Square Analyses of Significance Between American and International students Pertaining to Importance of Child Care. . . . . . . . . . 126

31. Distribution of Responses and Chi-Square Analyses of Significance Between American and International Students Pertaining to Importance of Student Health Services . . . . . 126

32. Distribution of Responses and Chi-Square Analyses of Significance Between American and International Students Pertaining to Importance of Psychological Counseling. . . . . . 127

33. Distribution of Responses and Chi-Square Analyses of Significance Between American and International Students Pertaining to Importance of Religious Services... . . . . . . 127

34. Distribution of Responses and Chi-Square Analyses of Significance Between American and International Students Pertaining to Importance of Campus Food Services. . . . . . . 128

35. Distribution of Responses and Chi-Square Analyses of Significance Between American and International Students Pertaining to Satisfaction of Campus Food Services. . . . . . . 128

36. Distribution of Responses and Chi-Square Analyses of Significance Between American and International Students Pertaining to Importance of Intercollegiate Athletic Programs . . 129

37. Distribution of Responses and Chi-Square Analyses of Significance Between American and International Students Pertaining to Importance of Social and Cultural Activities. . . 
38. Distribution of Responses and Chi-Square Analyses of Significance Between American and International Students Pertaining to Importance of Campus orientation Program. . . . . 130

39. Distribution of Responses and Chi-Square Analyses of Significance Between American and International Students Pertaining to Importance of Special Student Services. . . . . 130

40. Summary of the Probability Associated with All Chi-Squares of Importance and Satisfaction of International and American Students for Instruction. .

41. Summary of the Probability Associated with All Chi-Squares of Importance and Satisfaction of International and American Students for Academic Support.

42. Summary of the Probability Associated with All Chi-Squares of Importance and Satisfaction of International and American students for student Services . . . . . . . . . . .

43. Difference of Importance and Satisfaction Scores Between American and International Students for Instruction. . . . . . . . . . . . . 134

44. Difference of Importance and Satisfaction Scores Between American and International students for Academic Support . . . . . . . . . . 134

45. Difference of Importance and Satisfaction Scores Between American and International students for student Services . . . . . . . . 135

46. Needs Least Met. . . . . . . . . . 136 


\section{LIST OF FIGURES}

FIGURE

PAGE

1. Marketing and Environmental Factors. . . 44

2. Blueprint of Service Quality Influences. . 48

3. Gender of Respondents . . . . . . . . 94

4. Field of Study of Respondents. . . . . . 94

5. Academic Level of Participants . . . . 95

6. Main Source of Financial Support of

Respondents. . . . . . . . . 97

7. Reasons International Students Chose

U.S.A. . . . . ........ 104

8. Current Problems of Respondents. . . . 106 
CHAPTER I

INTRODUCTION

The success of any institution is ultimately dependent not only on the value of the product or service it offers, but on the level of satisfaction experienced by those whom it serves. This research study examines the adequacy of services provided to students of Portland state University (PSU), an urban state university located in Portland, Oregon. The assessment was based on the perceptions of a sample of undergraduate American and international students. This research was completed using two designs: the first design was a descriptive survey (Weisberg, Krosnick, \& Bowen, 1989) using a survey questionnaire, and the second design was a follow-up interview with a focus groups (Delene \& Bunda, 1991; Greenbaun, 1989). The survey questionnaire addressed students' evaluations of three broad areas of institutional offerings: the faculty and instructional quality, academic support services, and student services. The interview component provided an elaboration of the "what, why and how" of the survey findings. Assessment of higher education in the United States has been accomplished primarily through accrediting agencies (Delene \& Bunda, 1991). Delene and Bunda asserted that 
accreditation has focused on technical qualities such as faculty degrees, number of library holdings and volume of research funds. According to these authors, a new assessment model is needed, one that examines student experiences in institutions of higher learning in the same sorts of ways that market researchers examine the relationships between customers and the business institutions that provide them with goods and services. such research provides the business sector with the data it needs to satisfy the customer, and similar studies may help colleges and universities increase their rates of "customer satisfaction."

In today's competitive environment, where all students have many educational options to choose from, all factors that enable educational institutions to attract and retain students take on increased importance. Learning remains the university's mission---but a more diverse, older and more discriminating student body makes new demands on the system. The satisfaction of these demands is key to "marketing" the institution in the educational "marketplace." of course, universities have always marketed themselves by way of brochures and packets sent to guidance counselors and prospective students. The expansion of these efforts seems to date from the late 1970s, when colleges that had grown large over the past two decades found themselves competing for students in an unprecedented way due to an influx of 
independent-minded "untraditional" students and international applicants, at the same time that the pool of high-school graduates was shrinking and the first financial-aid cutbacks were beginning. During the 1970 s college guides and rating systems proliferated, and transferring between schools became more common. All of these conditions have intensified over the past 20 years, making the market model even more persuasive for those charged with building up the student body.

In this model, a college or university is seen as analogous to private service industries. This view is a departure from past practice, but it gives the researcher a new perspective on assessing the quality of the educational experience--and potentially provides new tools to address deficits uncovered.

Deficits to be uncovered are a given. Sometimes students bring their concerns to the immediate attention of the administration, faculty members or student government. Yet an attitude continues to exist that such complaints will not be heard, or will simply be brushed off. It is an attitude that pervades some campuses, is common to some university officials and even exists within the minds of some students as an internalized expression of a somewhat obsolete notion about the subservient position of the student to the institutional bureaucracy. As a result, many complaints are not expressed proinptly, or do not come to the 
attention of the administration. Whispers and moans about class size, inattentive professors, financial-aid problems or other concerns can undermine a school's reputation among students or the larger community, leading to fewer applicants of the highest caliber, less financial support from alumni and other difficulties.

Unless institutions put into practice regular "customer satisfaction checks," this dissatisfaction tends to remain under the surface. Without the opportunity to express dissatisfaction and see some constructive results, students tend to express their frustration about unmet needs via rallies, demonstrations and other forms of unrest; or they simply leave to find another institution that they hope will better meet their needs.

The concept of customer satisfaction originally emanated from, and is one of the primary concerns of, the local and international business world.

Hundreds of companies (perhaps thousands) measure customer satisfaction and try to integrate the findings into product and service market offerings, as well as their overall corporate strategy. (Schlossberg, cited in Delene \& Bunda, 1991, p. 3)

This international attention to customer satisfaction has led to a:

- . growing consensus that customers evaluate service quality by comparing their service quality expectations with their perceptions of the service quality they have experienced. Customer satisfaction is thought to occur when perceived service quality meets (or $\mid$ exceeds) service quality 
expectations. (Brogowicz, Delene, \& Lyth, 1990, p. 34)

Public institutions do not have quite the freedom that private institutions have to respond to student needs. Public institutions exist for the public; such institutions must serve broad-based needs that may bypass narrower, more specific needs of individuals and groups who make up a part of this public. In the case of visiting international students, the group or groups whose needs exist may not even have a particular voice in the voting constituency upon whose support the public institution must rely, but the institutions remains more committed to the source of funding--the public--than to the international students or any other group of students who may not have a voice in the voting. However, when a public situation has such a population among its student body, it behooves that institution to respond to the population's needs in order to maintain itself. Thus the market model is wholly applicable to its operation and the services it offers. This study hopes to provide PSU and the state of oregon with the kind of guidance and data that SNAPS (students Needs and Priorities Survey) (1989) provided California state University (CSU) and the state of California. Such data, as comparably collected in a narket model research framework, could give PSU the chance to make itself work for its customers and for its state. The uses of SNAPS that this study hopes to duplicate are many. One, is to make 
available to PSU policy makers "systematic, representative, and comparative findings on student needs, priorities and opinions." Furthermore, the findings may also "help structure the policy agenda itself," and may' "serve as an early warning system to inform the development of system policy." Too, the survey data can be "useful tools for responding to political requests . . for information on institutional outcomes," and can be "indispensable for explaining . . [PSU] policies, programs, and services designed to address unique student needs"; and the findings "can provide evidence to support funding requests and administrative initiatives and innovations in such things as advising, student services, campus social life, academic support programs and the curriculum" (Daigle, 1989, p. 2). The information that this study has generated, then, may contribute to a whole soul-change for PSU that, by making it more responsive to student needs and therefore more "marketable" and financially viable, may finally make it more attractive as well to the state as an investment repository for taxpayer money. In short, this study can be used to trumpet the likelihood of a much greater return on the investment.

For private institutions, be they businesses or universities, basing service offerings on what will make the greatest profit is a simple decision. The dance program is not bringing in enough tuition-paying students? cut it. 
But public colleges do not have the opportunity to be so reactive. Many of the most important decisions, from tuition levels to the number of employees available to assist students in the financial aid office to class size, are largely dictated by bureaucratic and legislative decisions beyond the institution's control. But there are many arenas for change even with these built-in constrictions.

For example, the idea of customer-based assessment has already been used on the oregon State University (OSU) campus. The OSU quality and service assessment system is called "Total Quality Management" (TQM).

The main tool used is employee teams, within which people who actually do the work come up with suggestions for improvements. Their ideas are based on reactions from customers--faculty members, students and groups that use a university service. (McMillen, 1991, p. 27)

In other words, "quality is defined by expectations of customers" (Delene \& Bunda, 1991, p. 3).

of course, the market model is only one way to look at educational institutions, and it is not always the most appropriate model for a given situation. For public institutions in particular, the market model can sometimes be too fluid to deal with rigid requirements set by Boards of Trustees, or state and federal governments. It simply provides another set of tools for assessment and evaluation. As the OSU TQM program illustrates, it may be easier to use at the departmental level, where there is greater 
flexibility, as opposed to the level of the whole institution. In chapter III, higher education as a service industry is discussed further.

The remainder of Chapter I describes the background and purpose of this study, provides a statement of the problem, defines terms and discusses the significance and limitations of the study.

\section{Background of the Study}

I became interested in the needs and satisfaction of students after having the opportunity to serve as a member of the legislative body of the Associated students of Portland State University (ASPSU) for two years and as assistant coordinator of the Inter-organizational Council for one year. I became aware of some of the academic and non-academic needs, problems and concerns of students at Portland State University from these experiences. In addition, I served the international students of Portland State University as coordinator of the organization of International Students (OIS) for two years. During my years as an international student myself, I have felt firsthand some of the important concerns of this group of students. I also have had the opportunity to teach several courses at Portland State University, including Introduction to Comparative Education, Introduction to Global Issues, and Introduction to Macintosh and Desktop Publishing; 
experiences that have allowed me to see the university from the instructor's perspective as well.

With more than half a decade of experiences and interactions with students, administrators, personnel, and the rest of the community, I have become well acquainted with students' interests and services at Portland state University. While this study involves both international and American students, who will be included for purposes of comparison, it focuses on international students. The rationale for this approach follows.

The presence of international students on university campuses in the United States will continue, and the universities' relationships with these constituents will prosper by understanding and satisfying their needs. Their university presence contributes significantly to international awareness and understanding, an important consideration at a time when countries are becoming more interdependent, economically and politically, as demonstrated dramatically during the Persian Gulf crisis of 1991 .

The education of international students can have far-reaching importance. The United States has long been looked upon as a leader in international efforts, but America's lack of preparation for economic and political leadership in a global picture that is moving away from the European/American axis of the past is becoming a concern. 
This concern was articulated in the report of the Advisory

Council for International Educational Exchange (1988)

chaired by Thomas A. Bartlett, former Chancellor of the

University of Alabama and of the Oregon state system of

Higher Education.

The role of the United States as a leader among nations is changing rapidly. Despite our position of international leadership for almost fifty years, we are ill-prepared for the changes in business, manufacturing, diplomacy, science and technology that have come with an intensely interdependent world.

Effectiveness in such a world requires a citizenry whose knowledge is sufficiently international in scope to cope with global interdependence.

other countries have had to recognize the educational implications of interdependence sooner than we, and are ahead of us in the international education of their students. Our educational system, particularly in colleges and universities, must adapi in order to develop new capacity in our people. The Advisory Council on International Educational Exchange believes that if we fail to internationalize sufficiently our educational institutions, including expansion of student opportunities for study and work abroad, we will irreversibly diminish the world status of the United States. (p. 1)

In addition to being a resource to improve international understanding, international students are an important source of revenue for|U.s. educational

institutions. International students pay more than double the amount resident students pay for tuition and other fees at Portland State University. In 1995, for instance, a resident full-time undergraduate student paid $\$ 1,020$ for tuition fee while a full-time undergraduate international 
student paid $\$ 3,036$ a term (PSU Catalog, 1994-95). This figure does not include other expenses such as food, educational materials, travel, recreation, room and board, etc., which indirectly provide additional contributions to the growth of the local and state economy.

Thus, for the reasons noted above, and because of the researcher's status and experience as an international student, the study is particularly concerned with international students' perceptions regarding the quality of institutional support services.

\section{Purpose of the Study}

The objectives of this research are to: (a) assess the needs of students and find out the extent to which they have been satisfied, (b) determine the extent to which international students' satisfaction of needs differ from those of native-born students, (c) determine the underlying factors behind the level of satisfaction of students using a focus-group interview process and (d) offer recommendations to policy-makers and program providers based on these data. The study's broader purpose is thus to gain a better understanding of the adequacy of higher education's institutional policies by relying on student perceptions of the quality of support services provided to them as consumers. 
This study develops policy, it does not test theory. Throughout the research and the presentation of the results, the aim has been pragmatic and practical: to provide relevant information that might help university administrators and policy-makers to formulate and develop policies which address demonstrable areas of student dissatisfaction. As a result, the study is premised in theory that the study itself does not question or try to validate. For instance, this study presumes and uses the theory that the difference between the high degree of importance a study places on a given area of concern and a low level of satisfaction a student experiences with results in that area of concern must yield frustration for the student. This, like other such premises, are taken as givens--which in itself constitutes a limitation to this research.

\section{Statement of the Problem}

Research into the assessment of service quality in higher education based on "customer" (student) satisfaction is insufficient. Few studies have been conducted to assess the needs of students and the extent to which these needs are being satisfied. No recent studies have been conducted that specifically compare the needs of American and international students to see if indeed international student needs are distinct and require special 
consideration, although many related studies have been undertaken, particularly in the 1950 s and 1960s, related to foreign-student assimilation, the success rate of specific programs for training elite students from developing nations, and the "brain drain" of bright students from other nations to the U.S. This study attempts to rectify that situation by researching the similarities and differences between domestic and international students' needs and, in turn, both groups' perception of how well those needs are being met at PSU.

For the purposes of this study, I have defined "American students" as those students born in the United States, and those who have permanent residency in the U.S. It is important to note that these American students do not form a monolithic block. There can be significant differences in opinion about the educational experience among American students, differences that often correlate strongly with socioeconomic background, race, sex, age and family obligations while attending school. A larger study that explores the international student population in depth would also likely find significant differences based on the same factors, as well as educational and national background.

These differences among individuals may at times be larger than those between the groups discussed here, American students and international students. Perception is 
a critical, yet easily overlooked, component in needs-assessment research. Even when people look at exactly the same thing, "each of [them] receives, organizes and interprets this sensory information in an individual way" (Kotler \& Armstrong, 1989, p. 132). However, perception in large institutions operates on the level of the group as well as the level of the individual. It is from this observation and assumption that this researcher believes significant differences in instructional, academic support, student services, sociocultural, financial and other individual needs can be discovered between U.S. and international students at Portland State University. Expectations and opinions on how needs should be met will also differ.

Works such as that of Astin (1982), Bassis and Guskin (1986), De Weert (1990), Ewell (1988), Hinchberger (1990), Leslie and Conrad (1986), and Moock and Jamison (1988) "vary significantly in their approaches to defining and measuring quality" (Delene \& Bunda, 1991, p. 2). As we move into an era where expectations for accountability in our educational system are increasing and resources are tight, the lack of knowledge about the needs satisfaction of our students, international and domestic, regarding the service quality of their institutions is a significant liability. Portland State University (PSU) is one of the hundreds of U.S. institutions of higher education that enroll 
significant numbers of international students. PSU enrolled over 800 students from more than 60 different countries in the fall of 1993. International students represented approximately $5 \%$ of the more than 14,000 graduate and undergraduate students enrolled at Portland State University in the Fall of 1993 (PSU Fall Term Fact Book, 1993).

There is a common understanding that human beings have various needs and that they tend to behave in ways that are intended to satisfy those needs (Lee, Abd-Ella, \& Burks, 1981). The literature on colleges reveals that students have particular problems and needs as they enter college. Some of these needs can include psychological or social support from fellow students and faculty; child care (Berdie, Pilapil, \& Im, 1968; Farber 1987); financial stability, study skills, career development skills, personal development and self-improvement, academic skill improvement (Daigle, 1981; Iyake \& Mendelsohn, 1986; Kitabchi \& Benjamin, 1984); attention to students' individual learning styles (Iyake \& Mendelsohn, 1986); and availability of referral services, and campus housing (Daigle, 1989).

Two theoretical frameworks are useful in understanding the situation of college students. The person-environment interaction theories "acknowledge the role of the individual's envixonment in shaping human behavior and development" (Pascarelle \& Terenzini, 1991, p. 38) and vice versa. One of the theories, popularized by Barker (1.968, 
1978) was "physical theory," the theory of "behavior settings." It explains that "environments select and shape the behavior of the people occupying the given setting, tending to influence them in similar ways despite their individual differences" (Pascarelle \& Terenzini, 1991, p. 39).

Another model that has attracted the most attention and underpins a substantial body of research on college students is Holland's (1985) "model environments." This model explains that:

where people congregate, they create an environment that reflects the types they are, and it becomes possible to assess the environment in the same terms as we assess people individually. (p. 4)

These theories explain that institutions, such as colleges and universities, have significant roles in shaping individual students' behavior and development. In a like manner, the students contribute significantly to creating the characteristics of their institution. Related to the theories mentioned above is the theory of work adjustment or:

correspondence between an individual and his or her environment, [which simply means] . . . suitability of the individual to the environment, and of the environment for the individual. (Culha, 1974, p. 34)

Each student has expectations for the institution he or she is in, and the institution also has expectations for the student. This theory posits that if the student's 
expectations are not met, the student may withdraw from the institution and look for another more suitable environment or the institution may push the student out.

Taken together, these frameworks suggest that the satisfaction of needs is a two-way stxeet, involving both the student and the environment into which he or she enters. Some students may present needs that the institutions should not or can not meet due to financial, political or procedural considerations. Some college environments fail to provide support for student needs that they should and can provide.

This project solicited information from students that can help PSU better assess the quality of its institutional service areas, including faculty and instructional quality, and of its current academic support and student services. In this study, student needs were determined by the descriptive survey and the survey results were complemented and enhanced by interviewing focus groups.

This study sought to answer the following broad questions:

1. What is the demographic profile of undergraduate students at Portland State University?

2. What is the importance of the various [need] service quality statements to international students at Portland State University? What is the current level of 
satisfaction of international students in regard to these [need] service quality statements?

3. What is the importance of the various [need] service quality statements to U.S. students at portland State University? What is the current level of satisfaction of U.S. students in regard to these [need] service quality statements?

4. Do U.S. and international students at Portland State University differ in the importance they assign to the [need] service quality statements? Do U.S. and international students differ in their level of satisfaction with the [need] service quality at Portland state University?

5. For each service quality statement, what is the relationship between the perceived importance and level of satisfaction for U.S. students? For each service quality statement, what is the relationship between the perceived importance and level of satisfaction for international students?

6. What are the perceived reasons for dissatisfaction concerning the service quality of U.S. and international students? What suggestions do these students have for improving the quality of services?

The focus-group interviews sought to expand upon the results of the descriptive survey. The focus-group approach is geared toward supplementing the first approach by 
explaining in greater detail why students are satisfied or dissatisfied with student services at Portland state University.

\section{Significance of the study}

The assessment of the adequacy and quality of services of an institution of higher education and the ensuing understanding of needs of students can provide important information that may be used to review characteristics of the environment as experienced by students. This study provides staff, faculty, administration, and other persons dealing with students on and off campus with more comprehensive information than is currently available.

The administration's understanding of student needs and the students' assessment of the quality of university services may provide productive ideas for improving services and implementing new programs. For students themselves, this project provided the opportunity to more clearly understand their own needs so that they, too, can make necessary personal adjustments.

\section{Basic Assumptions}

During the development of this study, several assumptions were made. These assumptions include:

1. It is assumed that this project will provide significant information for the appraisal of the institution 
based on the perception of student respondents, administrators and university personnel, and that educational leaders, policy-makers, the institution, its staff and students, and the whole university community will benefit from it.

2. It is assumed that "providers" (educational institutions) would like to provide "customers" or "clients" (students) with more effective services and are seeking ways to deliver excellent service with their limited available resources.

3. It is assumed that the anonymity of the questionnaire approach will allow for honest, straightforward responses to the questions in the survey questionnaire.

4. It is assumed that at least half of the students sampled will return the survey questionnaire.

5. It is assumed that a questionnaire and focus groups interviews would be the most comprehensive approach to gathering data and most appropriate for this study.

\section{Definition of Terms}

For this study, the following definitions are used:

American student: For this research, "American students" or "U.S. students" are those students who have citizenship or permanent residency in the United states and therefore enter U.S. universities without going through 
admissions procedures for foreign students, or paying foreign-student tuition. For this study only full-time undergraduate students were used.

Assessment: Assessment in this project is equated to evaluation. Popham (1988) explained:

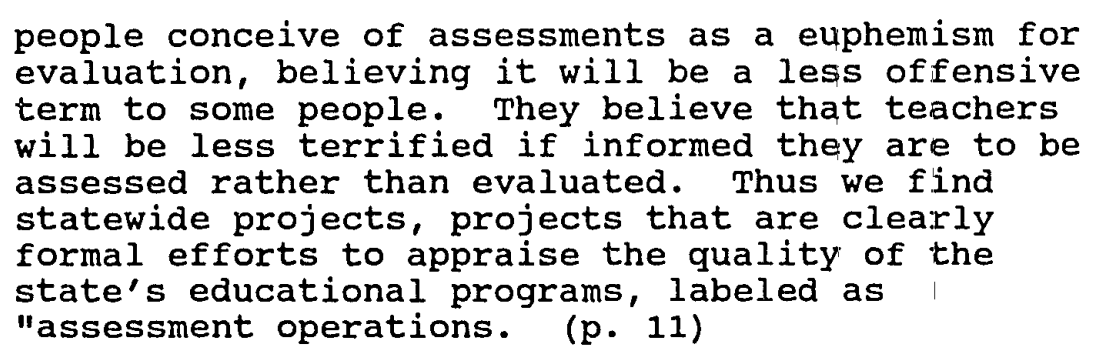

Educational Evaluation: Popham defined it as a formal appraisal of the quality of educational phenomena. The educational phenomena that are to be appraised can include many things, such as the outcomes of an instructional endeavor, the instructional programs that produced those outcomes, educational products used in educational efforts, or the goals to which educational efforts are addressed ( $p$. 7) .

Fields of study: The fields of study used $\mid$ in this investigation are subjects and areas from the classification of Instructional Programs used at Portland State University. Focus Group Interview: The focus group interview is a small, in-person, group qualitative marketing research technique developed in the 1950 s in reaction to/the limitations of large-sample polling techniques, which provided lots of numbers but little insight into what was 
really going on, the "'why' behind the numbers" (Bellenger, Bernhardt, \& Goldstucker, 1976).

International students: As defined herein, an international student is anyone who is enrolled in courses at institutions of higher education in the United States who is neither a citizen nor an immigrant (permanent resident) in this country. The term "international students" in this study is used interchangeably with "foreign students." For this study only undergraduate full-time students were used. Institutions of Higher Education: With respect to the United States, "institutions of higher education" is used to describe the group of colleges and universities listed in the HEP 1986 Higher Education Directory (Higher Education Publications Inc., Washington, DC ISBN $0-914927-04-3$ ) or to education beyond the secondary level. Institutions of higher education include colleges, universities, professional schools, teachers' colleges, junior and community colleges, institutes of technology, and technical institutes (AMIDEAST, 1983, p. 1).

[Need] Service Quality Statements: [Need] service quality statements referred to in this study are those items under the three broad areas of concern (instruction, academic support, and student services) found under item 27 of the survey questionnaire. Each of these represents a discrete issue on which students were asked to express their 
level of satisfaction by way of a ratings scale or a longer answer.

Needs: Kotler and Armstrong (1989, p. 5) defined humain needs as a state of felt deprivation in a person. Kotler and Armstrong differentiated human needs from wants by saying that wants are described lin terms of objects that will satisfy a need.

\section{Limitations}

This study is limited to the assessment of the quality of the services of Portland state University, an urban, public, medium-size state university in the northwest state of oregon, as perceived by international and American students in the questionnaire survey and interview of focus groups. While the ability to generalize the results of this study are limited, the survey instrument devised as a basis for this research could be used by other universities seeking similar information. The findings of this research are limited to the perceptions of respondents only. The findings of this study might or might not be indicative of the perceptions held by the other members of the population not responding.

With these limitations in mind, it is nonetheless possible to use these survey results to draw some conclusions about ways to enrich the educational experience at PSU, and to design programs intended to benefit students 
and improve their perceptions of the university. Administrators may also be able to use this research to improve their understanding of the unique problems facing international students, and to use this understanding as a basis for decisions and problem-solving.

Additional limitations of this research in a narrative form include:

1. The sample size is small. The results generated from a small sample size may be different from what might be found if the sample is larger or if the whole population were used. Therefore, the findings from this study may not necessarily reflect the perceptions of all PSU students.

2. Although every effort was made to have an equal number of male and female participants, the gender representation in the focus group of international students was limited to male students only. There may be cultural or other reasons for this, and future research should attempt to compensate for these.

3. Because of PSU's unique urban nature, the results of this research cannot necessarily be generalized to reflect conditions on other campuses.

4. Although every effort was made to avoid such mistakes, this study may be subject to errors in individual responses, reporting, calculations, tabulations, and interpretation of findings. 
5. The study's design did not cover every possibility-for example, it is not possible to assess the personality traits of each respondent, which could have a strong effect on individual perception of needs and satisfaction.

6. The two procedures used in this study are also limited, in that those students with limited English proficiency, lower interest in their educational opportunities and experiences, or simply with less time in which to answer surveys or attend focus group sessions might not have returned the survey, might have returned it partially completed, or might not have given each answer the high degree of thought needed for an accurate response.

7. Another possible limitation of this research study is that all the participating students were full-time students. Thus, the study fails to take into account the differences between full-time and part-time students, nor the extent to which certain needs and expectations peculiar to the latter group might generate levels of (dis)satisfaction in its members inconsistent with those this study generally reflects. In this instance, however, the limitation was necessary, since international students tend to be overwhelmingly full-time in their matriculation. Therefore, it made sense, given the central comparison the study makes between American and international students, to restrict both pools of student participants, American and international, to full-time enrollees at PSU. 
8. Still another limitation to this study is the fact that it assumes an equality of satisfaction needs among individuals. "Satisfaction" itself is not a demand different individuals equally have; some are more resigned or accepting than others, either lowering their satisfaction-level or rendering the whole concept of "being satisfied" largely irrelevant to those individuals. Furthermore, even for the same individual there can be a difference in the importance of satisfaction needs depending on the issue involved. If a particular issue is unimportant to a student, therefore, his or her satisfaction need in relation to it is very different than if the issue is critical. Thus, for instance, if a student already has lodging, his or her satisfaction need regarding campus housing is very different than if the student depends on campus housing for lodging. Because this study assumes an equality of satisfaction needs, the data it has generated is not always reliable.

9. Some focus group participants might, due to accidents of personality and despite the researcher's best efforts to facilitate a balanced discussion, have dominated the proceedings and therefore received undue attention. others might have faded into the background when, in fact, their opinions were of equal validity. 
10. As a study device, focus groups are subjective in nature, and even objective, statistical data can also be misconstrued.

11. Although the sample of students was as representative as possible, vagaries of the university's record-keeping, the U.S. Mail system and individual inclination to respond to a mailed survey had the potential to skew this study's results.

12. Finally, because the study group was limited to PSU students, results or trends found may not be applicable to all students at all institutions. 
CHAPTER II

REVIEW OF RELATED LITERATURE

Introduction

This chapter is divided into five sections. The first section briefly reviews the background and development of educational evaluation, theories and methodologies. section two reviews previous work on assessing service quality in higher education. Section three reviews previous studies related to needs of U.S. students. Section four reviews previous work related to needs and problems of international students. Section five presents the implications of previous work and establishes the link between previous research and this study.

Background and Development of of Educational Evaluation

"Evaluation in its broadest sense is appraising the quality of something" (Popham, 1988, p. 7). In education, evaluation is generally formal or systematic. Popham defined formal systematic educational evaluation as "a formal appraisal of the quality of educational phenomena" (p. 7), which in this study is the formal systematic appraisal of the service quality of three broad areas of an 
educational institution's offerings: faculty and instructional quality, academic support, and student services.

To be able to effectively implement any evaluation process, it is a prerequisite to determine the what, the who, and the why of the program to be evaluated (Raizen \& Rossi, 1981). This is often considered development of a "theory" or "philosophy" to explain the context or component and essence of the program (Bickman, 1987; Conrad \& Miller, 1987). These authors believed that developing the "theory" and "philosophy" will guide the subsequent evaluation methodology. Once the program theory or philosophy has been developed, evaluation activity can proceed to the next step by specifying the purpose of the evaluation. The most basic question asked before an evaluation is implemented is "What is the general purpose of the study?" As to its purpose, the most popular and common and universally recognized classification of evaluations are the formative and summative evaluation (DeRoche, 1981; Popham, 1988; Worthen \& Sanders, 1987). These concepts were expounded by Scriven (1967) in a classic essay that first distinguished the formative and summative roles in educational evaluation (Harcleroad, 1980; Popham, 1988). Both "formative and summative evaluations appraise programs or products that are built upon theories validated by the researcher" (Borich, 1985, p. 28). 
Formative evaluation (also called formative quality appraisal) and summative evaluation (as summative quality appraisal) as described by Popham (1988) have distinctive roles in evaluation. Formative evaluation is the process of applying quality-appraisal techniques to instructional programs that can be modified. The formative evaluator collects this data with the intention of improving such programs. Summative evaluation, on the other hand, focuses on completed programs of education. The summative evaluator's goals are to gather and analyze data on such programs and use the results to decide on whether to retain or adopt them.

As described by, Worthen and Sanders (1987), formative evaluation is undertaken while an educational program is in operation, providing|its directors with useful information on areas needing improvement. Summative evaluation, on the other hand, is conducted after a program has ended in order to provide consumers with information on the program's worth or merit.

The number of models and approaches to educational evaluation by individuals, organizations and different committees are numerous. However, there is agreement among evaluators that some type of organized evaluation procedures or methodologies are necessary to get results from the evaluation activity.| The procedures used depend on the 
field or discipline, and on the objectives toward which the evaluation process is aimed.

Chinapah and Miron (1990) indicated that no single technique or method is appropriate for the many types of evaluation in existence. Tried-and-true methods and techniques must be examined for applicability to the task at hand, then altered or adapted in light of the project's goals, the information available for evaluation and new tools available to researchers. They further wrote that:

- . evaluation must not always be limited to a single applied method. Two or more methods when used properly together, can often prove to be complementary and more effective. When using methods in combination, it is perhaps better to apply one in a more stringent manner; this allows the evaluation study to be generalized. (p. 41)

In accordance with this recommendation, this particular research makes use of an interview component to supplement and complement the results of the descriptive assessment survey posed by this study.

The last three decades have seen tumultuous changes in the field of evaluation. Much of its growth has been due to the continuing efforts, particularly among government agencies, to better understand the ongoing process of social change and to respond with more effective programming (Chinapah \& Miron, 1990). Berk (1981) and Rossi and Wright (1976) have pointed out that the impetus for much of the growth of evaluation activities is the "evaluation research lobby," which includes legislators, planners, program 
managers and foundation executives. Chinapah and Miron concluded that it is these professionals who have been the driving force behind the growth and application of evaluation. In the field of education, accountability plays a significant role for educational evaluation. Put bluntly, "taxpayers want the schools to deliver evidence that they are giving the society its money's worth" (Popham, 1988, p. 9) .

Two distinct evaluation approaches, quantitative and qualitative, have been widely used in the field of educational evaluation. Chinapah and Miron (1990) explained which type to use by saying, - . the decision about which type of technique to use in the assessment will largely depend on the design of the evaluation as well as on the type and quality of information being sought. Nonetheless, conscientious use of both qualitative and quantitative research together could result in more useful outcomes. (p. 45)

Chinapah and Miron (1990) described the shift from a single methodology to a combination of methodologies in evaluation:

In the recent years it could be said that more emphasis was being diverted from the traditional dominance of the quantitative approach, meaning the qualitative approach is increasingly being considered. Traditional qualitative methods include case-studies and participant observation. Traditional quantitative methods include randomized experiments and probability. Even today there still seems to be an unfailing debate between them as to which is the most effective.

The recent growth of evaluation and a shift from a single to a combination of methodology has witnessed the development of better knowledge and 
technical procedures. Sample survey procedures, combined with other methods such as experimental methods have proved to be a very competent and effective means of assessing project and programs. (p. 41)

Patton (1975) argued that the application of qualitative evaluation designs and methods in the social sciences can be viewed as an "alternative paradigm" to the conventional "dominant paradigm." His distinction between the dominant (quantitative) and the alternative (qualitative) paradigm is illustrated in Table 1. "These two paradigms can complement and supplement each other, depending on the nature of the program under assessment" (Chinapah \& Miron, 1990, p. 41). This particular study uses both the quantitative and qualitative approach in an attempt to get the most reliable and useful information available.

Table 1

Basic Paradigms of Educational Evaluation.

Dominant Paradigm

\section{Quantitative}

-concerned about reliability -objective

- distant from data

- focused on impact of components - concerned about outcomes - for scientists

- large samples

- interested in generalizations

- tends to ignore interactions
Alternate Paradigm

\section{Qualitative}

-concerned about validity

- subjective

-close to data

- holistic analysis

- concerned about process

- for practitioners

- case-studies

- interested in uniqueness

opicks up individual

treatment interactions 
Indeed, Chinapah and Miron (1990) offered a number of suggestions regarding educational evaluation that this study saw fit to follow because of their fundamental soundness.

They pointed out for instance, that:

educational evaluation should neither be a fault-finding nor a one-shot exercise . . . evaluation can often be used as a tool to legitimize consensus among various interest groups while leaving the possibility of managing conflicting issues and situations. (p. 23)

This study adopted this perspective as a guiding principle, along with Chinapah and Miron's contention that:

genuine educational evaluation should utilize an open-ended strategy. Researchers should use a combination of different methods and techniques, complementing each other; this methodology will contribute to improving: (a) the quality of information collected; (b) the choice of evaluation instruments; and (c) information processing, analysis and reporting. (p. 23)

In line with this perspectives, this study is conceived of as a formal or systematic educational evaluation. Popham (1988) defined systematic educational evaluation "as a formal appraisal of the quality of educational phenomena" (p. 7). This is different from informal, everyday evaluative acts, such as appraising the quality of a car or a single course. It implies the use of structured evaluation procedures that can be repeated--as indeed is critical, since such evaluation should be conducted continually (Barrow, 1989). For that reason, both U.S. and international students were studied, in order to provide an opportunity for comparison. Demographic data were collected 
in an attempt to uncover any underlying causes for dissatisfaction or, indeed, for differences in the satisfaction level of these two student groups or subgroups within either group. And, finally, specific information was collected from individuals participating in the focus groups to give human voice to the information gathered, providing an adjunct to cold statistics, and a more "human-centered" forum for complaint and discussion than a questionnaire. Popham's (1988) definition of the term asserts that systematic educational evaluation is, by nature, formal; this definition involves an:

appraisal of quality or, in other words, a determination of worth. The educational phenomena that are to be appraised can include many things, such as an outcome of an instructional endeavor, the instructional programs that produced those outcomes, educational products used in educational efforts, or the goals to which educational efforts are addressed. (p. 7)

This particular research appraises the quality of three educational phenomena: faculty and instructional quality, academic support, and student services at Portland state University. This research attempts to gather information and to "use that information in reaching judgments regarding quality" (Popham, 1988, p. 8). Statistical information from the questionnaire is presented and analyzed according to demographic criteria, as are the more subjective comments of the focus-group participants.

There are two distinct roles of evaluation, as pointed out by Popham (1988). As has been discussed earlier, 
formative evaluation refers to appraisal of quality focused on instructional programs that are still capable of being modified. The formative evaluator gathers information regarding the worth of aspects of an instructional sequence in order to make the sequence better. While formative evaluators attempt to appraise such programs in order to inform the program developers on how to ameliorate deficiencies in their instruction, the heart of formative evaluation is to gather empirical evidence regarding the efficacy of various components of the instructional sequence and then to consider this evidence in order to isolate deficits and suggest modifications.

This researcher wants to draw conclusions, not make actual decisions. Popham (1988) differentiates between the educational researcher and the educational evaluator, based on their goals. Whereas the researcher is interested in understanding phenomena purely to understand the phenomena better, the evaluator has the more pragmatic aim of wanting to understand phenomena better "in order to guide someone's action." Furthermore, whereas the educational researcher hopes for findings marked by generality, the educational evaluator is narrowly focused on a specific educational program and "what decisions to make about it" (p. 11). Such decision this researcher aims to leave to others, with the prospect that the findings of this research will make such decisions easier for others to make. 
The following section reviews some of the works related to assessing the quality of higher education.

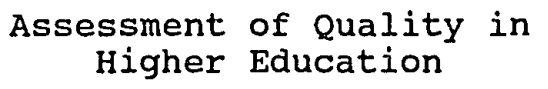

Astin (1982) presented five traditional approaches to the assessment of the quality in American higher education: the nihilist, the reputational, the resource measures, the outcome measures, and the value-added approaches. He explained each of these approaches:

The nihilist view believes that the quality of undergraduate education cannot be defined or measured because the activities of the institutions are too complex and varied, because different institutions have different objectives - Reputational measures argues that quality in this view is whatever people think it is.. . The resource measures equate quality with an institution's educational resources: highly trained and prestigious faculty members, affluence, and bright students . . Outcome measures argue that the ultimate test of an institution's quality lies not in its reputation or in its resources but rather in the quality of its products . . . Value-added measures, another popular assessment method, is also known as the institutional impact approach. (pp. 10-15)

Astin (1982) explained the difficulty of using these traditional approaches. The nihilist view denies that valid quality assessment is possible at all. The resource approach correlates level of quality to the amount of resources (which is, in effect, a value-added argument), but there is little empirical evidence to support such a direct relationship. 
In addition, Astin (1982) noted the reputational and resource approaches limit the possibility of system quality because resources, including the best faculty and students, are finite. Astin said:

In a highly competitive and meritocratic society, the distribution of these resources tends to become highly skewed, with just a few colleges and universities at the top and the majority of the institutions being regarded as mediocre. I (pp. 11-12)

He added that resource-based concepts of quality tend to cause educational institutions to expend their energies on accumulating resources rather than on finding ways to utilize resources more effectively. Value-based concepts of quality are also limited, Astin noted, because the data needed is complex and potentially controversial, and the process of gathering it can be time-consuming.

According to Delene and Bunda (1991) the nihilist, the reputational, the resource-based, the outcome-based, and the value-added approaches do not recognize that in the unique world of education, student and parental choices are dominant forces in institutional selection and strongly impact most other decisions made during matriculation. For that reason, although this researcher takes into account the effect of perception (an important component of the reputational approach), this study attempts to move beyond mere opinion to ferret out the motivation behind the opinion. 
Other significant work in the field (Ewell, 1988) focused on changing strategies and the funding implications of various assessment prograns within the dynamics of American higher education.

Additional work by others (Hinchberger, 1990; Leslie \& Conrad, 1986; Bassis \& Guskin, 1986) likewise articulated value-added, "fitness for use," funding levels, and the declination of standards; a resource approach via state allocations; and research and scholarship as measures of quality in American higher education.

Overseas, Delene, and Bunda (1991, pp. 1-2) referenced several reports. A report on Canadian higher education advocates an approach focused on student development (Gilbert \& Evers, 1989). A report on higher education in Africa used descriptive data on instructional materials and class size to comment on quality (Moock \& Jamison, 1988). A report on Dutch higher education, on the other hand, defined quality in terms of goals and resource input factors (De Weert, 1990).

Both foreign and domestic research have varied significantly in the approaches researchers have taken to defining and measuring quality. Using any one of these studies as a strict guide for evaluating student support services becomes questionable when higher education is viewed as a complex service industry (Delene \& Bunda, 1991). Delene and Bunda argued that: 
as a service industry, most institutions in higher education are dependent upon customer decisions for a significant portion of their revenue and the attraction of new customers (students) from word-of-mouth referrals, a classic marketing activity. (p. 2)

Portland State University, then, must offer such support services and other inducements as to optimize itself to be chosen by students as it competes for these customers with area community colleges, business, trade and technical schools. Like any paying customer, students will naturally enough want to go to a school where they feel they will be well treated, well accommodated and appreciatively responded to. In short, they want "their" school to be responsive to them. By addressing levels of student (dis) satisfaction, this study provides a way for PSU to gauge just how "responsive" to them the University's students feel the university is. In turn, these results and revelations may be used by the University to make itself more "customer-ready."

"Quality is defined by the expectations of customers" (p. 5). Delene and Bunda supported this hypothesis by presenting the findings from a research study on hospital patient satisfaction conducted by Press and Garvey (1991) involving 73,000 patients from 124 hospitals. Reflecting the importance for these patients of "bedside manner" over technical skills, the findings--among them, that patients make "judgments about their care based on how they are treated," and that [patients'] beliefs that their medical 
care is 'good' may contribute as much as one-third to the actual healing process" (p. 5)--Delene and Bunda adapted into generalized hypotheses applicable to higher education. Among these are that students judge their education based on how college personnel--faculty and staff--treat them, and that students' beliefs that their education is 'good' may contribute as much as one-third to their educational process" (p. 3). In short, in either the medical or the educational setting, customer satisfaction is not a peripheral matter but one central to the customer's perception of that setting, and to the progress he or she makes within that setting.

A student-satisfaction model of service-quality research has implications that go beyond choice of methodology. According to Delene and Bunda (1991), this model demands that institutions look at and treat students as customers, a change that is already occurring in numerous for-profit and non-profit organizations. As this change continues to occur, it will become increasingly incumbent on schools like PSU to address issues of student satisfaction in order to remain competitive and enhance/their competitiveness. Countless matters will arise that will require PSU or another school to approach them with a "business mindset" in order to properly handle them. For example, a drop or rise in the quality of applicants could be tied to market factors by institutional managers and 
addressed with marketing or service changes, as business managers do with customers (James, Alsalam, Conaty, \& To, 1989). Again, this research study, by focusing on the satisfaction levels of student-customers, should help ease University administrators, officials and other personnel into just such a mindset.

In this study, a "market driven model" for the assessment of service quality in higher education and its implications for service management is presented. This model will be applicable to a full array of university service offerings, including financial aid, residence halls, dining services, and records and registration services.

Higher Education as a Service Industry

Delene and Bunda (1991) characterize higher education as a service industry. The market offerings of service industries are characterized by three primary attributes: the intangible nature of the core offering (product or service), the simultaneous nature of service production and service consumption, and the customer's participation in the production and delivery of the service. For example, the lecture is "produced" by the professor as it is simultaneously "consumed" by the student. It is interesting to note that the U.S. Department of Commerce has classified educational services as service industries (p. 4). 
The products and services offered by institutions of higher education include degrees and courses of study, which carry varying prices and are available at many locations from a variety of institutions. Educational services are presented to prospective buyers through a mix of promotional materials, including direct mail and telephone solicitations, campus tours, discounts (via financial aid and scholarship offers), and the provision of a package of institutional support services. In addition to core service offering, students may also receive employment and placement assistance, housing, health services, and recreational facilities, although degree and courses remain the core market offering.

Prospective buyers (students) sort through the offerings of various institutions and make their choices based on the internal, institutionally determined offerings and related support services, as well as on buyer-specific external variables such as social, cultural, legal, political, economic and technological factors. Colleges and universities have little or no control over these factors. of course, the perceived value of specific religious affiliation makes such colleges more attractive to some students, and federal and state statutes that limit the portability of financial aid also affect students' choices. Admission criteria based on parental demographics constitute political constraints, as do institutional quotas on 
admissions to certain university departments. These external, uncontrollable factors may serve as an accelerator or brake on individual choice, or restrict the courses, degree and services (Delene \& Bunda, 1991, pp. 4-6).

Figure 1 illustrates the marketing and environmental factors which affect the institutional choice of prospective students (and their parents).

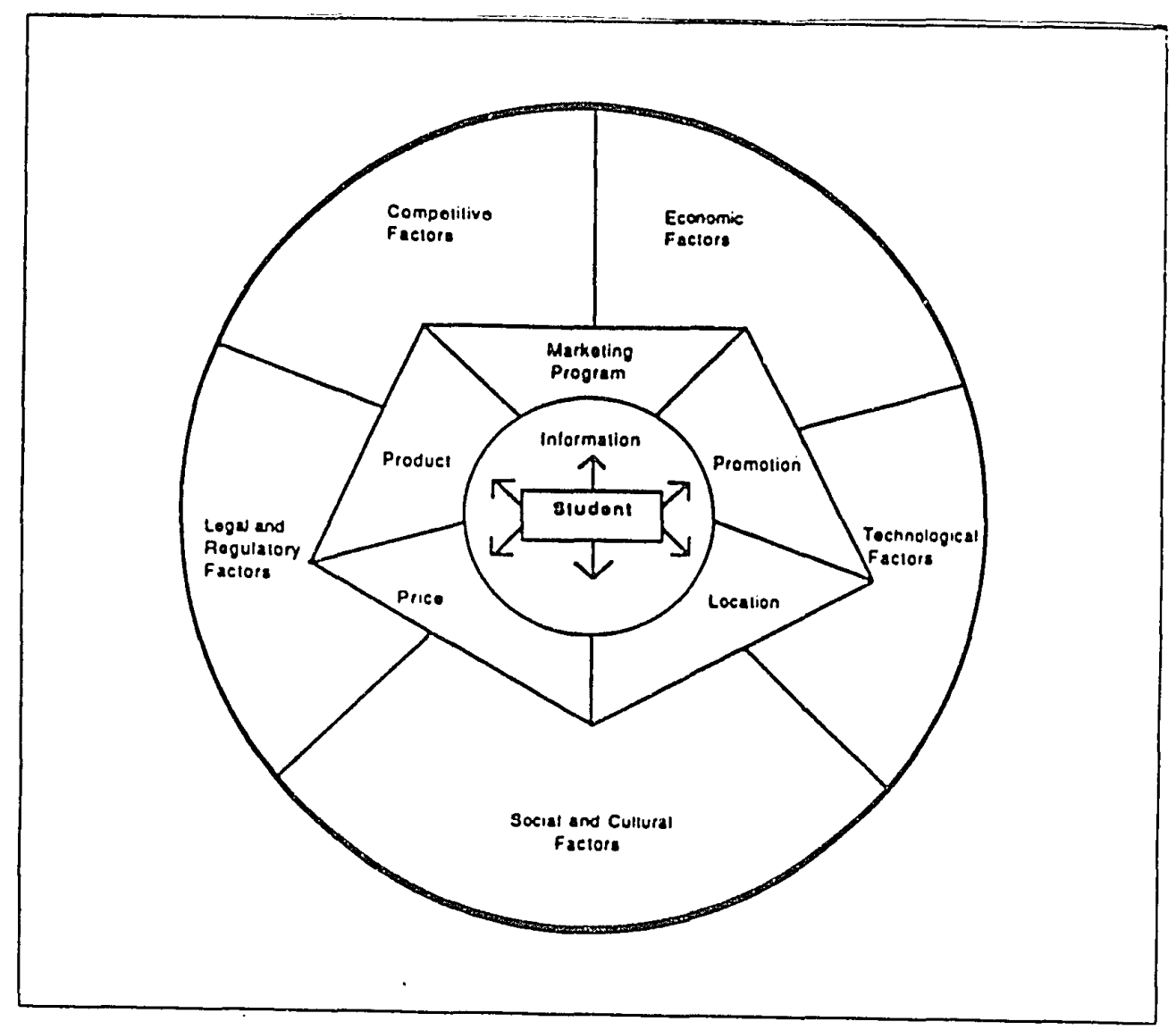

Figure 1. Marketing and environmental factors. Adapted from Delene and Bunda (1991, p. 15). 
This illustration applies to the instance of a university a traditional marketing model in terms of those factors-product (or service), price, promotion, etc., as well as various external environments--that a non-profit organization routinely considers when it determines market offerings. To be sure, regarding Portland State University, the application of this marketing model does not result in an exact fit; the school is obliged to account for factors that in no way are a part of the marketing model. For instance, a public university may have formal goals unrelated to the model, such as increasing the number of persons trained to fill specific occupations, such as elementary-level educators, forestry experts or general-practice physicians; or providing a community service to the town or state in which it is located. As in the case of a private university, a public one also has a paramount goal the production of learning--not just in the education of students but in the contributions its faculty make to scholarship, research and invention. Nevertheless, the illustrated model is extremely helpful in sketching the broad outlines of the "business mindset" PSU and other public (and private) universities can adopt in order to enhance the degree of student-customer satisfaction they generate, thus in turn enhancing their competitiveness in terms of recruiting and maintaining students, and in turn enhancing the institution's financial viability. 
According to Delene and Bunda (1991), customer satisfaction should be the central, radial concern of a university, whose "customer" is the student. This centrality "is reinforced in market-oriented companies by the continuous research and measurement of customer satisfaction." Such research has revealed that customer satisfaction is closely tied-in with customer expectations and the degree to which the product or service the company offers meets those expectations. In term of a student's expectations, this inevitable "are modified by actual institutional experience." It is this modified expectations which form a student's judgment or assessment that a student communicates to others, giving a school its word-of-mouth reputation, upon which so much of the school's market drawing-power depends. Therefore, whatever about the school inspires or instigates a student's assessment of it should be of paramount interest to the school, which can translate such knowledge into making the school more appealing and conducive to its customer-students. In sum, the "market-driven view of education as a major service industry" that Delene and Bunda (1991) promoted "establishes the basis for the assessment and measurement of service quality" (p. 8).

If colleges and universities recognize the provision of high-quality educational service as an important competitive advantage, they can either change their promotional 
activities to improve student (customer) expectations or, alternatively, alter the college's services themselves to create the desired change in expectation. Either choice requires costly, long-term adjustments, but the experiences of businesses indicates that customers are most satisfied-and most likely to remain customers--when expectations and experience are closely matched (Delene \& Bunda, 1991, pp. $6-7)$.

In order to begin this process, institutions must determine how students form their initial expectations about the educational services they are to receive, as well as determine what institutional units provide services to students and how well they do so.

Each item in Figure 2 is linked with the outside rim path to the other items and is a two-way path of influence on expectations and continuing institutional experience. Additionally, each individual unit, represented by the spoke of the wheel is linked to the global service quality rating of the institution.

Several implications for the design of student support services were underscored by Delene and Bunda (1991, pp. 9-11). Among them is that there should be a match between the kind and extent of support services the institution claims to offer and what it is capable of providing and in fact provides. Where there is no such match--as in the case of a college bulletin proffering photographs of a 
student-filled placement office and numerous on-campus job recruiters when the institution either provides no such services or does so in a lower capacity than the photographs suggest--the student, misled, (rightfully) feels "cheated."

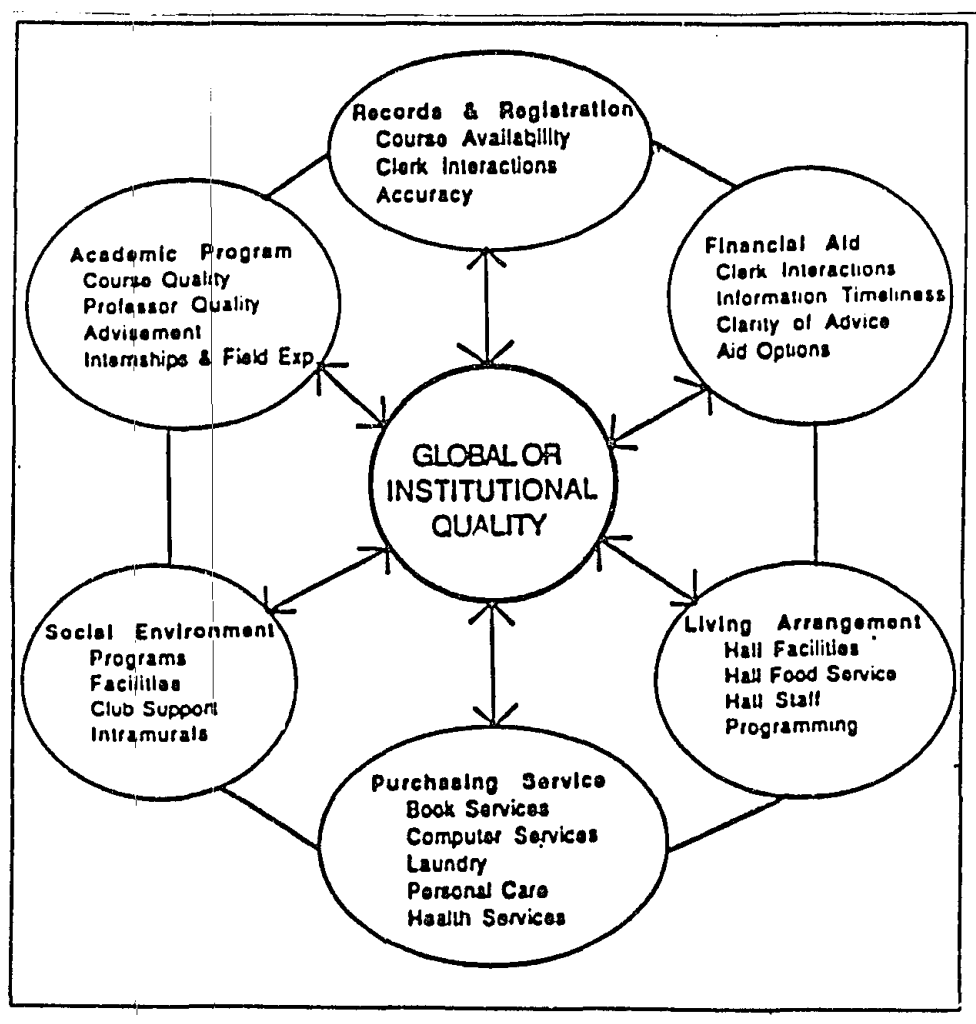

Figure 2. Blueprint of service quality influences. [Adapted from Delene and Bunda, $(1991$, p. 16).]

Another aspect is that the relative amount of resource allocation to services that the institution provides should roughly match the relative importance of these services to the students themselves. Furthermore, there is the overarching matter of atmospherics--the degree to which 
school faculty, staff and administrators, because it has been conveyed to that they should do so, generally conduct themselves vis-a-vis students, and decision-make regarding students, with the needs and interest of the students foremost in their minds. Along with this, there should be a "shift from a focus on process" on the part of the institution so that at every point the school is decisively responsive to the needs of individual students. For instance, if a student has an unresolved credit transfer problem, this issue, as well as any other, should be resolved--clearly, definitively, with no "pass-along" of the student to some other link in a bureaucratic chain--"by the initial contact person regardless of whether that contact person is a member of the faculty, the record office staff or admission personnel." In sum, the school should be at the service of the students, not vice versa.

clearly, school administrators need reliable guidance in the matter of so radically reshaping or reconstituting the university mindset. A "strong/internal marketing program," Delene and Bunda (1991) concluded, "should help administrators in higher education define service quality and support its measurement in their respective institutions" (p. 11). Moreover, the authors seek to contextualize the service quality assessment they advocate even more broadly, not only by recommending that the assessment of the service quality of any campus unit must be 
made with reference to all other units of the campus, but by also relating such an assessment to "the global measure of service quality" (p. 12). In short, no university unit exists in isolation of other units of the university, and no university can reach reasonable self-assessment in isolation of the service quality provided by other schools inside and outside the nation's borders. Higher education is part of a global market.

Measures constructed for the path analysis, rather than taking root in historic goals or existing policies, should be based on student expectations regarding service quality (Delene \& Bunda, 1991; Daigle, 1989). The research study conducted by Zeithaml, Parasuraman, and Berry (1990) suggested 10 determinants in designing an instrument to measure service lquality: access, communication, competence, courtesy, credibility, reliability, responsiveness, security, tangibles, and understanding and knowing the customers. Eliciting information from students as to how well they perceive PSU to be "performing" in this areas, therefore, was the deliberate aim of the questionnaire and interviews for this research study. In either forum, what students were asked, specifically or generally, was formed and informed by this aim. 
Research on Service Quality Assessment

in Higher Education

Hundreds of evaluative studies have been carried out at higher education institutions in the United States in past two decades. These studies vary significantly in their intent, focus, goals and perspectives. Three representative evaluative reports are featured in this section.

One of these reports, conducted at CSU in the 1980s, concentrated on one state system with several campuses. Its main purpose was to provide the system with a wide range of policy and research data for use within the system (Daigle, 1989). Specifically, some of these data were intended to provide the system with bases for comparison of its several campus units and of csU to other institutions, survey data about students (family backgrounds; employment, educational and life goals; transfer plans, etc.), and evidence, from SNAPS findings, "to support funding requests and administrative initiatives and innovations in such things as advising, student services, campus social life, academic support programs, and curriculum" (p. 2). In this last respect, although somewhat indirectly, the collected data suggested the kind of responsiveness to student concerns and sensitivities with which this present research study is more directly concerned.

Whereas the CSU study was one of an intermittent series of such studies conducted by the university, other internal 
evaluations elsewhere, occur annually. One of these, the Annual Evaluation and Report (AER) undertaken at Michigan State University, impacts planning and budgeting at the university (Munitz \& Wright, 1980). The AER system relies on self-evaluations from each department assessing strengths and weaknesses in such areas as instruction, research and professional activities, public service, and information on needs not otherwise addressed. These evaluations from all departments are then coordinated at the at the dean's office, which provides further assessment to help the central administration with its final qualitative determination: Student participation, which is encourage, also makes a contribution to a second section of the AER that is focused on the university's plans for the future which are codified into both "college change plan" and a "college flexibility plan," which are returned to the office of Institutional Research, which then forwards to the provost its own summary of departmental trends and issues of concern. This, in turn, the provost discusses with the respective deans, who in turn discuss it with their department chairs. In the final stage of the AER process, the findings are used to generate budget recommendations by the provost.

Another, one-shot program evaluation was undertaken in 1975 at the University of Houston's Central Campus. This accreditation self-study, which the Southern Association of 
Colleges and schools (SACS) reviewed, sought to delineate the school's educational mission relative to that of three other campuses in the University of Houston system, and to formulate responses to changes in Houston's dynamic population.

In particular, a steering committee made up of faculty, students and administrators evaluated each degree program and develop quality goals with a five-year timetable in an effort to chart a viable course between enrollment demands and funding realities. Each college in the university developed a mission statement and assembled standard student and faculty data packages (student enroliments, graduation rates, faculty and staff workloads, etc.).

These data packages were intended to address more than a dozen criteria used in evaluating the colleges' various programs. Although some of the criteria, such as "program consistency with central campus role and scope," were structural in nature, many more reflected an interest in, and a responsiveness to, student satisfaction. These included current and potential faculty quality, student demand to major in a given program, the "demand of non-majors for program courses," the "adequacy of library holdings to support the program," the adequacy of program facilities and equipment," and the "comparative advantage of the program over others offered elsewhere" (Munitz \& Wright, 1980, p. 32) 
This last criterion in particular shows the extent to which it and other of the criteria point the college in the direction of avowed competitive marketability.

The full steering committee reviewed preliminary evaluations, and then interviewed each dean in order to determine "the relative centrality of [each] program to both its college mission and that of the institution as a whole" (Munitz \& Wright, 1980. p. 32). The steering committee's final report provided not only evaluations but specific recommendations.

Unlike the California State University (Daigle, 1989), Michigan State University (Munitz \& Wright, 1980), and University of Houston (Munitz \& Wright, 1980) studies, and countless other similar or related studies, this present study focuses exclusively on the needs and levels of student satisfaction based upon "market driven model." This fact places this study in a small minority. Indeed, only one such other study (Culha, 1974) that this study has unearthed involved a comparison made between domestic and international students regarding student satisfaction. As a result, another difference emerges between this study and those preceding it, of which the three studies that have been summarized are representative. Whereas those institutional studies, tied up with the existence and future of their respective schools, take "a long view," this study focuses on individuals--students--who tend to be "tied up" 
to their school only so long as they are in attendance. Theirs is a short-term view, based solely on their own perceptions; they are not committed per se to the institution they are attending. However, the needs of these students, because they will be replaced by other students with similar needs, may be used to ascertain, in certain aspects, the needs of the university itself. Assessment such as the one undertaken for this study could be made part of similar evaluative efforts, in order to measure student needs and satisfaction with ongoing efforts by the institution.

\section{Needs and Satisfaction of} American students

As students, U.S. students have varying needs, and the degree to which each if these is satisfied may differ. However, few research studies were conducted on the needs and satisfactions of college students in the U.S. prior to the campus disturbances of the 1960s. This section presenting related early and contemporary works on needs and satisfaction of American students, shows how little has been done in this area.

Roy (cited in Culha, 1974) developed a College Satisfaction Index (CSI) in 1949, which was modified and used by Gamelin in 1953. Gamelin's investigation focused on the satisfaction levels of college freshmen from 10 Minnesota colleges. In 1968, Berdie, Pilapil, and Im 
adapted the college Satisfaction Index to study the satisfaction of graduating seniors at the University of Minnesota.

In 1970, Betz, Klingensmith and Menne examined the relationships between aspects of student satisfaction and three demographic variables: sex, type of residence, and year in college. They found that the type of residence was related to satisfaction with the academic aspects of college, with working conditions and with social life. The following year, Betz, Klingensmith and Menne developed an instrument, the college student Satisfaction Questionnaire (CSSQ), which consisted of 70 items representing five scales (Working Conditions, Compensation, Quality of Education, Social Life and Recognition)--areas of concern, in general, far afield from the concerns of international students. The Theory of Work Adjustment (Dawis, England, \& Lofquist, 1954) was the theory behind the investigation made by Culha (1974). Culha found out that both U.S. and international students "had high needs on almost every aspect of academic life studied . . [and] that foreign students are less satisfied with academic life, than American students" (p. 117). Culha also found out that the:

degree of similarity between the culture of the native country and the host country is related to academic satisfaction--the more similar the cultural background is to the American culture, the more satisfied the foreign student group with aspects of academic life. (p. 117) 
An interesting but not quite relevant dissertation in education at Portland State University is Changhua Wang's Friendship Patterns of Chinese Students and Their Adjustment in the United States (1993). This dissertation does, however, touch on these students' sense of cultural dislocation, which in turn leads to the friendship patterns they form, with Americans as well as among themselves, as part of their adjustment to their new and strange environment.

In 1981, Daigle summarized the results of a needs survey for 8,564 students at 12 campuses of the California State University system. He reported on student needs and priorities while attending California State University, including life goals and educational priorities, attitudes concerning academic and social experiences on campus, and institutional and personal problems. Findings varied by age, ethnicity, sex and class level (lower and upper division and graduate division day and evening students). Findings included: career considerations dominated all other educational priorities; the most pervasive student goals focused on practical and immediate rewards; campus choice was influenced by program availability and reputation, as well as cost and convenience to home and work; academic concerns were more important to students than campus support services or social activities; $30 \%$ gave generally negative evaluations of instructional quality, citing poor 
communications skills and lack of interpersonal concern among faculty; and about one-fourth expressed serious concerns about college finances. External factors (e.g., family obligations, job, finances, personal problems) were cited by $40 \%$ as impeding the achievement of educational objectives, while campus obstacles were noted by $25 \%$. similar studies were conducted in the same state in 1984 and 1989.

Barrow (1989) suggested that multiple sources of information should be used to assess student needs. There are two reasons for this. One, of course, is that the corroboration of results lends added credibility to the information gathered. The other is that a more complete picture of a student needs comes about, with information from one source completing the information gathered from other sources. Apart from the students themselves, there are many number of groups of individuals whose interaction with students make them worth listening to in assessing student needs. For instance, counselors have been identified as playing an important role in students' lives. Their role is to liscen to, encourage and assist students, and to have clear perceptions of the diversity of student needs (Farber, 1987). According to Farber's research, counselors can help the administration to form a fuller picture of student needs, including academic interests, co-curricular activities, mental and physical health, 
economic support, and family/social commitment, based on their interactions with students.

\section{Problems and Needs of International students in U.S. Higher Education}

Few contemporary research studies have been conducted on the problems and needs of international students in U.S. higher education. The extremely limited nature of such research is amply suggested by the fact that, by telephone (April 1995), the following individuals confirmed to me that they also were unfamiliar with the existence of such research: Gary Althen, University of Iowa; Mark Mendenhall, School of Business, University of Tennessee at Chattanooga; Dan Landis, University of Mississippi; Tod Davis, Institute of International Education, New York; and Elizabeth Bell, Field Services Program, National Association of Foreign Student Affairs (NAFSA). (This researcher also found no relevant studies more recent than 1970 at the Intercultural Communication Institute Library in Beaverton, Oregon.) None of these studies compare U.S. and international students to see if indeed international students' problems and needs are distinctive and require special consideration. Nevertheless, some recent studies have been useful with this study. For instance, this study adapted for its purpose part of the questionnaire used by Daigle (1989). Moreover, some of the questions posed to international students as part of this study were derived from the results of other 
recent studies. For instance, Boyer and sedlacek (1986) found financial expenses to be of paramount concern to international students at the University of Maryland at College Park. Therefore, questions related to such financial concerns were formulated to this study. Several older studies, though have identified some problems of international students that remain relevant, as indeed this study indicates. Kincaid (1951) found that on seven California campuses, international students from developing nations reported no serious problems in communication, finance, housing or academic life. However, he found that a need to improve extracurricular activities was indicated. He emphasized the need to increase the interactions between international students and American families. Opportunity for travel in the U.S. was also emphasized. Cannon (1959) also identified some of the major problems of international students while attending American institutions of higher education. Among these were communication, finance-related difficulties and academic requirements.

A number of studies were conducted on the subject of international students in the U.S. during the 1950 s and 1960s; about half of these related to the "brain drain" phenomenon that caused many international students to stay in the U.S. rather than return to their home countries. The remainder include general surveys on international students, 
including research into predicting their academic performance in the U.S. based on various tests as well as on degrees or credentials earned in their home countries; and studies on their cultural, academic and social assimilation while in the U.S. and upon their return home.

While most of this data is over 30 years old, some of it is still valid as background material for the researcher into the education of international students. However, during the 1950s and 1960s the majority of international students in the U.S. were participants in U.S. government-sponsored programs to educate "elites" for developing or friendly nations, such as the programs administered by AID, or were participants in similar programs directed by their own home countries (Spaulding, Flack, Tate, Mahon, \& Marshall, 1976). Although such programs still exist, the majority of international students who attend American universities today are self-selected rather than brought in through specific programs with goals of indoctrination in particular political beliefs or building a cadre of skilled professionals to fuel overseas development.

Moore (1965) identified the problems of international students as follows: (a) English proficiency, (b) culture, (c) differences between American educational system and foreign student's "home" educational system, (d) adjustment 
period, (e) legal, (f) academic performance, (g) social adjustment, and (h) inadequacy of financial resources. Similar to Moore's (1965) findings were those of Rising and Copp (1968), where English language proficiency was identified as the major problem. Coupled with this problem were accommodations, American food, shopping, privacy, transportation, etiquette and use of facilities. Boyer and sedlacek (1986) found that although international students have strong academic skills, high educational aspirations and positive attitudes towards their school, they still face many difficulties in their adjustment to higher education in the U.S. The study was conducted with 164 incoming international students at the University of Maryland at College Park. The results indicated that international students took their education quite seriously and valued it both for the intrinsic reward of academic pursuit and for career-related reasons. However, the students anticipate that the hardest part of adjusting to college involved meeting financial expenses. Schliessmann (1986) also found that criticism of the university by international students was inhibited because many international students come from countries where free speech is not a political right and where many feel it is improper to criticize their government or its institutions. Some students indicated privately that they feared being reported to their government by their student colleagues if 
they spoke out in the U.S. This can have a "chilling effect" on international student participation in student government or in groups attempting to put pressure on the university to meet specific student demands. After all, student demands on universities in other nations have been met with force, as in the ongoing student unrest in Korea and France in the 1970s and 1980s, the Tiananmen Square killings in China in 1989, and the Mexico City University massacre in 1968. It is important to keep student fears such as these in mind when working with this population. Although there appears to be growing concern about the needs of international students, research on these needs has been limited. There have been studies on needs for special counseling for international students (Altscher, 1976; walter, 1978), assistance in learning to budget their time efficiently and achieve satisfactory grades (Molla \& Sedlacek, 1989), more relevant education (Coombs, 1961; Jenkins, 1983; Moore, 1965; Sanders \& Ward, 1970), more extracurricular activities (Arubayi, 1979; Canter, 1967; Kincaid 1951), more opportunities to improve their ability to speak English (Eid \& Jordan-Domschot, 1989; Deressa \& Beavers, 1988), work opportunities on campus (Eid \& Jordan-Domschot, 1989; Molla \& Sedlacek, 1989), and encouraging a continuing relationship with the U.S. academic community after returning home (Eberhard, 1970; Mackson, 1975). However, there has been little comprehensive 
research conducted to indicate how well such needs are satisfied under the current practices (Lee et al., 1981). The study by Culha (1974) is one of the few that have focused on international student needs and satisfaction. Culha compared the needs and satisfactions of international students at the University of Minnesota to those of a group of U.S. students. He used two instruments, the Foreign Student Importance Questionnaire (FSIQ) and the Foreign Student Satisfaction Questionnaire (FSSQ). Ninety FSIQ and 90 FSSQ questionnaires were sent to a randomly selected sample of foreign and U.S. students. The areas compared included: ability utilization, achievement, social activity, creativity, living conditions, social status, basic values, friends, university rules and procedures, instructors, curriculum, counseling-advising, opportunities to become familiar with the U.S. culture, emotional security, financial security, and overall satisfaction. The only difference between the two groups was found on the emotional security scale, on which the U.S. student group scored higher than the foreign student group. This study, like many others, has limited generalizability, because the study was conducted on one campus (Lee et al., 1981).

In 1981, Dr. Motoko Lee of Iowa State University conducted a nationwide survey to assess the self-perceived needs of Agency for International Development (AID) sponsored students and other sponsored and non-sponsored 
students. The nearly 1,900 students who responded to the questionnaire were composed of students from 102 nations in 30 selected universities. The findings concluded that in every category of needs, needs were not satisfied to the level of students' expectations, even though most of the needs were satisfied to a certain degree, rather than unsatisfied. Needs for practical experience, financial needs, pre-return information needs and anticipated post-return needs (to students' own country) were among the least-met needs for international students.

In the review of this literature and consultation with students and student personnel professionals, the following general areas of need for students were identified and/or implied: (a) faculty and instruction, (b) academic support, and (c) student services. These three areas of needs delineate the three broad areas that chiefly contribute to a student's successful academic experience. The first, faculty and instruction, relates directly to classroom learning; the second, academic support, includes those facilities and services that the university provides--such as libraries and labs--that help students with their learning outside the classroom; and the third, student services, includes those facilities and services--such as campus housing and child care--that more generally help students, in non-academic areas. All three contribute to an atmosphere and an environment in which students are better 
able or less well able to function successfully as students, depending on the degree of excellence and the amount of support the university provides in these areas.

\section{Implications and conclusion}

A review of the literature indicates that while there are hundreds (even thousands) of research evaluations carried out yearly on specific programs, very few studies focus on students' appraisal of service quality in higher education. Instead, as stated by Bassis and Guskin (1986) indicate, they base their assessments of schools and school programs on such considerations as funding levels, the availability of state resources to be allocated, and research and scholarships--all of which, by ignoring them, suggest a failure to appreciate the centrality of student needs. Moreover, although these studies are all evaluations, they vary significantly in their approaches to defining and measuring quality (Delene \& Bunda, 1991).

Lee et al.'s (1981) Needs of Foreign students from Developing Nations at U.S. Colleges and Universities, and Culha's (1974) Needs and Satisfactions of Foreign students at the University of Minnesota, are both descriptive survey assessments. The "how's" and the "why's" of student needs and their satisfaction have not been sought by these studies, and these studies were undertaken one and two decades ago, respectively. Other studies referenced in this 
study show that U.S. and international students have problems and needs that higher education needs to address. This research-based study attempts to fill the gap between this and previous studies by using techniques more common to business to assess the service quality of one institution of higher education in the United States by its customers (students). Findings of the descriptive statistical assessment survey were used in a focus-group setting to further understand and relate the propositions in this proposal. Demographic data were also collected in order to make explicit at least some of the underlying causes of student satisfaction or the lack of it.

The above strategies also identified the present problems and needs of students attending institutions of higher education in general and Portland State University in particular. Very few contemporary studies have been conducted on the needs and satisfaction of international students. Almost none compare U.S. and international students, and almost none look at potential effects of various variables. The world changes rapidly, and so do the problems and the needs of students. A study undertaken five years ago might bring entirely different results today, even on the same campus. Therefore, U.S. institutions need to keep up in their understanding of student needs brought about by these changes. Hopefully, this study will help administrators, faculty and staff understand some needs that 
international and domestic students may have at Portland State University.

Furthermore, this study may add to knowledge of

customer (student)-driven quality evaluation. Madaus,

Scriven, and stufflebeam (1983) asserted that:

there is a need for expanded efforts to educate researchers and evaluators to the availability of new techniques, to try out and report the results using the new techniques, and to develop additional techniques. In all of these efforts, the emphasis must be on making methodology fit the needs of society, its institutions, and its citizens, rather than vice versa. (p. 18)

This research is geared toward accomplishing this goal.

Madaus et al. (1983) further argued that:

evaluation professionals must ensure that efforts to improve their profession are geared to the service needs of their clients, not merely designed to serve their private or corporate needs. Ultimately, the value of program evaluation must be judged in terms of its actual and potential contributions to improving learning, teaching and administration, health care and health, and in general the quality of life in our society. (p. 18)

This research hopes to serve that purpose as well.

And finally, as Popham (1988) pointed out,

there is a continuing drive toward educational accountability in this country. Taxpayers want the schools to deliver evidence that they are giving the society its money's worth. supplying this evidence characteristically requires educational evaluation. School boards, lawmakers, and administrators have to be provided with evaluation reports that indicate how well the schools have been working. The state's citizens have to be supplied with evaluations of various aspects of the state's educational enterprise. (p. 9) 
This project may provide some such evidence. It is therefore concluded that this study is necessary and timely. In summary, Chapter II is an attempt to bridge the gap between theoretical and methodological prescriptions for educational evaluation and practice. Related studies on educational evaluation were presented along with their implications, to delineate the relationship of this study to previous undertakings. 
CHAPTER III

\section{METHODS AND PROCEDURES}

Introduction

This chapter explains the framework of the study by defining the design, conceptual framework, research questions, study propositions, samples, instruments, procedures and data analyses.

\section{Research Design}

The design of this study is twofold: a descriptive survey (Weisberg et al., 1989) and a descriptive focus-group study (Delene \& Bunda, 1991; Greenbaun, 1989; Hayes \& Tatham, 1989). These methods were determined to be most appropriate for this type of study because they do by nature solicit extensive information, which leads to new evidence and adds knowledge to the field of educational research. The first method was used to gather and describe the subjects demographically and to discern the relationships of the different variables and the quality of services of Portland State University, which is the central focus of this study. The second method was used to further explore the reasons behind the survey's results, and uses focusgroup sessions. 
The integration of the two methods into: one research venture is highly: recommended by Chinapah and Miron (1990), and Hoaglin (1982), who posited that survey results can lead to a new evidence for further exploration inla focus group study.

Conceptual Framework

This study was developed from several conceptual perspectives:

1. Evaluation and assessment theories, |personenvironment interaction theories and the theory of work adjustment, all of which supplement one another in some way;

2. Consultation with students and student personnel professionals, as well as the researcher's personal experience, which/were used to generate background information questionnaire items;

3. Daigle's (1989) questionnaire items/on needs and satisfactions, which, with a few modifications, were found most appropriate and reliable for this study. (The Daigle questionnaire was/used several times on different campuses at California State University);

4. Although the primary objective of this research study is to generate descriptive information/and araw conclusions, the generated information may also be used for "formative" purposes (Stufflebeam, 1983; Worthen \& Sanders, 1987); 
5. The concepts and procedures of gathering information chosen are associated with the "management" and "consumer" approaches of evaluations (Delene \& Bunda 1991; Worthen \& Sanders, 1987); and

6. The focus-group study, an additional approach to this research, was used to complement and explained the result of the first approach, a descriptive survey.

Research Questions

This research sought to answer the following broad questions:

1. What is the demographic profile of students at Portland State University?

2. What is the importance of the various [need] service quality statements to international students at Portland State University? What is the current level of satisfaction of international students in regard to these [need] service quality statements?

3. What is the importance of the various [need] service quality statements to U.S. students at Portland State University? What is the current level of satisfaction of U.S. students in regard to these [need] service quality statements?

4. Do U.S. and international students at Portland State University differ in the importance they assign to the [need] service quality statements? Do U.S. and 
international students differ in their level of satisfaction with the [need] service quality at Portland state University?

5. For each service quality statement, what is the relationship between the perceived importance and level of satisfaction for U.S. students? For each service quality statement, what is the relationship between the perceived importance and level of satisfaction for international students?

6. What are the perceived reasons for dissatisfaction concerning the service quality of American and international students? What suggestions do these students have for improving the quality of services?

\section{Variables}

The variables of importance are the adequacy of: (a) Instruction, (b) Academic Support, and (c) student services as perceived and rated by a random sample of U.S. and international undergraduate students at portland state University. The demographic variables are: status of students (U.S. and international), gender, length of stay at PSU, age, academic level and major fields of study.

\section{Instrumentation}

The first segment of this study, the descriptive survey, contains two sets of data. The data were gathered 
from a survey mailed to 225 international and 225 U.S. fulltime undergraduate students at Portland state University during the spring of 1993. (Part-time U.S. students were not studied because foreign nationals on student visas need to attend full-time to fulfill their legal obligations.) The first set of data was used to generate demographic information. Some of these data include: student status (international [F-1 visa] or domestic [U.S. citizen and permanent resident]), gender, field of study (academic major), length of stay at PSU, planned length of stay in U.S., age, academic level, and other information, such as sources of financial support for college education, living arrangements, grade point average (GPA), reason for selecting PSU, problems while in school, and hours spent in studying.

The researcher expected that many of these variables would be found to have an impact on levels of needsatisfaction, indicating areas for further study and, potentially, for changes in institutional policy or services. It seemed likely that this demographic data would bring trends in student needs into focus: for example, the data might suggest that foreign students who live on-campus have a greater or lesser need for tutoring services than those who live off-campus.

The second set of data addressed student evaluations of campus instruction, academic support and student services. 
This set of data assessed U.S. and international student needs, with respondents assigning a value to each need regarding instruction, academic support and student services, and registering their level of satisfaction with how each need is being met at PSU.

After obtaining permission from Human Subject Review Committee, a random sample of international and U.S. students was selected from the records of the office of Institutional Research and Planning at Portland state University.

The second component of this study, the focus group study, invited students to assist the researcher in interpreting the meaning of the results of the first design, guided by the propositions stated earlier. The focus groups were made up of a sample of international and U.S. students chosen to ensure that any patterns or areas of interest were thoroughly addressed and explained.

Two research instruments, one a questionnaire and another focus group interview, were used in this study. The first part of the questionnaire included 26 questions concerning demographic and background information. The second part of the instrument, adapted from Daigle's (1989) Student Needs and Priorities Survey, was designed to allow respondents to assess how well their needs for instruction, academic support and student services were being met, and to rank them according to importance. Daigle's $(1.981,1989)$ 
questionnaire has been tested and found valid and reliable and has been proven to work well in gathering desired information for the purpose of evaluating three broad areas of educational assessment--faculty and instructional quality, academic support, and student services. Each of the items in column A (degree of importance of needs) has four possible answers that respondents are asked to rank on a scale of: 1--very unimportant, 2--somewhat unimportant, 3--somewhat important, and 4--very important. Items in column B (satisfaction of needs) also have four possible answers that respondents may rank on a scale of: 1--very unsatisfied, 2--somewhat unsatisfied, 3--somewhat satisfied, and 4 --very satisfied.

A four-point Likert scale from "very unimportant" to "very important," and "very unsatisfied" to "very satisfied" was used. "The option for including an "undecided," or neutral, position was eliminated to avoid a potential minimal variation of responses. When a neutral position is an option, the research tends to assess the respondents' knowledge" (Masciocchi, 1990). This study was consciously designed to obtain a definite opinion from respondents.

A general evaluation of instruction, academic support and student services, as well as an open-ended question, were included at the end of the questionnaire. Although Daigle's (1989) questionnaire has proven to have worked well and has been tested for its validity and 
reliability in the past surveys at 18 different California State University and college campuses in 1981 and 1989, the instrument was still pilot-tested. The purpose of administering the pilot test of the questionnaire was to find out whether or not the questionnaire was capable of gathering data that would answer the research questions of the study and whether the questionnaire items conveyed the meaning intended by the researcher. As part of the pilot test, interviews were conducted personally by the researcher to find out whether the questionnaire was clearly understood by the respondent and to find out specifically which items were hard to understand and in need of change.

The researcher sought the assistance of English as Second Language (ESL) instructors for the distribution of questionnaires for pilot testing among international students in Level 1 to Level 4 (these levels categorize the degree of proficiency in the English language, Level 1 being the least proficient). Out of 20 questionnaires distributed, 14 were returned. Comments and critiques were compiled, resulting in revisions in its content and form. Revisions were again made based on feedback from the researcher's adviser and other faculty members. The questionnaire was then finalized and approved by my dissertation committee members.

The final questionnaire was conceived after consultation with students and student personnel 
professionals, a review of various types of evaluation and assessment questionnaires, and an exhaustive review of applicable literature. Students and staff were interviewed regarding their opinions on the problems, needs and other concerns of students. The information gathered was then incorporated into a new instrument, also based in part on Daigle's (1989) questionnaire, which was found to be the most appropriate existing $\mid$ instrument.

The following importance and satisfaction-level questionnaire items, with|few modifications, were adapted from the "Student Needs and Priorities Survey" (SNAPS) (Daigle, 1989) conducted on California State University campuses in 1989 (see Table 2). The selected items below were used with permission/from Dr. Stephen Daigle of the Office of the Chancellor, California State University (see letter in appendix). Daigle initiated and is responsible for the surveys conducted at CSU in 1981, 1984, 1987 and 1989. In the SNAPS, the options for the respondents to determine the satisfaction of their needs are "excellent," "good," "fair," "poor" and "very poor." The options "very unsatisfied," "somewhat unsatisfied," "somewhat satisfied," and "very satisfied" were/used in this study because the writer thinks it more appropriate for this research. Items followed by $(*)$ were added, primarily because of the significance of these items as observed by this writer. The (*) signs were deleted in the actual questionnaire. 
Table 2

[Need] Service Quality Items and open-Ended Questions

\section{INSTRUCTION}

Instructional quality

Accessibility of the faculty

Fairness of faculty treatment of students in general

Faimess of testing and grading

Intellectual stimulation from faculty

Content of courses

Class size

Other: please specify*

\section{ACADEMIC SUPPORT}

Library collections

Library service

Lab facilities

Computer facilities

Academic advising services on campus

Pre-college advising

Pre-transfer advising

Catalog (Bulletin) and Schedule of Classes

Variety of courses offered

Availability of courses to finish degree on time*

Tutoring/basic skills services

Convenience of class scheduling

Other: Please specify*
STUDENT SERVICES

Campus housing

Recreation programs/activities

Student organizations*

Religious services*

Child care

Parking

Student health service

Psychological counseling

Financial aid office

Job search services*

Campus food services

Intercollegiate athletic programs

Career guidance from faculty

Career guidance from Career Planning Office

Social and cultural activities

Campus orientation programs

Special student services (e.g., affirmative action)

Other: please specify*

Please rate PSU in general according to its:* Faculty and instructional quality Academic support services Student services

Campus experience as a whole

If the university could change two things that would improve the quality of your life as a student at PSU, what would those be?*

Is there anything else you would like to say about your stay at Portland State University?*

Procedures and Analyses

The final copy of the questionnaire, a cover letter assuring confidentiality, informed consent form and prestamped envelope, were sent to randomly selected

international and U.S. students via bulk mail, which was received by the addressee within approximately 10 days. 
Addresses of students were obtained from the PSU Institutional Research and Planning office after having obtained permission from Human Subject Review Committee. There were three additional mailings to provide complete follow-up after the original mailing. The first follow-up was a postcard reminder, which was sent to everyone one week after the mailing of the original questionnaire. This served as both a "thank you" for those who have already sent back the completed questionnaire and as a friendly reminder to those who had not. The second follow-up, scheduled for three weeks later, was sent to those who had not responded, as indicated by records kept by the researcher. The second follow-up duplicated the original mailing except for the cover letter, which informed the prospective respondent that the questionnaire has not been received and appealed for its return (Dillman, 1978). The third and final follow-up occurred seven weeks after the original mailing. This final follow-up consisted of phone calls to students emphasizing the importance of the return of the questionnaire.

\section{Assessment Survey}

The first part of the instrument includes the background information asked of each respondent. The second part is composed of faculty/instructional, academic support, and student services items. The respondents were asked to make a choice under column $A$ as to whether they feel the 
item is "very unimportant," "somewhat unimportant,"

"somewhat important," or "very important." Under column B, respondents were asked to make a choice as to how well each "need" item has been satisfied in their case, choosing from "very unsatisfied," "somewhat unsatisfied," "somewhat satisfied," or "very satisfied." Another set of items was included that asked respondents to rate PSU on its overall faculty and instructional quality, academic support services, student services, and campus experience as a whole. There were five possible answers for each item: "excellent," "good," "fair," "poor," or "very poor." Openended questions were included in the last part of the questionnaire so respondents could offer other information about their stay at Portland State University.

Returned questionnaires were coded and responses were tabulated and presented as applicable. Except for items 4, 5, and 15 (length of stay at PSU, age and GPA, respectively), the percentage of respondents selecting each response category for each item on the "Background Information" part of the questionnaire was reported. Responses to the three open-ended questions were separately reported, based on a content analysis. For items 4, 5 and 15, frequency distributions, means and standard deviation were calculated. With the exception of item 1, which indicates citizenship status, these computations were done twice, once for U.S. students and once for foreign students. 
For each item in question 27 , the section in which students rate their needs and assess their level of satisfaction with each of them, the percentage of U.S. respondents falling in each importance response category was calculated. Also, for each item in question 27 , the percentage of U.S. respondents falling in each satisfaction response category was calculated separately. This process was repeated for the international students. Further calculations were done to find out the "most" and "least" satisfied groups, "most satisfied" and "least satisfied" items, and "most important" and "least important" items as perceived by the respondents. In questilon 28 , the percentage of U.S. and foreign student respondents were calculated. The data were computed using the systems for Statistics (SYSTAT, 1992) software package. Responses to questions 29 and 30 were also reported.।

\section{Focus Group study}

Focus groups made up of a demographically representative sample of international and American students to provide opportunities to further research patterns suggested by the survey results were conducted. These groups provided a forum for the fesearcher to derive further reasons behind differences in respondents' level of satisfaction regarding the faculty and instructional quality, academic support and student support services. 
The focus group interview or group depth interview is a

concept based on the assumption that individuals who share a problem will be more willing to talk about it amid the security of others sharing the problem. It offers a means of obtaining in-depth information on a specific topic through a discussion group atmosphere which allows an insight into the behavior and thinking of individual group members. Rather than using a structured question and answer methodology, the procedure is to encourage a group to discuss feelings, attitudes, and perception about the topic being discussed. The focus group interview is one of the qualitative marketing research techniques develop in the 1950's in relation to the large sample polling techniques which provided lots of numbers but little insight into what was really going on, the "why" behind the numbers. (Bellenger et al., 1976, p. 24)

The focus group, a tool widely used in business marketing, incorporates the best aspects of the individual interview with a group discussion format that can help the interviewer bring important points into relief.

According to other researchers in the field, segments of the student population shown through traditional survey instruments and analysis to deviate significantly from the norm, to skew the overall results or to show a nonstandard relationship among the determinants of quality can be studied with more precision via focus groups or observational studies. As one such team put it, "focus group information can provide in-depth qualitative research information about aspects of service quality which are different from student expectations" (Delene \& Bunda, 1991, p. 15). 
For this study, a representative group of focus-group participants was identified via the questionnaire and were encouraged to come by invitation. It is important to note that only the researcher had the "key" to matching the questionnaires to student names: only a number appeared on the actual questionnaires. Further, respondents were offered the option of eschewing consideration for the focus group study. Follow-up phone calls were conducted to ensure that a representative group was present on the date or dates of the focus group session. All proceedings were audiotaped (with permission from the interviewees) to verify notes. The proceedings of the focus group were then analyzed, and are presented in a separate chapter. The discussion below considered who were included in the focus groups, how many were in the focus groups, facilities and selection of the location for the focus group sessions, duration of the focus group sessions, the moderator's guide and how results were reported.

Two sets of focus groups were formed, based upon responses to the satisfaction questionnaire and addressing each of the following broad areas: faculty and instructional quality, academic support and student services. The researcher selected 10 participants for each of the two focus groups. Although there is no generally accepted guideline as to the ideal number of participants for a focus group, the most widely recommended number is 
between 8 and 12 members (Greenbaun, 1989; Bellenger et al., 1976; Taynan \& Drayton, 1988). There are disadvantages if the group is too small or too large. The following are the disadvantages of a focus group fewer than eight persons:

1. The database in which to draw information is not large enough to provide maximum input.

2. The group dynamics do not work as well with small numbers of people as they do with larger numbers (within tolerance limit).

3. Small groups are more likely to communicate to the respondents that they have been chosen to be the expert rather than the average consumer who communicates what he or she personally feels. (Greenbaun, 1989, p. 38)

The disadvantages of larger focus groups (more than 10) according to Greenbaun (1989) are:

1. Large groups are more difficult to control than smaller ones.

2. In large groups, it is often difficult to stimulate an effective group interaction.

3. With large groups, it is much more difficult to probe for input from the participants. (p. 39)

The facility or location of the focus group sessions was at Portland state University. This researcher requested a convenient room to accommodate all participants where a tape recorder could be operated. The tape recorder, run by electricity, was backed up by batteries in case of power interruptions.

A two-hour duration was set for each of the focus group sessions. Payne (cited in Hayes \& Tatham, 1989) believed that "two hours is approximately the outside limit for a 
productive group session (p. 32). This researcher, acting as the moderator, followed the following characteristics of a good moderator suggested by Langer (cited in Hayes \& Tatham, 1989):

(1) genuinely interested in hearing other people's thoughts and feelings; (2) expressive of their own feelings; (3) animated and spontaneous; (4) a sense of humor; (5) emphatic; (6) able to admit their own biases; (7) insightful about people; (8) expressing thought clearly; (9) being flexible. (p. 32)

A four-page Moderator's Guide was prepared and used by this researcher. Included were the following, as suggested by Greenbaun (1989):

(1) A statement of the group objectives - this is a guide for everyone in the group to understand the purpose of the group sessions.

(2) Identification of the group composition - this guide identifies the key criteria for participant selection.

(3) Introduction instructions. A brief outline for the moderator with introductory remarks to make at the beginning of the session. It should include:

* statement of the purpose of the group, for the benefit of the participants

* a reminder to point out the taping (audio and video) of the session

* the rules of the group, including: only one person may talk at a time; all participants must speak up; smoking is not allowed; participants must be honest with responses

* the guidelines for participant introductions, in term of what type of information is desired from each participant. 
(4) warm-up topics. This section indicates the topic areas that the moderator should use to begin the discussion.

(5) general topic discussion. This section outlines the principal areas the moderator 1 wishes to cover that relate to the general concept being discussed: in this case, the quality asseissment of the services at Portland state University and the level of satisfaction of students.

(6) specific discussion.| This section provides specific questions and areas of discussion in order to achieve the objectives of the group.

(7) running time clack. A marginal notation on the guide as to the specific time that should be allocated to each section.

(8) close. This section/ should indicate the use of any open-ended discussion that might help to add insight into the perspectives expressed by the group members. (pp. 77-78)

The results of the focus group sessions are the basis of Chapter $V$ of this thesis. Chapter $V$ presents a detailed discussion of the materials included in the moderator's guide, and includes a large number of applicable verbatim comments excerpted from the tapes.

The following were the preliminary interview protocols for selected sample students. I These questions were based on the research questions and study propositions:

1. Describe for me the university (PSU) that you are presently attending.

2. Describe for me the quality of services of this university.

3. Describe for me the faculty members that teach in this university. 
4. Describe for me the instructional quality of this university.

5. Describe for me the students that attend this university.

6. Describe for me the student services in this university.

7. Describe for me the academic support being provided by this university.

8. Describe for me the level of satisfaction of students in this university.

9. Suggest or recommend ideas to improve the quality of its services of PSU to its constituents.

10. Describe for me other concerns you have about this university.

These written interview protocols were left open-ended for the interviewees to express other concerns they might have. Every effort was made to satisfy data collection procedures and data analysis as outlined by Greenbaun (1989), and stewart (1990).

Summary

This research study employed two research designs. The first design appraised three broad areas of student concerns: faculty and instructional quality, academic support and student services. The second design described in-depth the current status and practices concerning these 
students' areas of concern, answered the "why" questions suggested by the first design and related them to the propositions posed in this study.

This study provides additional research-based information in the field of educational evaluation that can be used by postsecondary education practitioners and others to evaluate service quality and make policy recommendations to better meet student needs. However, the study's design does not cover every possibility--for example, it is not possible to assess the personality traits of each respondent, which could have a strong effect on individual perception of needs and satisfaction. The two procedures used are also limited, in that those students with limited English proficiency, lower interest in their educational opportunities and experiences, or simply with less time in which to answer surveys or attend focus group sessions might not have returned the survey, might have returned it partially completed, or might not have given each answer the high degree of thought needed for an accurate response. Some focus group participants might, due to accidents of personality and despite the researcher's best efforts to facilitate a balanced discussion, have dominated the proceedings and therefore received undue attention. others might have faded into the background when, in fact, their opinions were of equal validity. As a study device, focus 
groups are subjective in nature, and even objective, statistical data can also be misconstrued.

Finally, although the sample of students was as representative as possible, vagaries of the university's record-keeping, the U.S. postal system and individual inclination to respond to a mailed survey had the potential to skew this study's results. And because the study group was limited to PSU students, results or trends found may not be applicable to all students at all institutions. 
CHAPTER IV

SURVEY RESULTS

This chapter presents the results of the survey questionnaire sent to 450 international and American undergraduate students at Portland State University in the spring and summer of 1993. The results are organized to answer the five major research questions of this study. There are five sections in this chapter. The first section presents the description of the respondents. The second section discusses the importance of the various [need] service quality items to international students at Portland State University and their current level of satisfaction in regard to these [need] service quality items. The third section discusses the importance of the various [need] service quality items to U.S. students at Portland State University and their current level of satisfaction in regard to [need] service quality statements. The fourth section presents the comparison of the importance international and U.S. students assign to the [need] service quality items and their level of satisfaction with these [need] service quality items at Portland State University. Section five presents the relationship between perceived 
importance and level of satisfaction for both international and U.S. students.

\section{Description of Participants}

Portland State University accumulates its own data on student profiles. However, as its annual fact book reveals, the University does not ask a number of those questions of students the responses to which might have proved useful to this study. In particular, it elicits no "choice data"; for instance, it does not ask its international students why they chase PSU over other U.S. schools, or whether they plan to stay in the U.S. following their education. Such data this research might have used to help determine the level and kind of expectations these students were bringing with them into the University's academic and social environment; in turn, these expectations might have shed light on subsequent satisfaction these students experienced. Instead, PSU generally confines its student profiles to the most basic kinds of data--gender, age, and academic status, for example.

There were 450 questionnaires distributed to undergraduate students at Portland State University. Two hundred twenty-five were sent to international students and 225 to American students. Nine questionnaires for international students were returned due to changed or incorrect addresses. A total of 232 completed 
questionnaires were returned, a $53 \%$ return rate with $49 \%$ for international students, and 55\% for American students (see Table 3).

Table 3

Distribution and Return Rate of the Questionnaires

\begin{tabular}{lccc}
\hline Status & Distributed & Returned & Return Rate \\
\hline International & $216 *$ & 106 & 498 \\
American & 225 & $124 * \star$ & 558 \\
\hline
\end{tabular}

*excludes the nine people whose questionnaires were returned as undeliverable

**excludes the two people whose questionnaires did not have responses to any gingle item.

of the 232 respondents, 126 were Americans (55t) and 106 were international students or $49 \% ; 112$ were males or 48\%, and 117 were females (or 50\%), with 3 (1\%) not indicating gender (see Figure 3 ).

The most chosen major was business administration (30\%), followed by those with a liberal arts or sciences major (28\%), engineering and applied sciences major (17\%), fine and performing arts (5\%), education (3\%), health and physical education (2\%), urban and public affairs (2\%), social work (.43\%), or majors other than the above (10\%). Three percent did not indicate their major (see Figure 4). 


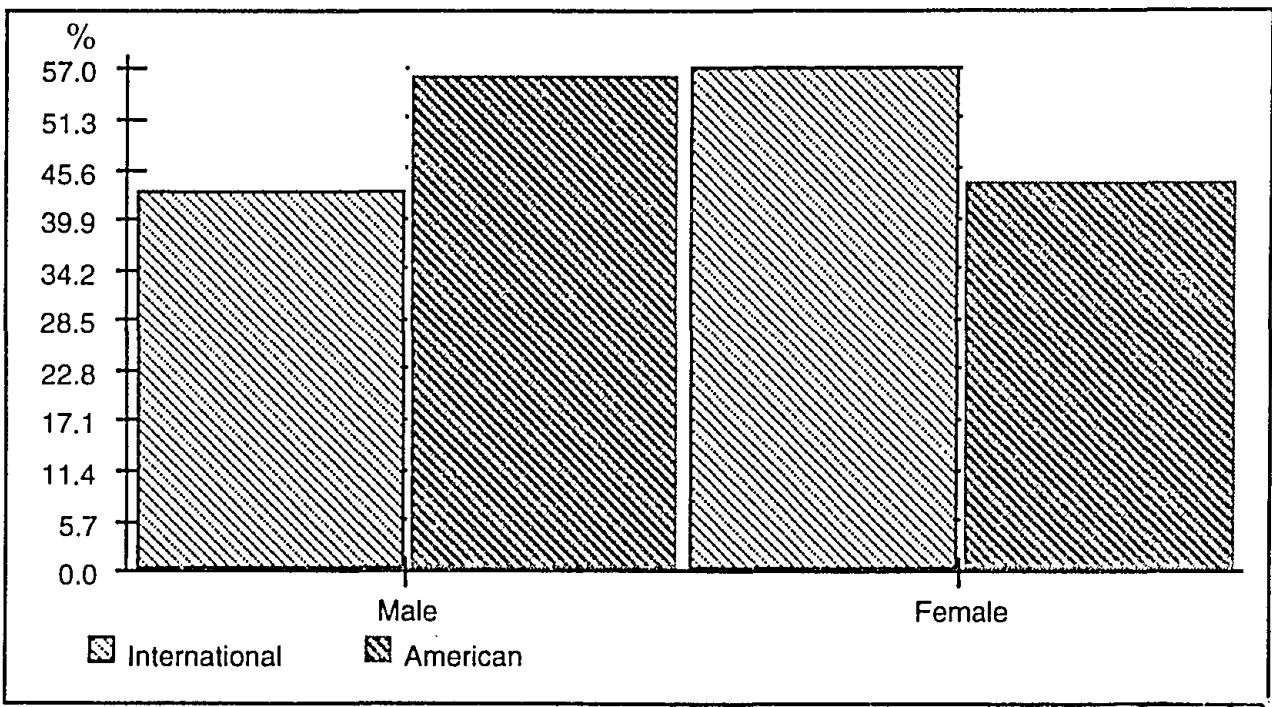

Figure 3. Gender of respondents.

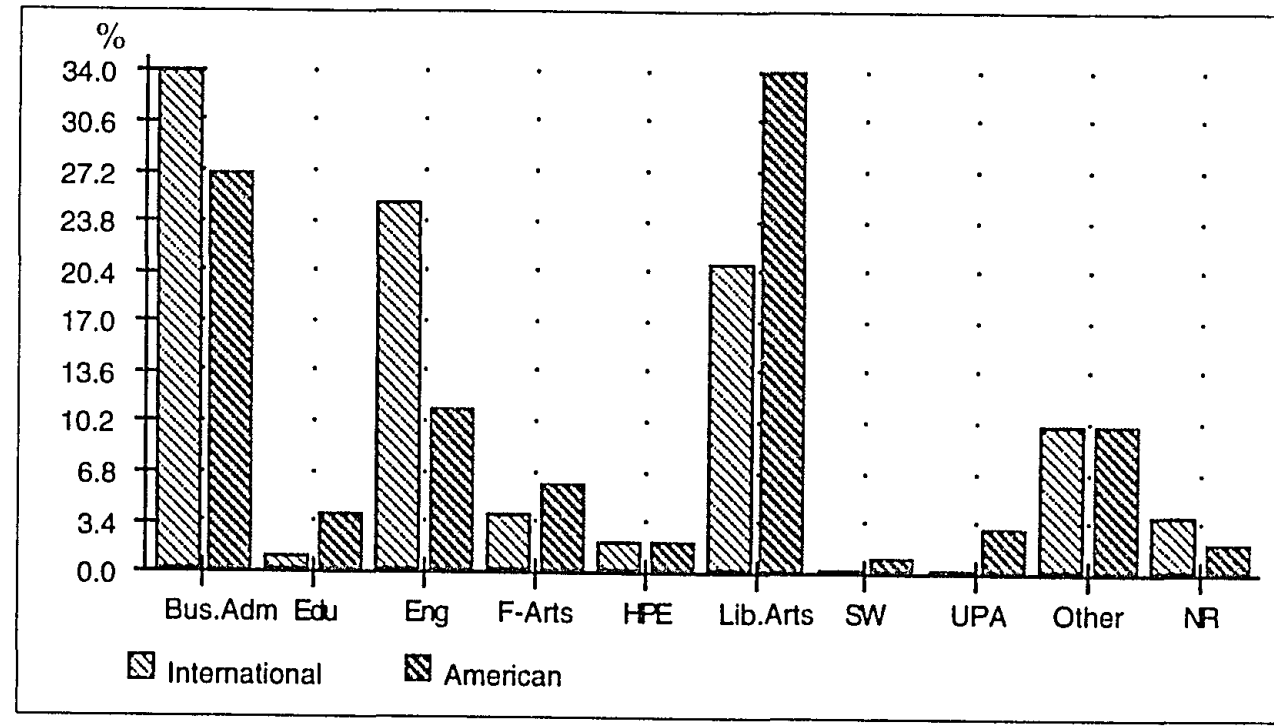

Figure 4. Field of study of respondents.

The average number of years international students had been in the U.S. was three years, with the average stay at 
PSU two years. For American students, the average stay at PSU was also two years. The average age of international respondents was 24 , while among the U.S. students the average was 25 . The majority of the respondents were seniors (33\%), followed by juniors (31\%), freshmen (12\%), sophomores (108), and others (118). Two percent did not indicate their position at PSU (see Figure 5).

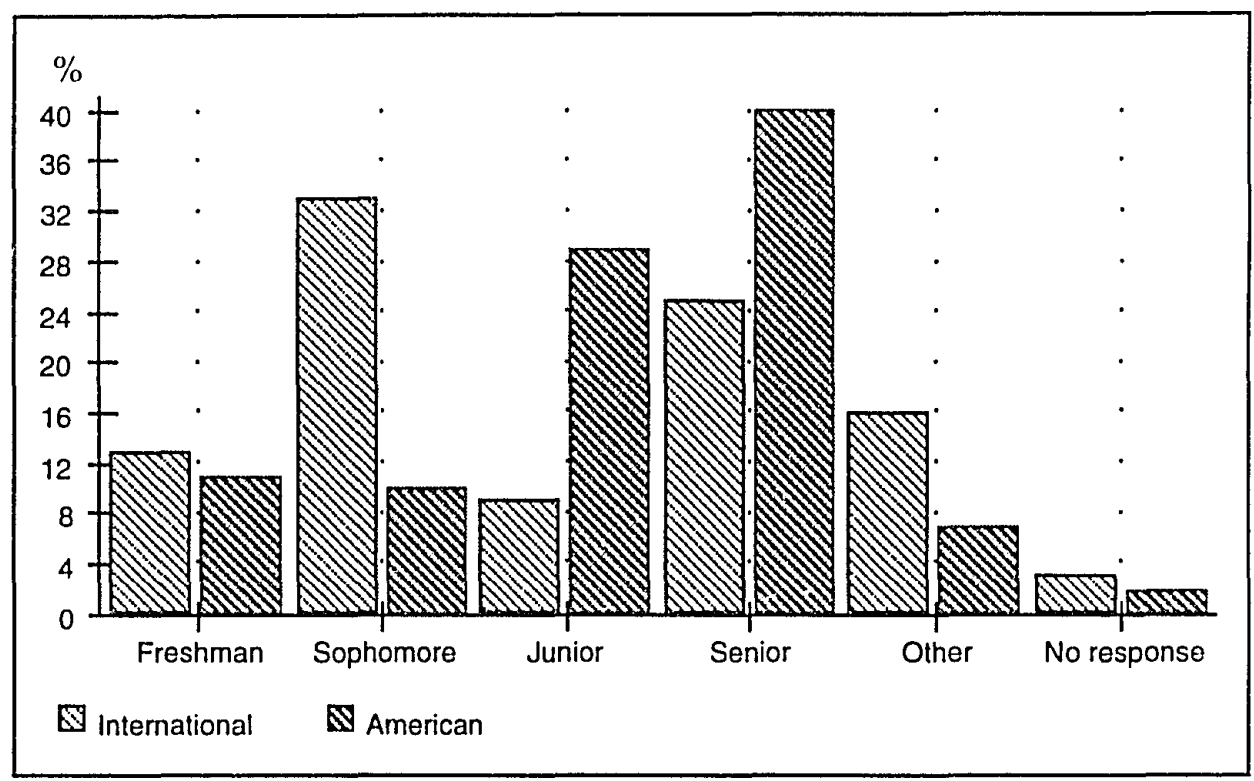

Fiqure 5. Academic level of participants.

Among international students, $85 \%$ are single, 28 are married and live with their spouse, and 128 are married but not living with their spouse. Among U.S. students, $72 \%$ are single, 218 are married and live with their spouse, and $1 \frac{8}{6}$ are married but not living with their spouse. Five percent 
of American students fell into a category other than those above (see Table 4).

Table 4

Marital Status of Participants

\begin{tabular}{lcc}
\hline Marital status & Inter'l $\%$ & U.S. 8 \\
\hline Single & 85 & 72 \\
Married (living with spouse) & 02 & 21 \\
Married (not living with spouse) & 12 & 01 \\
No response & 00 & 02 \\
Other & 01 & 05 \\
\hline
\end{tabular}

The main source of financial support for international students was family assistance, which was relied on by 728 , with $16 \%$ self-supporting, $8 \%$ on scholarships, $1 \%$ with loans, and 38 receiving their main support from other sources. For U.S. students, $37 \%$ are self-supporting, $29 \%$ rely on family assistance, $17 \%$ have loans, $4 \frac{8}{8}$ are on scholarships and $11 \%$ derived financial assistance from other sources (see Figure 6).

Thirty-eight percent of the international students live by themselves, followed by $32 \%$ who live with friends, $18 \%$ who live with their family, and $12 \%$ who live in some other situation. One percent did not indicate their living situation. A full 48 of American students live with their family; $18 \%$ live by themselves; $16 \%$ live with friends; and American students $18 \%$ live in situations other than the 
above. Two percent did not respond to the question (see Table 5).

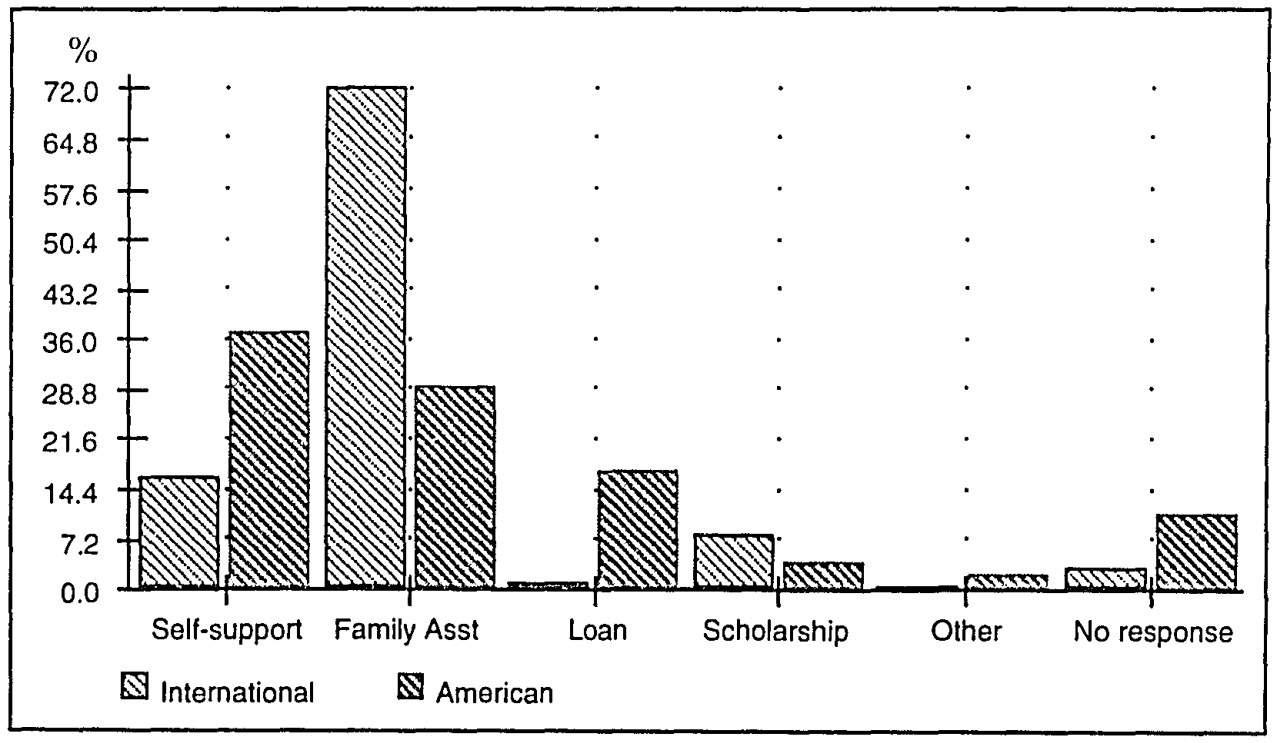

Figure 6. Main source of financial support of respondents.

of the international students, $42 \%$ live in apartments, $32 \%$ in dorms and $22 \%$ in houses. On the other hand, American students $56 \%$ lived in houses, $33 \%$ in apartments, and $7 \%$ lived in dorms.

The majority of international students, $76 \%$, perceived their parents as belonging to the middle class. Ten percent said their parents were upper class, 108 said their families were of the lower class, and 48 described their family situation as fitting some other category. The majority of American students, in this case $71 \%$, also perceived their parents as belonging to the middle class; 178 to the lower 
class; and $6 \%$ to the upper class, with $3 \%$ describing their family as something other than the above categories. Three percent offered no response to this question.

Most international students got to schooll by walking, the choice of $65 \%$. Twenty percent take the bus, $14 \%$ arrive by car and 18 did not respond to the question. Fifty-one percent of the international students said they do not own a car, while $47 \%$ said they do own one and $2 \%$ gave no response. For American students, going to school by car was the method of choice for $44 \%$. Thirty-three percent took the bus, $13 \%$ walk, $9 \%$ used some other method of transportation and $1 \%$ did not respond. Seventy-five percent of American students said they own a car, $23 \%$ said they do not, and $2 \%$ did not respond (see Table 5).

Among international student, $33 \%$ said they believe that their understanding of written English is very good, with $38 \%$ saying it is good, $23 \%$ fair, $3 \%$ poor and $3 \%$ not responding. Among American students, $92 \%$ considered their understanding of written English to be very well (see Table 6).

Thirteen percent of the international students said they spend less than five hours a week studying, $47 \%$ study 5 to 12 hours a week, and $39 \%$ spend over 12 hours a week studying. For American students, $11 \%$ spend less than five hours studying each week, 528 require five to 12 hours, and $33 \%$ study for over 12 hours (see Table 6). The average GPA 
for international students is 3.16 on a four-point scale;

U.S. students earned an average GPA of 3.12 .

Table 5

Living Situation, Living Quarters, and Perception of Economic/Class Background, Automobile Ownership, and Method of Going to School

\begin{tabular}{|c|c|c|}
\hline Variable & Inter'l 8 & U.S. $\%$ \\
\hline \multicolumn{3}{|l|}{ Living situation } \\
\hline By self & 38 & 48 \\
\hline with own family & 32 & 18 \\
\hline with friends & 18 & 16 \\
\hline other & 12 & 18 \\
\hline \multicolumn{3}{|l|}{ Living quarters } \\
\hline Dorm & 32 & 07 \\
\hline House & 22 & 56 \\
\hline Apartment & 42 & 33 \\
\hline other & 02 & 02 \\
\hline No response & 02 & 02 \\
\hline \multicolumn{3}{|c|}{$\begin{array}{l}\text { Perception of economic/ } \\
\text { class backaround }\end{array}$} \\
\hline Wealthy class & 10 & 06 \\
\hline Middle class & 76 & 71 \\
\hline Lower class & 10 & 17 \\
\hline Other & 04 & 03 \\
\hline No response & 00 & 03 \\
\hline \multicolumn{3}{|l|}{ Automobile ownership } \\
\hline Yes & 47 & 75 \\
\hline No & 51 & 23 \\
\hline No response & 02 & 02 \\
\hline \multicolumn{3}{|c|}{ Method of going to school } \\
\hline By car & 14 & 44 \\
\hline By bus & 20 & 33 \\
\hline By walking & 65 & 13 \\
\hline other & 00 & 09 \\
\hline No response & 01 & 01 \\
\hline
\end{tabular}


Table 6

Understariding Level for Written English/

Average Hours Spent Studying/Week

\begin{tabular}{lcc}
\hline Variable & Inter'l \& U.S. \& \\
\hline $\begin{array}{l}\text { Understanding level, for written English } \\
\text { Very well }\end{array}$ & 33 & \\
Good & 39 & 03 \\
Fair & 23 & 02 \\
Poor & 03 & 00 \\
NR & 03 & 02 \\
Average hours spent, studying/week & & \\
Less than 5 hours & & 11 \\
5-12 hours & 13 & 52 \\
over 12 hours & 47 & 33 \\
No response & 39 & 03 \\
\end{tabular}

International studentis, who are often prevented by law from working at off-campus: jobs, had less demanding work schedules. Eighteen percent said they work less than 10 hours per week, $22 \%$ work between 10 and 20 hours, and $7 \%$ work over 20 hours, while $53 \%$ do not work at all. For American students, $16 \%$ said they work less than 10 hours a week, 29\% work between 10 and 20 hours, $38 \%$ work over 12 hours per week, and $17 \%$ dol not work (see Table 7). 
Table 7

Percentage of Respondents' Average Hours spent Working/Week

\begin{tabular}{lcc}
\hline Average Hours Spent Working/Wk & Inter'l \& & U.S. 8 \\
\hline Less than 10 hours & 18 & 16 \\
$10-20$ hours & 22 & 29 \\
Over 20 hours & 7 & 38 \\
Do not work & 53 & 17 \\
\hline
\end{tabular}

Twenty-three percent of international students define themselves religiously as Christian, $34 \%$ are Buddhist, $13 \%$ are Moslem, $2 \%$ are Jewish, and $29 z$ espouse no religion. Among American students, $52 \%$ are Christian, $1 \%$ Buddhist, $4 \%$ Muslim, $3 \%$ Jewish, $29 \%$ have no religion, and $10 \%$ belong to other religion or did not respond. When asked if religious beliefs and/or practices have changed significantly while at PSU, $88 \%$ of international students said they have not, while $8 \%$ said some change has occurred while at college. Ninetytwo percent of American students said their religious beliefs and/or practices remain unchanged since entering school, with $6 \%$ experiencing change (see Table 8 ).

Fifty-four percent of international respondents attended student orientation sessions at PSU; $46 \%$ did not. However, among U.S. students $41 \%$ attended and $56 \%$ did not. Twenty-seven percent of international students said they had attended other U.S. institutions of higher learning; $73 \%$ had not. Among American students, 628 had attended another 
higher education institution before coming to PSU, with $36 \%$ responding that they had not (see Table 9).

Table 8

Percentage of Respondents' Religion at Home, Changed Religious Beliefs/Practices at School

\begin{tabular}{lcc}
\hline Variable & Inter'l $\%$ & U.S. $\%$ \\
\hline *eligion at home & & \\
Christian & 23 & 52 \\
Buddhist & 34 & 01 \\
Moslem & 13 & 04 \\
Jewish & 02 & 03 \\
Other religion/no response & 00 & 10 \\
None & 28 & 29 \\
Changed Religious beliefs/pract. & & \\
at school & & \\
No & 88 & 92 \\
Yes & 08 & 06 \\
No response & 04 & 02 \\
\hline
\end{tabular}

Table 9

Percentage of Respondents who Attended PSU

Student orientation and Attended other HE Institution in U.S.

\begin{tabular}{lcc}
\hline Variable & Inter'l \& U.S. 8 \\
\hline Attended PSU orientation & & \\
$\quad$ Yes & 54 & 41 \\
No & 46 & 56 \\
No response & 00 & 02 \\
Attended other HE institution in U.S. & & \\
$\quad$ Yes & 27 & 62 \\
No & 73 & 36 \\
\hline$\star \star \star$
\end{tabular}


only 128 of international students said they plan to stay in the U.S. permanently. Sixty percent said they wish to return to their nation of origin after completing their studies. Nineteen percent said they would like stay permanently in the U.S. but cannot, $11 \%$ gave an answer other than the above, and $1 \%$ did not respond (see Table 10).

Table 10

Percentage of Respondents who Plan to Stay Permanently in U.S.

Plan to Stay Permanently in U.S. Inter'l \& U.S. \&

\begin{tabular}{lll}
\hline Yes & 12 & 85 \\
Yes, but can't & 19 & 00 \\
No & 57 & 07 \\
Other & 11 & 06 \\
No response & 01 & 02 \\
\hline
\end{tabular}

Thirty-four percent of international students said their most important reason for selecting the U.S. as a place to study is to gain specialized skills and knowledge of their field, followed by $18 \%$ who cited the reputation or prestige of the U.S., $15 \%$ seeking to improve their language skills, 78 who said schooling is part of a plan to stay permanently in the U.S., $5 \%$ who want to learn more about the U.S., and $2 \%$ who want to learn more about the U.S. system of education. Fifteen percent gave other reasons, with $3 \%$ not responding (see Figure 7). As to why they chose PSU as place of study, $37 \%$ of international students responded they 
know one or more people at the school, $27 \%$ like the location, 98 had been to PSU before, $8 \%$ said the tuition is cheaper than that of comparable institutions, 78 said the university has good facilities, and 5\% said PSU provided the desired degree offerings. Eight percent offered other reasons.

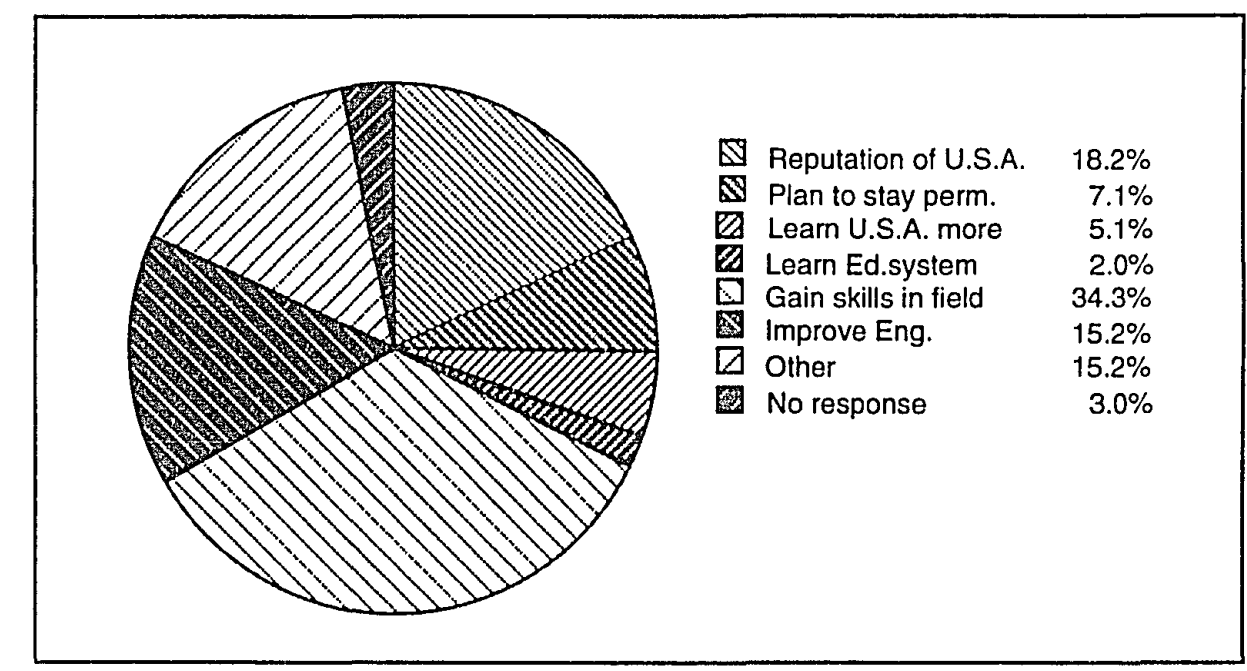

Figure 7. Reasons international students chose U.S.A.

For U.S. students, location was the persuasive factor for the majority, cited by 63\%, followed by 98 who favor PSU due to inexpensive tuition, 98 desirable degree offerings, $9 \%$ knowing a person here, $4 q$ having been to PSU before, $2 \%$ good facilities, and 28 other reasons. Two percent did not respond (see Table 11).

Thirty-nine percent of the international students learned about Portland State University from friends, 33\% 
from family members, $15 \%$ from printed materials, 48 from teachers or counsellors, $4 \%$ from educational agencies, and $5 \%$ from other sources: For American students, 25\% indicatied family members were the source of information about PSU, followed by $25 \%$ who referred to printed materials, $13 \%$ informed by friends, $13 \%$ by teachers or counselors, $4 \%$ by educational agencies, 138 by other sources, and 78 no response (see Table 11).

Table 11

Percentage of Respondents' Reasons Why They Chose PSU, and How Students Learned about PSU

\begin{tabular}{|c|c|c|}
\hline Variable & Inter' 1 \% & U.S. $\%$ \\
\hline \multicolumn{3}{|l|}{ Reason students chose PSU } \\
\hline Been here before & 09 & 04 \\
\hline Good facilities & 07 & 02 \\
\hline Location & 27 & 63 \\
\hline Knows person at PSU & 37 & 09 \\
\hline Reputation & 00 & 00 \\
\hline Degree offerings & 05 & 09 \\
\hline Tuition is cheaper & 08 & 09 \\
\hline Other & 07 & 02 \\
\hline No response & 00 & 02 \\
\hline \multicolumn{3}{|l|}{ How students learned about PSU } \\
\hline From family members & 33 & 25 \\
\hline From friends & 39 & 13 \\
\hline From printed materials & 15 & 25 \\
\hline From educational agencies & 04 & 04 \\
\hline From teachers/counselors & 04 & 13 \\
\hline other & 05 & 13 \\
\hline No response & 00 & 07 \\
\hline
\end{tabular}

International students indicated that their biggest current problems were financial, with $25 \%$ experiencing 
difficulties. Twenty-one percent said their greatest problem was language and communication, followed by cultural differences with an $8 \%$ share, academic difficulty with $7 \%$, and other difficulties for $7 \%$. A full $30 \%$ of international student respondents indicated that they do not have any serious problems at this time. Financial problems also top the list for American students, with 448 indicating current money trouble. Academic difficulty was the concern mentioned most often after that, with $10 \%$ having difficulties with coursework. Six percent cited loneliness, 28 language or communication, $1 \%$ cultural differences and $9 \%$ other problems, with $25 \%$ indicating they do not have any major problems at this time (see Figure 8 ).

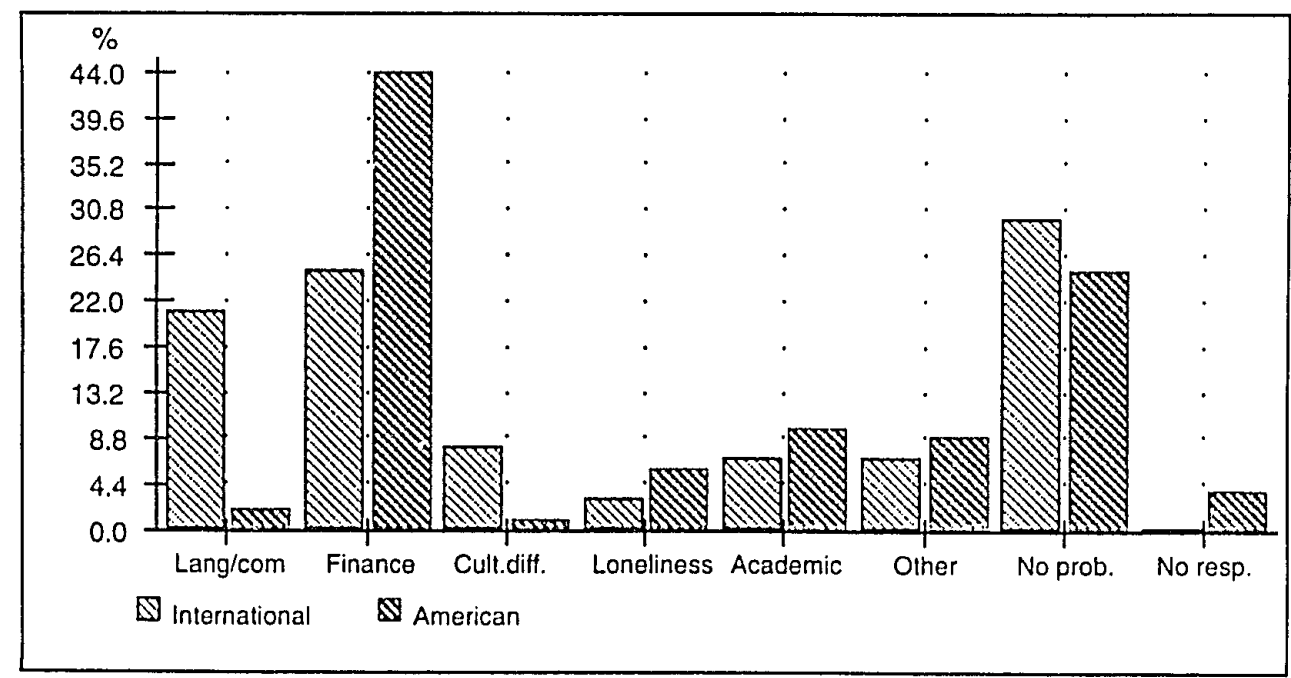

Figure 8. Current problems of respondents. 
Results for Research Question \#2

What is the importance of the various [need] service quality statements to international students at Portland State University? What is the current level of satisfaction of international students in regard to these [need] service quality statements?

The following section presents the descriptive analysis of each [need] service quality items for international students. The focus is on 27 th question with 41 items for importance and 41 items for satisfaction. The importance rating scale included four possible responses, with 1 meaning "very unimportant," 2 meaning "somewhat unimportant," 3 meaning "somewhat important," and 4 meaning "very important." The satisfaction level scale included five possible responses, with 1 meaning "very unsatisfied," 2 meaning "somewhat unsatisfied," 3 meaning "somewhat satisfied," 4 meaning "very satisfied," and 0 meaning "not applicable." A table is presented to illustrate the results for each item. Each table includes the mean responses.

\section{Instruction}

The following [need] service quality items are considered by majority of international students as "very important" in the category of instruction (see Table 12): instructional quality was cited by $75 \%$, fairness of faculty treatment of students by 75\%, fairness of testing and 
grading by $75 \%$, contents of courses by $73 \%$, intellectual stimulation from faculty by 55\%, and accessibility of the faculty by 55\%. Class size was seen as "somewhat important" by 438 .

As to level of satisfaction, the following [need] service quality items under the instruction heading were said to be "somewhat satisfied": instructional quality, according to $61 \%$, fairness of testing and grading for $62 \%$, intellectual stimulation from faculty for 58\%, accessibility of the faculty for 53\%, fairness of faculty treatment of students for 53\%, content of courses for $45 \%$, and class size, said 418

Table 12

Percentage of Importance and Satisfaction Responses of International Students for Instruction $(\underline{N}=106)$

\begin{tabular}{|c|c|c|c|c|c|c|c|c|c|c|}
\hline \multirow[b]{2}{*}{ Instruction } & \multicolumn{5}{|c|}{ Importance } & \multicolumn{5}{|c|}{ Satisfaction } \\
\hline & VU & SU & SI & VI & NR & VU & SU & SS & VS & NR \\
\hline Instructional quality & 1 & 2 & 19 & 75 & 3 & 5 & 10 & 61 & 15 & 9 \\
\hline Accessibility of faculty & 1 & 5 & 37 & 55 & 0 & 4 & 11 & 53 & 21 & 11 \\
\hline Fairn. fac. treat. of stud. & 1 & 4 & 14 & 75 & 6 & 6 & 19 & 53 & 14 & 8 \\
\hline Faimess of test. \& grad. & 1 & 4 & 18 & 75 & 3 & 6 & 11 & 62 & 18 & 7 \\
\hline Intellect. stimul. fr. fac. & 1 & 5 & 34 & 55 & 6 & 6 & 12 & 58 & 11 & 13 \\
\hline Contents of courses & 1 & 3 & 22 & 73 & 2 & 5 & 15 & 45 & 25 & 10 \\
\hline Class size & 2 & 8 & 43 & 41 & 6 & 7 & 16 & 41 & 26 & 11 \\
\hline
\end{tabular}

VU = very unimportant/very unsatisfied; SU = somewhat unimportant/somewhat unsatisfied; SI = somewhat important; VI = very important; SS = somewhut satisfied; VS = very satisfied; NR = no response/not applicable 
Academic support

In the category of academic support, the following items were considered "very important" (see Table 13): 77q rated availability of courses to finish on time this highly, $76 \%$ convenience of class scheduling, $75 \%$ computer facilities, $74 \%$ the variety of courses offered, $74 \%$ library collections, $70 \%$ library service, $69 \%$ academic advising services on campus, $69 \%$ lab facilities, $60 \%$ catalog (bulletin) and schedule of classes, $50 \%$ tutoring/basic skills services, and $41 \%$ pre-transfer advising from previous college. Judged as "somewhat important" by $32 \%$ was' precollege advising from high school.

As to level of satisfaction, students said they were "very satisfied" with the following [need] service quality items: $41 \%$ listed library services, $38 \%$ library collections, and $36 \%$ catalog (bulletin) and schedule of classes. Forty-seven percent said they were "somewhat satisfied" with lab facilities, 448 with tutoring/basic skills services, $40 \%$ with convenience of class scheduling, $36 \%$ with the variety of courses offered, $36 \%$ with the availability of courses to finish degree on time, 348 with computer facilities, $33 \%$ with academic advising services on campus, $26 \%$ with pre-college advising from high school, and $26 \%$ with pre-transfer advising from previous college. 
Table 13

Percentage of Importance and Satisfaction Responses of International students for Academic

Support $(\underline{N}=106)$

\begin{tabular}{|c|c|c|c|c|c|c|c|c|c|c|}
\hline \multirow[b]{2}{*}{ Academic Support } & \multicolumn{5}{|c|}{ Importance } & \multicolumn{5}{|c|}{ Satisfaction } \\
\hline & VU & SU & SI & VI & NR & $\mathrm{VU}$ & SU & SS & VS & NR \\
\hline Library collection & 2 & 1 & 23 & 74 & 0 & 9 & 19 & 30 & 38 & 4 \\
\hline Library service & 1 & 2 & 25 & 70 & 2 & 7 & 13 & 35 & 41 & 5 \\
\hline Lab facilities & 1 & 4 & 22 & 69 & 5 & 6 & 16 & 47 & 18 & 13 \\
\hline Computer facilities & 3 & 3 & 16 & 75 & 3 & 9 & 25 & 34 & 24 & 8 \\
\hline Acad advi. serv. camp. & 2 & 5 & 21 & 69 & 3 & 17 & 21 & 33 & 17 & 12 \\
\hline Pre-college adv. fr h.s. & 8 & 10 & 32 & 27 & 22 & 18 & 8 & 26 & 6 & 52 \\
\hline Pre-trans. adv. prev col. & 5 & 7 & 30 & 41 & 18 & 5 & 10 & 26 & 15 & 44 \\
\hline Cat.(bulletin) \& sch. class & 3 & 3 & 30 & 60 & 4 & 2 & 18 & 35 & 36 & 9 \\
\hline Tutor./basic skills serv. & 0 & 9 & 27 & 58 & 7 & 6 & 20 & 44 & 16 & 14 \\
\hline Variety of cour. offered & 1 & 1 & 22 & 74 & 3 & 9 & 33 & 36 & 15 & 7 \\
\hline Avail. of cour. finish deg. & 1 & 2 & 18 & 77 & 2 & 13 & 35 & 36 & 7 & 9 \\
\hline Convenience class sched. & 1 & 4 & 15 & 76 & 4 & 13 & 27 & 40 & 11 & 9 \\
\hline
\end{tabular}

$\overline{\mathrm{VU}}=$ very unimportant/very unsatisfied; SU = somewhat unimportant/somewhat unsatisfied; SI = somewhat important; VI = very important; SS = somewhat satisfied; VS = very satisfied; NR = no response/not applicable

\section{Student Services}

In the student services category the following were considered "very important" (see Table 14): 698 listed the admissions office, $65 \%$ the registrar's office, $64 \%$ student health services, 598 career guidance from faculty, 58\% campus housing, $58 \%$ job search services, 518 career guidance from career planning office, 51\% parking, $46 \%$ campus food services, $42 \%$ social and cultural activities, $42 \%$ financial aid office, $42 \%$ recreation programs/activities, $41 \%$ special students services and $33 \%$ the intercollegiate athletic 
program. Considered "somewhat important": student

organizations, so rated by $44 \%$, the campus orientation

program for $42 \%$, psychological counseling for $33 \%$, and child

care for 28\%. Religious services were considered "somewhat

unimportant," with a $27 \%$ rating.

Table 14

Percentage of Importance and Satisfaction Responses

of International students for

student Services $(\underline{N}=106)$

\begin{tabular}{|c|c|c|c|c|c|c|c|c|c|c|}
\hline \multirow[b]{2}{*}{ Student Services } & \multicolumn{5}{|c|}{ Importance } & \multicolumn{5}{|c|}{ Satisfaction } \\
\hline & VU & SU & SI & VI & NR & VU & SU & SS & vs & NR \\
\hline Admission office & 2 & 0 & 28 & 69 & 1 & 19 & 26 & 31 & 16 & 8 \\
\hline Registrar's office & 1 & 4 & 27 & 65 & 1 & 10 & 23 & 37 & 19 & 11 \\
\hline Campus housing & 3 & 8 & 28 & 58 & 4 & 16 & 12 & 36 & 16 & 20 \\
\hline Recrea. prog/activities & 4 & 9 & 41 & 42 & 3 & 8 & 13 & 47 & 15 & 17 \\
\hline Student organizations & 3 & 17 & 44 & 33 & 3 & 4 & 15 & 50 & 14 & 17 \\
\hline Child care & 13 & 14 & 28 & 27 & 17 & 2 & 6 & 24 & 3 & 65 \\
\hline Parking & 5 & 9 & 24 & 51 & 11 & 17 & 16 & 23 & 9 & 35 \\
\hline Student health services & 1 & 7 & 25 & 64 & 4 & 6 & 15 & 39 & 22 & 18 \\
\hline Psycho. counseling & 7 & 16 & 33 & 30 & 14 & 2 & 4 & 33 & 14 & 47 \\
\hline Financial aid office & 11 & 6 & 22 & 42 & 14 & 10 & 7 & 28 & 8 & 47 \\
\hline Religious services & 20 & 27 & 22 & 17 & 14 & 7 & 8 & 28 & 8 & 49 \\
\hline Job senrch services & 4 & 9 & 20 & 58 & 8 & 10 & 14 & 34 & 9 & 33 \\
\hline Campus food services & 2 & 8 & 34 & 46 & 9 & 25 & 16 & 25 & 11 & 23 \\
\hline Intercolleg. ath. prog. & 7 & 24 & 28 & 33 & 8 & 8 & 16 & 33 & 11 & 32 \\
\hline Career guidance from fac. & 1 & 6 & 26 & 59 & 8 & 11 & 16 & 36 & 8 & 28 \\
\hline Car. guid. fr Car. Pl. Off & 2 & 10 & 25 & 51 & 11 & 11 & 18 & 30 & 5 & 36 \\
\hline Social \& cult. activities & 2 & 9 & 40 & 42 & 7 & 8 & 16 & 38 & 13 & 25 \\
\hline Campus orient. prog. & 0 & 10 & 42 & 41 & 7 & 3 & 12 & 44 & 16 & 25 \\
\hline Special student services & 4 & 12 & 32 & 41 & 11 & 4 & 8 & 32 & 8 & 48 \\
\hline
\end{tabular}

VU = very unimportant/very unsatisfied; SU = somewhat unimportant/somewhat unsatisfied; SI = somewhat important; VI = very important; SS = somewhat satisfied; VS = very satisfied; $N R=$ no response/not applicable 
When rating student services, $50 \%$ of international students said they were "somewhat satisfied" with student organizations, recreation programs/activities were so rated by $47 \%$, campus orientation programs by 448 , student health services by $39 \%$, social and cultural activities by $39 \%$, registrar's office by $37 \%$, campus housing by $36 \%$, career guidance from faculty by $36 \%$, job search services by $34 \%$, intercollegiate athletic programs by $33 \%$, psychological counseling by $33 \%$, special student services by 328 , admissions office by $31 \%$, career guidance from career planning office by $30 \%$, financial aid office by $28 \%$, religious services by $28 \%$, campus food services by $25 \%--w i t h$ 25\% responding that they are "very unsatisfied," child care by 248 , and parking by $23 \%$.

\section{Results for Research Question \#3}

What is the importance of the various [need] service quality statements to American students at Portland state University? What is the current level of satisfaction of American students in regards to these [need] service quality statements?

\section{Instruction}

The following [need] service quality items were considered by the majority of American students as "very important" in the category of instruction (see Table 15): instructional quality (85\%), fairness of testing and grading 
$(82 \%)$, fairness of faculty treatment of students (74q), content of courses $(74 \%)$, intellectual stimulation from faculty (65\%) and accessibility of the faculty (45\%). Class size was judged as somewhat important (43q). As to their level of satisfaction the following [need] service quality items under Instruction were ranked by American students as "somewhat satisfied": Instructional quality (61\%), content of courses (61\%), intellectual stimulation from faculty (53\%), accessibility of the faculty (51\%), fairness of faculty treatment of students (48\%), fairness of testing and grading (44\%) and class size (33\%).

Table 15

Percentage of Importance and Satisfaction Responses of American students for Instruction $(\underline{\mathrm{N}}=124)$

\begin{tabular}{|c|c|c|c|c|c|c|c|c|c|c|}
\hline \multirow[b]{2}{*}{ Instruction } & \multicolumn{5}{|c|}{ Importance } & \multicolumn{5}{|c|}{ Satisfaction } \\
\hline & VU & SU & SI & VI & NR & VU & SU & SS & vS & NR \\
\hline Instructional quality & 2 & 0 & 8 & 85 & 1 & 2 & 10 & 61 & 22 & 5 \\
\hline Accessibility of faculty & 2 & 6 & 44 & 45 & 3 & 5 & 13 & 51 & 28 & 3 \\
\hline Faimess of fac. treat.of stud. & 2 & 6 & 4 & 74 & 4 & 4 & 9 & 48 & 34 & 5 \\
\hline Fairness of testing \& grading & 2 & 0 & 12 & 82 & 5 & 4 & 11 & 44 & 36 & 5 \\
\hline Intellectual stimulation fr. fac. & 2 & 3 & 25 & 65 & 5 & 4 & 12 & 53 & 22 & 9 \\
\hline Contents of courses & 2 & 1 & 19 & 74 & 5 & 3 & 11 & 61 & 19 & 6 \\
\hline Class size & 6 & 15 & 43 & 33 & 4 & 5 & 17 & 33 & 29 & 16 \\
\hline
\end{tabular}

$\overline{\mathrm{VU}}=$ very unimportant/very unsatisfied; SU = somewhat unimportant/somewhat unsatisfied; SI = somewhat important; VI = very important; SS = somewhat satisfied; VS = very satisfied; $\mathrm{NR}=$ no response/not applicable 
Academic Support

In the category of academic support, the following items were considered very important (see Table 16): availability of courses needed to finish degree on time $(77 \%)$, variety of courses offered (68\%), convenience of class scheduling (67\%), academic advising services on campus (64\%), catalog (bulletin) and schedule of classes (63\%), library collections (55\%), library services (46\%), computer facilities (45\%), pre-college advising from high school (37\%), lab facilities (36\%), pre-transfer advising from previous college (32\%) and tutoring/basic skills services $(30 \%)$.

Under the academic support category, the majority of American students said they/were "very satisfied" with regards to the following [need] service qualities: Catalog (bulletin) and schedule of classes (47\%), library collections (41\%), and library services (40\%). They said they were "somewhat satisfied" with lab facilities (40\%), convenience of class scheduling (32\%), variety of courses offered (41\%), availability of courses to finish degree on time (30\%), computer facilities (28\%), tutoring/basic skills services (25\%), pre-collegeladvising from high school (21\%) and pre-transfer advising from previous college (198). Students said their need for academic advising services on campus was "somewhat unsatisfied" (26\%)." 
Table 16

\begin{abstract}
Percentage of Importance and Satisfaction Responses of American Students for Academic

Support $(\underline{\mathrm{N}}=124)$
\end{abstract}

\begin{tabular}{|c|c|c|c|c|c|c|c|c|c|c|}
\hline \multirow[b]{2}{*}{ Academic Support } & \multicolumn{5}{|c|}{ Importance } & \multicolumn{5}{|c|}{ Satisfaction } \\
\hline & VU & SU & SI & VI & NR & VU & SU & SS & VS & NR \\
\hline Library collection & 6 & 5 & 32 & 55 & 2 & 4 & 9 & 35 & 41 & 11 \\
\hline Library service & 2 & 4 & 44 & 46 & 4 & 7 & 9 & 37 & 40 & 7 \\
\hline Lab facilities & 5 & 19 & 36 & 33 & 7 & 2 & 7 & 40 & 7 & 44 \\
\hline Computer facilities & 6 & 12 & 29 & 45 & 7 & 5 & 20 & 28 & 18 & 29 \\
\hline Acad advi.serv. on campus & 6 & 5 & 21 & 64 & 5 & 26 & 26 & 24 & 15 & 11 \\
\hline Pre-college adv. fr high school & 11 & 13 & 25 & 37 & 14 & 16 & 15 & 21 & 9 & 39 \\
\hline Pre-transfer adv. fr. prev coll. & 10 & 10 & 24 & 32 & 24 & 10 & 14 & 19 & 9 & 48 \\
\hline Catalog (bulletin) \& sched.class & 3 & 4 & 24 & 63 & 6 & 1 & 9 & 35 & 47 & 8 \\
\hline Tutoring/basic skills services & 11 & 22 & 27 & 30 & 10 & 4 & 9 & 25 & 17 & 45 \\
\hline Variety of courses offered & 2 & 2 & 23 & 68 & 5 & 11 & 22 & 41 & 22 & 4 \\
\hline Avail. of courses to finish deg. & 2 & 3 & 13 & 77 & 5 & 16 & 28 & 30 & 17 & 9 \\
\hline Convenience class scheduling & 3 & 2 & 21 & 67 & 6 & 15 & 21 & 32 & 26 & 6 \\
\hline
\end{tabular}

$\mathrm{VU}=$ very unimportant/very unsatisfied; $S U$ = somewhat unimportant/somewhat unsatisfied; SI = somewhat important; VI = very important; $S S=$ = somewhat satisfied; VS = very satisfied; $N R=$ no response/not applicable

\title{
Student Services
}

In the student services category, the following were considered "very important" (see Table 17): Registrar's office (53\%), career guidance from faculty (53\%), parking (52\%), financial aid office (51\%), student health services (43\%), job search services (43\%) and career guidance from career planning office (418). Considered "somewhat important" were the Admissions office (41\%), campus food services (40\%), student organizations (33\%), social and 
cultural activities $(32 \%)$, campus orientation program (28q) and psychological counseling (27\%). Recreation

programs/activities were considered "somewhat unimportant" (34q). Considered very unimportant were religious services (40\%), child care (38\%), the intercollegiate athletic program (33\%), campus housing (328) and special student services (25\%).

Student services which American students considered themselves to be "somewhat satisfied" with were the Registrar's office 46\%), Admissions office (46\%), campus food services (39\%), student health services (37\%), social and cultural activities (37\%), career guidance from faculty (368), job search services (368), student organizations (35\%), recreation programs/activities (33\%), campus orientation programs (30\%), parking (28\%), special student services (28\%), psychological counseling (27\%), career guidance from the career Planning office (27\%), Financial Aid office (26\%), intercollegiate athletic programs (23\%), campus housing (13\%, although for a $67 \%$ majority this item did not apply), religious services (12\%) and child care (118.) 
Table 17

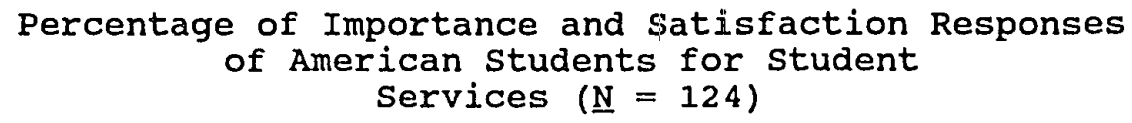

\begin{tabular}{|c|c|c|c|c|c|c|c|c|c|c|}
\hline \multirow[b]{2}{*}{ Student Services } & \multicolumn{5}{|c|}{ Importance } & \multicolumn{5}{|c|}{ Satisfaction } \\
\hline & VU & SU & SI & VI & NR & VU & SU & SS & VS & NR \\
\hline Admission office & 3 & 3 & 41 & 38 & 4 & 9 & 15 & 46 & 24 & 6 \\
\hline Registrar's office & 4 & 6 & 32 & 53 & 5 & 6 & 13 & 46 & 27 & 8 \\
\hline Campus housing & 32 & 20 & 21 & 14 & 13 & 2 & 6 & 13 & 5 & 74 \\
\hline Recreation prog./activ. & 19 & 34 & 25 & 13 & 9 & 0 & 10 & 33 & 9 & 48 \\
\hline Student organizations & 17 & 33 & 33 & 11 & 6 & 3 & 10 & 35 & 7 & 45 \\
\hline Child care & 38 & 16 & 12 & 21 & 13 & 3 & 4 & 11 & 2 & 80 \\
\hline Parking & 13 & 13 & 4 & 52 & 8 & 16 & 13 & 28 & 11 & 32 \\
\hline Student health serv. & 10 & 13 & 23 & 43 & 10 & 2 & 8 & 37 & 22 & 31 \\
\hline Psychological counsel. & 19 & 19 & 27 & 25 & 10 & 2 & 2 & 27 & 7 & 62 \\
\hline Financial aid office & 10 & 10 & 16 & 16 & 7 & 10 & 19 & 27 & 15 & 29 \\
\hline Religious services & 40 & 21 & 16 & 16 & 7 & 5 & 3 & 12 & 5 & 75 \\
\hline Job search services & 10 & 3 & 27 & 43 & 7 & 6 & 6 & 36 & 11 & 41 \\
\hline Campus food services & 11 & 16 & 40 & 27 & 6 & 11 & 22 & 39 & 12 & 16 \\
\hline Intercolleg. ath. prog. & 33 & 24 & 20 & 18 & 6 & 6 & 8 & 23 & 11 & 52 \\
\hline Career guidance fr. fac. & 4 & 10 & 27 & 53 & 6 & 9 & 26 & 36 & 10 & 19 \\
\hline Car. guid. Career Pl.Of & 6 & 12 & 27 & 41 & 14 & 10 & 10 & 27 & 9 & 44 \\
\hline Social \& cultural activ. & 13 & 27 & 32 & 18 & 10 & 5 & 8 & 37 & 13 & 37 \\
\hline Campus orientation prog. & 13 & 25 & 28 & 21 & 10 & 4 & 13 & 30 & 6 & 47 \\
\hline Special student services & 25 & 21 & 17 & 21 & 16 & 4 & 9 & 28 & 7 & 52 \\
\hline
\end{tabular}

$\mathrm{VU}=$ very unimportant/very unsatisfied; SU = somewhat unimportant/somewhat unsatisfied; SI = somewhat important; VI = very important; SS = somewhat satisfied; VS = very satisfied; $N R=$ no response/not applicable

Results for Research Question \#4

Do U.S. and international students at Portland state University differ in the importance they assign to the [need] service quality statements? Do U.S. and international students differ in their level of satisfaction 
with the [need] service quality at Portland state University?

There were eighteen needs items on the questionnaires that showed significant differences when they were rated for importance and four needs items when they were rated for satisfaction by American and international students. Two were in the instruction categoxy, five fell under the category of in academic support (library collections, library services, lab facilities, computer facilities and tutoring), thirteen were in the student services category under importance (Admissions office, housing, recreation programs/activities, student organizations, child care, student health services, psychological counseling, religious services, campus food services, intercollegiate athletic programs, social and cultural activities, campus orientation programs and special student services), two under satisfaction (admissions office and campus food services.) These differences were also significant when the no response/not applicable responses were excluded. Distribution of responses and chi-square analyses for significant chi-squares are presented in Tables 18-39. Tables 40-42 present a summary of the probability associated with all chi-square computation.

International and American students did not differ significantly in the importance that they assigned to the items in the Instruction category. However, on the two 
items they did differ significantly in their level of satisfaction, with international students expressing less satisfactions in regard to the fairness of faculty treatment of students and fairness of testing and grading (see Tables 18-19)

In the area of academic support, International and American students differed significantly in the importance that they assigned to five items, but they did not differ significantly in their level of satisfaction. International students placed greater importance than did American students on the library collections and services, laboratory facilities, computer facilities, and tutoring (see Tables 20-24).

In the area of student services, International and American students differed in the importance that they assigned to 13 items; they differed in expressed level of satisfaction on two items. International students placed greater importance to and express less satisfaction in than did American students to Admission office and campus food services (see Tables 25-28). In comparison with American students, International students placed greater importance on Campus Housing, Recreational Programs/activities, student Organizations, Child Care, Student Health Services, Psychological Counseling; Religious Services, Intercollegiate Athletic Programs, Social and Cultural 
Activities, Campus orientation Programs, and special student Services (see Tables 29-39).

Table 18

Distribution of Responses and Chi-square Analyses of Significance Between American and International Students Pertaining to Satisfaction of Fairness of Faculty Treatment of students

\begin{tabular}{|c|c|c|c|c|c|c|c|c|c|c|}
\hline \multicolumn{2}{|c|}{ Status } & 0 & 1 & 2 & 3 & 4 & Total & Chi-S & df & p \\
\hline \multirow[t]{2}{*}{ A } & 9 & 4.84 & 4.03 & 8.87 & 48.39 & 33.87 & 53.91 & 14.981 & 5 & .010 \\
\hline & $\underline{\mathbf{f}}$ & 6 & 5 & 11 & 60 & 42 & 124 & & & \\
\hline \multirow[t]{2}{*}{ I } & $\%$ & 7.55 & 6.60 & 18.87 & 52.83 & 14.15 & 46.09 & & & \\
\hline & $\underline{f}$ & 8 & 7 & 20 & 56 & 15 & 106 & & & \\
\hline \multirow[t]{2}{*}{ Total } & $\%$ & 4.78 & 1.30 & 5.22 & 13.48 & 50.43 & 24.78 & & & \\
\hline & $\underline{\mathbf{f}}$ & 14 & 12 & 31 & 116 & 57 & 230 & & & \\
\hline
\end{tabular}

$\mathrm{A}=$ American students; $\mathrm{I}=$ international students; $0=$ no response/not applicable; 1 = very unsatisfied; 2 = somewhat unsatisfied; 3 = somewhat satisfied; 4 = very satisfied; Chi-S = chisquare; $\underline{\mathrm{df}}=$ degrees of freedom; $\mathrm{p}=$ probability

Table 19

Distribution of Responses and Chi-Square Analyses of Significance Between American and International students pertaining to satisfaction of Fairness of Testing and Grading

\begin{tabular}{|c|c|c|c|c|c|c|c|c|c|c|}
\hline Status & & 0 & 1 & 2 & 3 & 4 & Total & Chi-S & $\underline{\mathrm{df}}$ & $\mathbf{p}$ \\
\hline \multirow[t]{2}{*}{ A } & $\mathscr{p}$ & 4.84 & 4.03 & 11.29 & 44.35 & 35.48 & 53.91 & 11.471 & 5 & .043 \\
\hline & $\mathbf{f}$ & 6 & 5 & 14 & 55 & 44 & 124 & & & \\
\hline \multirow[t]{2}{*}{ I } & $\%$ & 6.61 & 6.60 & 11.32 & 57.55 & 17.92 & 46.09 & & & \\
\hline & $\underline{f}$ & 7 & 7 & 12 & 61 & 19 & 106 & & & \\
\hline \multirow[t]{2}{*}{ Total } & $\%$ & 5.65 & 5.22 & 11.30 & 50.43 & 27.39 & 100 & & & \\
\hline & $\underline{f}$ & 13 & 12 & 26 & 116 & 63 & 230 & & & \\
\hline
\end{tabular}

$\mathrm{A}=$ American students; $\mathrm{I}=$ international students; $0=$ no response/not applicable; $1=$ very unsatisfied; 2 = somewhat unsatisfied; 3 = somewhat satisfied; 4 = very satisfied; Chi-S = chisquare; $\underline{\mathrm{df}}=$ degrees of freedom; $\mathbf{p}=$ probability 
Table 20

\section{Distribution of Responses and Chi-Square Analyses of Significance Between American and International students Pertaining to Importance of Library Collections}

\begin{tabular}{|c|c|c|c|c|c|c|c|c|c|c|}
\hline \multicolumn{2}{|l|}{ Status } & 0 & 1 & 2 & 3 & 4 & Total & Chi-S & $\underline{\mathrm{df}}$ & $\mathfrak{p}$ \\
\hline A & $\%$ & 2.42 & 5.65 & 4.84 & 32.26 & 54.84 & 100.00 & 9.852 & 2 & 0.007 \\
\hline & f & 3 & 7 & 6 & 40 & 68 & 124 & & & \\
\hline I & $\%$ & 0.94 & 1.89 & 0.94 & 22.64 & 73.58 & 100.00 & & & \\
\hline & $\underline{f}$ & 1 & 2 & 1 & 24 & 78 & 106 & & & \\
\hline Total & $\%$ & 1.74 & 3.91 & 3.04 & 27.83 & 63.48 & 100.00 & & & \\
\hline & f & 4 & 9 & 7 & 64 & 146 & 230 & & & \\
\hline
\end{tabular}

$\mathrm{A}=$ American students; $\mathrm{I}=$ international students; $0=$ no response/not applicable; 1 = very unsatisfied; 2 = somewhat unsatisfied; $3=$ somewhat satisfied; $4=$ very satisfied; Chi-S $=$ chisquare; $\underline{\mathrm{df}}=$ degrees of freedom; $\mathbf{p}=$ probability

NOTE: The no response category was deleted and the 1 and 2 categories were combined because of low expected frequencies.

Table 21

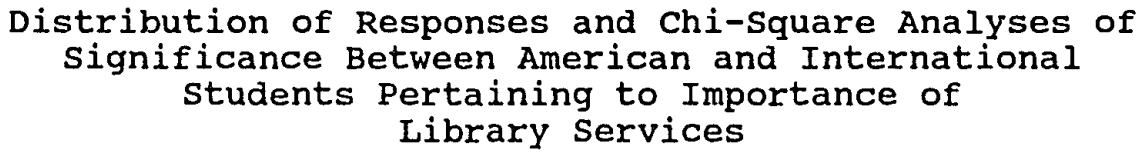

\begin{tabular}{|c|c|c|c|c|c|c|c|c|c|c|}
\hline \multicolumn{2}{|l|}{ Status } & 0 & 1 & 2 & 3 & 4 & Total & Chi-S & df & p \\
\hline \multirow[t]{2}{*}{ A } & $\%$ & 2.42 & 2.42 & 4.03 & 44.35 & 46.77 & 53.91 & 12.560 & 2 & 0.002 \\
\hline & $\underline{f}$ & 3 & 3 & 5 & 55 & 58 & 124 & & & \\
\hline \multirow[t]{2}{*}{ I } & $\%$ & 1.89 & 0.94 & 1.89 & 25.47 & 69.81 & 46.09 & & & \\
\hline & $\underline{\mathbf{f}}$ & 2 & 1 & 2 & 27 & 74 & 106 & & & \\
\hline \multirow[t]{2}{*}{ Total } & 8 & 2.17 & 1.74 & 3.04 & 35.65 & 57.39 & 100.00 & & & \\
\hline & $f$ & 5 & 4 & 7 & 82 & 132 & 230 & & & \\
\hline
\end{tabular}

A = American students; I = international students; $0=$ no response/not applicable; 1 = very unsatisfied; 2 = somewhat unsatisfied; 3 = somewhat satisfied; $4=$ very satisfied; Chi-S $=$ chisquare; $\underline{\mathrm{df}}=$ degrees of freedom; $\mathfrak{p}=$ probability

NOTE: The no response category was deleted and the 1 and 2 categories were combined because of low expected frequencies. 
Table 22

$$
\begin{gathered}
\text { Distribution of Responses and chi-square Analyses of } \\
\text { Significance Between American and International } \\
\text { students Pertaining to Importance of } \\
\text { Laboratory Facilities }
\end{gathered}
$$

\begin{tabular}{|c|c|c|c|c|c|c|c|c|c|c|}
\hline Status & & 0 & 1 & 2 & 3 & 4 & Total & Chi-S & $\mathrm{df}$ & $\mathrm{p}$ \\
\hline \multirow[t]{2}{*}{ A } & $\%$ & 7.26 & 4.84 & 19.35 & 35.48 & 33.06 & 53.91 & 33.360 & 4 & 0.000 \\
\hline & $\underline{f}$ & 9 & 6 & 24 & 44 & 41 & 124 & & & \\
\hline \multirow[t]{2}{*}{ I } & $\%$ & 4.72 & 0.94 & 3.77 & 21.70 & 68.87 & 46.09 & & & \\
\hline & $\underline{\mathbf{f}}$ & 5 & 1 & 4 & 23 & 73 & 106 & & & \\
\hline \multirow[t]{2}{*}{ Total } & $\%$ & 6.09 & 3.04 & 12.17 & 29.13 & 49.57 & 100.00 & & & \\
\hline & & $\underline{\mathbf{f}}$ & 14 & 7 & 28 & 67 & 114 & 230 & & \\
\hline
\end{tabular}

$\mathrm{A}=$ American students; $\mathrm{I}=$ intemational students; $0=$ no response/not applicable; $1=$ very unsatisfied; 2 = somewhat unsatisfied; $3=$ somewhat satisfied; $4=$ very satisfied; Chi-S $=$ chi-

\begin{tabular}{|c|c|c|c|c|c|c|c|c|c|c|}
\hline Status & & 0 & 1 & 2 & 3 & 4 & Total & Chi-S & $\underline{\mathrm{df}}$ & $\mathrm{p}$ \\
\hline \multirow[t]{2}{*}{ A } & $\%$ & 5.65 & 6.45 & 12.10 & 29.84 & 45.97 & 53.91 & 21.867 & 4 & 0.000 \\
\hline & $\underline{f}$ & 7 & 8 & 15 & 37 & 57 & 124 & & & \\
\hline \multirow[t]{2}{*}{ I } & $\%$ & 2.83 & 2.83 & .83 & 16.04 & 75.47 & 46.09 & & & \\
\hline & $\underline{f}$ & 3 & 3 & 3 & 17 & 80 & 106 & & & \\
\hline \multirow[t]{2}{*}{ Total } & $\%$ & 4.35 & 4.78 & 7.83 & 23.48 & 59.57 & 100.00 & & & \\
\hline & $\underline{f}$ & 10 & 11 & 18 & 54 & 137 & 230 & & & \\
\hline
\end{tabular}
square; $\underline{\mathrm{df}}=$ degrees of freedom; $\mathfrak{p}=$ probability

Table 23

$$
\begin{gathered}
\text { Distribution of Responses and chi-Square Analyses of } \\
\text { Significance Between American and International } \\
\text { Students Pertaining to Importance of } \\
\text { Computer Facilities }
\end{gathered}
$$

$\mathrm{A}=$ American students; $\mathrm{I}=$ international students; $0=$ no response/not applicable; 1 = very unsatisfied; 2 = somewhat unsatisfied; $3=$ somewhat satisfied; $4=$ very satisfied; Chi-S $=$ chisquare; $\underline{\mathrm{df}}=$ degrees of freedom; $\mathrm{p}=$ probability 
Table 24

\section{Distribution of Responses and Chi-Square Analyses of Significance Between American and International Students Pertaining to Importance of Tutoring Facilities}

\begin{tabular}{|c|c|c|c|c|c|c|c|c|c|c|}
\hline \multicolumn{2}{|l|}{ Status } & 0 & 1 & 2 & 3 & 4 & Total & Chi-S & $\underline{\mathrm{df}}$ & $\mathrm{p}$ \\
\hline A & $\%$ & 8.06 & 11.29 & 22.58 & 27.42 & 30.65 & 53.91 & 28.794 & 4 & 0.000 \\
\hline & $\underline{f}$ & 10 & 14 & 28 & 34 & 38 & 124 & & & \\
\hline \multirow[t]{2}{*}{ I } & $\%$ & 6.60 & 0.00 & 8.49 & 27.36 & 57.55 & 46.09 & & & \\
\hline & $\underline{f}$ & 7 & 0 & 9 & 2 & 9 & 61 & 106 & & \\
\hline \multirow[t]{2}{*}{ Total } & $\%$ & 7.39 & 6.09 & 16.09 & 27.39 & 43.04 & 100.00 & & & \\
\hline & $\underline{\mathbf{f}}$ & 17 & 14 & 37 & 63 & 99 & 230 & & & \\
\hline
\end{tabular}

$\mathrm{A}=$ American students; $\mathrm{I}=$ intemational students; $0=$ no response/not applicable; $1=$ very unsatisfied; 2 = somewhat unsatisfied; $3=$ somewhat satisfied; $4=$ very satisfied; Chi-S $=$ chisquare; $\underline{\mathrm{df}}=$ degrees of freedom; $\mathbf{p}=$ probability

Table 25

Distribution of Responses and Chi-Square Analyses of Significance Between American and International

students Pertaining to Importance of Admissions office

\begin{tabular}{lllllllllll}
\hline Status & & 0 & 1 & 2 & 3 & 4 & Total & Chi-S & df & p \\
& & & & & & & & & & \\
A & $\%$ & 2.42 & 3.23 & 13.71 & 41.94 & 38.71 & 53.91 & 25.760 & 2 & .000 \\
& $\underline{f}$ & 3 & 4 & 17 & 52 & 48 & 124 & & & \\
I & \% & 0.94 & 1.89 & 0.00 & 28.30 & 68.87 & 46.09 & & \\
& $\underline{f}$ & 1 & 2 & 0 & 0 & 73 & 106 & & \\
Total & $\%$ & 1.74 & 2.61 & 7.39 & 35.65 & 52.61 & 100.00 & & \\
& 4 & 6 & 17 & 82 & 121 & 230 & & &
\end{tabular}

$\mathrm{A}=$ American students; $\mathrm{I}=$ international students; $0=$ no response/not applicable; $1=$ very unsatisfied; 2 = somewhat unsatisfied; 3 = somewhat satisfied; $4=$ very satisfied; Chi-S = chisquare; $\underline{\mathrm{d} f}=$ degrees of freedom; $\mathrm{p}=$ probability

NOTE: The no response category was deleted and the 1 and 2 categories were combined because of low expected frequencies. 
Table 26

\section{Distribution of Responses and Chi-Square Analyses of Significance Between American and International students Pertaining to satisfaction of Admission office}

\begin{tabular}{|c|c|c|c|c|c|c|c|c|c|c|}
\hline \multicolumn{2}{|l|}{ Status } & 0 & 1 & 2 & 3 & 4 & Total & Chi-S & df & $\mathbf{p}$ \\
\hline \multirow[t]{2}{*}{ A } & $\%$ & 1.68 & 9.24 & 15.97 & 47.90 & 25.21 & 53.85 & 13.773 & 4 & .008 \\
\hline & $\underline{f}$ & 2 & 11 & 19 & 57 & 30 & 119 & & & \\
\hline \multirow[t]{2}{*}{ I } & 96 & 3.92 & 19.61 & 27.45 & 2.35 & 16.67 & 46.15 & & & \\
\hline & $\underline{f}$ & 4 & 20 & 28 & 33 & 17 & 102 & & & \\
\hline \multirow[t]{2}{*}{ Total } & $\%$ & 2.71 & 14.03 & 21.27 & 40.72 & 21.27 & 100.00 & & & \\
\hline & $\underline{f}$ & 6 & 31 & 47 & 90 & 47 & 221 & & & \\
\hline
\end{tabular}

$\mathrm{A}=$ American students; $\mathrm{I}=$ international students; $0=$ no response/not applicable; $1=$ very unsatisfied; 2 = somewhat unsatisfied; $3=$ somewhat satisfied; $4=$ very satisfied; Chi-S $=$ chisquare; $\underline{\mathrm{df}}=$ degrees of freedom; $\mathbf{p}=$ probability

NOTE: The no response category was deleted because of low expected frequencies.

Table 27

Distribution of Responses and Chi-Square Analyses of Significance Between American and International Students Pertaining to Importance of Campus Housing

\begin{tabular}{|c|c|c|c|c|c|c|c|c|c|c|}
\hline \multicolumn{2}{|l|}{ Status } & 0 & 1 & 2 & 3 & 4 & Total & Chi-S & $\underline{\text { df }}$ & p \\
\hline \multirow[t]{2}{*}{ A } & 96 & 11.29 & 32.26 & 20.16 & 21.77 & 14.52 & 53.91 & 68.726 & 4 & .000 \\
\hline & $\underline{f}$ & 14 & 40 & 25 & 27 & 18 & 124 & & & \\
\hline \multirow[t]{2}{*}{ I } & 8 & 3.77 & 2.83 & 7.55 & 28.30 & 57.55 & 46.09 & & & \\
\hline & $\underline{f}$ & 4 & 3 & 8 & 30 & 61 & 106 & & & \\
\hline \multirow[t]{2}{*}{ Total } & $\%$ & 7.83 & 18.70 & 14.35 & 24.78 & 34.35 & 100.00 & & & \\
\hline & $\underline{f}$ & 18 & 43 & 33 & 57 & 79 & 230 & & & \\
\hline
\end{tabular}

$\mathrm{A}=$ American students; $\mathrm{I}=$ international students; $0=$ no response/not applicable; $1=$ very unsatisfied; 2 = somewhat unsatisfied; 3 = somewhat satisfied; 4 = very satisfied; Chi-S = chisquare; $\underline{\mathrm{df}}=$ degrees of freedom; $p=$ probability 
Table 28

Distribution of Responses and Chi-Square Analyses of

Significance Between American and International

students Pertaining to Importance of

Recreation Programs/Activities

\begin{tabular}{|c|c|c|c|c|c|c|c|c|c|c|}
\hline Status & & 0 & 1 & 2 & 3 & 4 & Total & Chi-S & df & $\mathfrak{p}$ \\
\hline \multirow[t]{2}{*}{ A } & 8 & 7.26 & 19.35 & 34.68 & 25.81 & 12.90 & 53.91 & 51.060 & 4 & 0.000 \\
\hline & $\mathbf{f}$ & 9 & 24 & 43 & 32 & 16 & 124 & & & \\
\hline \multirow[t]{2}{*}{ I } & $\%$ & 3.77 & 3.77 & 9.43 & 40.57 & 42.45 & 46.09 & & & \\
\hline & $\underline{f}$ & 4 & 4 & 10 & 43 & 45 & 106 & & & \\
\hline \multirow[t]{2}{*}{ Total } & $9 \%$ & 5.65 & 12.17 & 23.04 & 32.61 & 26.52 & 100.00 & & & \\
\hline & $\underline{f}$ & 13 & 28 & 53 & 75 & 61 & 230 & & & \\
\hline
\end{tabular}

$\mathrm{A}=$ American students; $\mathrm{I}=$ international students; $0=$ no response/not applicable; $1=$ very unsatisfied; 2 = somewhat unsatisfied; 3 = somewhat satisfied; $4=$ very satisfied; Chi-S $=$ chisquare; $\underline{\mathbf{d f}}=$ degrees of freedom; $\mathbf{p}=$ probability

Table 29

Distribution of Responses and Chi-Square Analyses of Significance Between American and International Students Pertaining to Importance of student organizations

\begin{tabular}{|c|c|c|c|c|c|c|c|c|c|c|}
\hline Status & & 0 & 1 & 2 & 3 & 4 & Total & Chi-S & $\underline{\mathrm{df}}$ & $\mathrm{p}$ \\
\hline \multirow[t]{2}{*}{ A } & $\%$ & 4.84 & 17.74 & 33.06 & 33.06 & 11.29 & 53.91 & 32.606 & 4 & .000 \\
\hline & $\underline{f}$ & 6 & 22 & 41 & 41 & 14 & 124 & & & \\
\hline \multirow[t]{2}{*}{ I } & $\%$ & 2.83 & 2.83 & 16.98 & 44.34 & 33.02 & 46.09 & & & \\
\hline & $\underline{f}$ & 3 & 3 & 18 & 47 & 35 & 106 & & & \\
\hline \multirow[t]{2}{*}{ Total } & $\%$ & 3.91 & 10.87 & 25.65 & 38.26 & 21.30 & 100.00 & & & \\
\hline & $\underline{f}$ & 9 & 25 & 59 & 88 & 49 & 230 & & & \\
\hline
\end{tabular}

$\mathrm{A}=$ American students; $\mathrm{I}=$ international students; $0=$ no response/not applicable; $1=$ very unsatisfied; 2 = somewhat unsatisfied; 3 = somewhat satisfied; 4 = very satisfied; Chi-S $=$ chisquare; $\underline{\mathrm{df}}=$ degrees of freedom; $\mathrm{p}=$ probability 
Table 30

$$
\begin{gathered}
\text { Distribution of Responses and chi-square Analyses of } \\
\text { Significance Between American and International } \\
\text { Students Pertaining to Importance } \\
\text { of Child Care }
\end{gathered}
$$

\begin{tabular}{|c|c|c|c|c|c|c|c|c|c|c|}
\hline \multicolumn{2}{|l|}{ Status } & 0 & 1 & 2 & 3 & 4 & Total & Chi-S & df & $\mathrm{p}$ \\
\hline A & 9 & 12.10 & 38.71 & 16.13 & 12.10 & 20.97 & 53.91 & 23.531 & 4 & .000 \\
\hline & $\underline{f}$ & 15 & 48 & 20 & 15 & 26 & 124 & & & \\
\hline \multirow[t]{2}{*}{ I } & $\%$ & 16.98 & 13.21 & 14.15 & 28.30 & 27.36 & 46.09 & & & \\
\hline & $\underline{\mathbf{f}}$ & 18 & 14 & 15 & 30 & 29 & 106 & & & \\
\hline \multirow[t]{2}{*}{ Total } & $\%$ & 14.35 & 26.96 & 15.22 & 19.57 & 23.91 & 100.00 & & & \\
\hline & & $\underline{\mathbf{f}}$ & 33 & 62 & 35 & 45 & 55 & 230 & & \\
\hline
\end{tabular}

$\mathrm{A}=$ American students; $\mathrm{I}=$ international students; $0=$ no response/not applicable; $1=$ very unsatisfied; 2 = somewhat unsatisfied; 3 = somewhat satisfied; 4 = very satisfied; Chi-S = chisquare; $\underline{\mathrm{df}}=$ degrees of freedom; $\mathrm{p}=$ probability

Table 31

$$
\begin{gathered}
\text { Distribution of Responses and chi-Square Analyses of } \\
\text { Significance Between American and International } \\
\text { Students Pertaining to Importance of } \\
\text { student Health Services }
\end{gathered}
$$

\begin{tabular}{lllllllllll}
\hline Status & & 0 & 1 & 2 & 3 & 4 & Total & Chi-S & df & D \\
\hline A & $\%$ & 8.87 & 10.48 & 13.71 & 23.39 & 43.55 & 53.91 & 18.192 & 4 & .001 \\
& $\mathrm{f}$ & 11 & 13 & 17 & 29 & 54 & 124 & & & \\
$\mathrm{I}$ & $\%$ & 3.77 & 0.94 & 6.60 & 24.53 & 64.15 & 46.09 & & \\
& $\mathrm{f}$ & 4 & 1 & 7 & 26 & 68 & 106 & & \\
Total & $\%$ & 6.52 & 6.09 & 10.43 & 23.91 & 53.04 & 100.00 & & \\
& $\underline{f}$ & 15 & 14 & 24 & 55 & 122 & 230 & & \\
\end{tabular}

$\mathrm{A}=$ American students; $\mathrm{I}=$ international students; $0=$ no response/not applicable; $1=$ very unsatisfied; 2 = somewhat unsatisfied; 3 = somewhat satisfied; $4=$ very satisfied; Chi-S $=$ chisquare; $\underline{\mathrm{df}}=$ degrees of freedom; $\mathbf{p}=$ probability 
Table 32

\section{Distribution of Responses and Chi-Square Analyses of Significance Between American and International students Pertaining to Importance of Psychological Counseling}

\begin{tabular}{|c|c|c|c|c|c|c|c|c|c|c|}
\hline Status & & 0 & 1 & 2 & 3 & 4 & Total & Chi-S & $\underline{\mathrm{df}}$ & p \\
\hline \multirow[t]{2}{*}{ A } & $\mathscr{\%}$ & 8.06 & 19.35 & 19.35 & 27.42 & 25.81 & 53.91 & 10.186 & 4 & .037 \\
\hline & $\underline{f}$ & 10 & 24 & 24 & 34 & 32 & 124 & & & \\
\hline \multirow[t]{2}{*}{ I } & $\%$ & 14.15 & 6.60 & 16.04 & 33.02 & 30.19 & 46.09 & & & \\
\hline & f & 15 & 7 & 17 & 35 & 32 & 106 & & & \\
\hline \multirow[t]{2}{*}{ Total } & $\%$ & 10.87 & 13.48 & 17.83 & 30.00 & 27.83 & 100 & & & \\
\hline & $\underline{f}$ & 25 & 31 & 41 & 69 & 64 & 230 & & & \\
\hline
\end{tabular}

$\mathrm{A}=$ American students; $\mathrm{I}=$ international students; $0=$ no response/not applicable; $1=$ very unsatisfied; 2 = somewhat unsatisfied; 3 = somewhat satisfied; $4=$ very satisfied; Chi-S $=$ chisquare; $\mathrm{df}=$ degrees of freedom; $\mathrm{D}=$ probability

Table 33

Distribution of Responses and Chi-Square Analyses of Significance Between American and International Students Pertaining to Importance of Religious Services

\begin{tabular}{|c|c|c|c|c|c|c|c|c|c|c|}
\hline \multicolumn{2}{|c|}{ Status } & 0 & 1 & 2 & 3 & 4 & Total & Chi-S & $\underline{\mathrm{df}}$ & $\mathrm{p}$ \\
\hline \multirow[t]{2}{*}{ A } & $\%$ & 5.65 & 41.13 & 20.97 & 16.13 & 16.13 & 53.91 & 14.568 & 4 & .006 \\
\hline & $\underline{\mathbf{f}}$ & 7 & & 51 & 26 & 20 & 20 & 124 & & \\
\hline \multirow[t]{2}{*}{$I$} & $\%$ & 14.15 & 19.81 & 7.36 & 21.70 & 16.98 & 46.09 & & & \\
\hline & $\underline{\mathbf{f}}$ & 15 & 21 & 29 & 23 & 18 & 106 & & & \\
\hline \multirow[t]{2}{*}{ Total } & $\%$ & 9.57 & 31.30 & 3.91 & 18.70 & 16.52 & 100.00 & & & \\
\hline & $\underline{\mathbf{f}}$ & 22 & 72 & 55 & 43 & 38 & 230 & & & \\
\hline
\end{tabular}

$\mathrm{A}=$ American students; $\mathrm{I}=$ international students; $0=$ no response/not applicable; 1 = very unsatisfied; 2 = somewhat unsatisfied; 3 = somewhat satisfied; 4 = very satisfied; Chi-S = chisquare; $\underline{\mathrm{df}}=$ degrees of freedom; $\mathrm{p}=$ probability 
Table 34

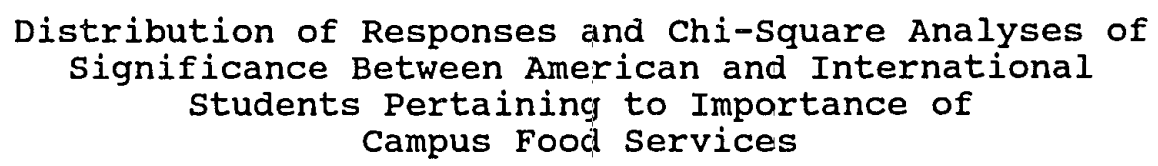

\begin{tabular}{|c|c|c|c|c|c|c|c|c|c|c|}
\hline Status & & 0 & 1 & 2 & 3 & 4 & Total & Chi-S & df & $\mathbf{p}$ \\
\hline \multirow[t]{2}{*}{ A } & $\%$ & 4.03 & 11.29 & 16.13 & 41.13 & 27.42 & 53.91 & 18.843 & 4 & .001 \\
\hline & f & 5 & 14 & 20 & 51 & 34 & 124 & & & \\
\hline \multirow[t]{2}{*}{ I } & $\%$ & 9.43 & 1.89 & 8.49 & 33.96 & 46.23 & 46.09 & & & \\
\hline & $\underline{f}$ & 10 & 2 & 9 & 36 & 49 & 106 & & & \\
\hline \multirow[t]{2}{*}{ Total } & $\bar{q}$ & 6.52 & 6.96 & 12.61 & 37.83 & 36.09 & 100.00 & & & \\
\hline & $\underline{f}$ & 15 & 16 & 29 & 87 & 83 & 230 & & & \\
\hline
\end{tabular}

$\mathrm{A}=$ American students; $\mathrm{I}=$ international students; 0 = no response/not applicable; 1 = very unsatisfied; 2 = somewhat unsatisfied; 3 = somewhat satisfied; $4=$ very satisfied; Chi-S = chisquare; $\underline{\mathrm{df}}=$ degrees of freedom; $\mathbf{p}=$ probability

Table 35

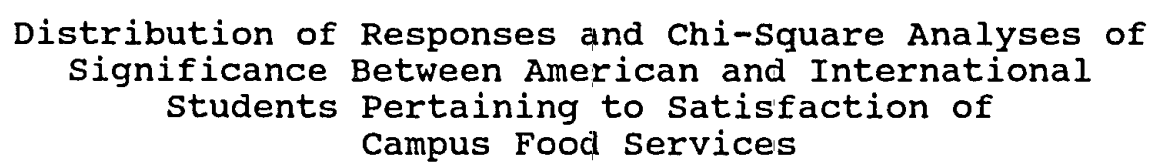

\begin{tabular}{|c|c|c|c|c|c|c|c|c|c|c|}
\hline \multicolumn{2}{|l|}{ Status } & 0 & 1 & 2 & 3 & 4 & Total & Chi-S & df & $\mathfrak{p}$ \\
\hline A & $\%$ & 11.86 & 11.86 & 22.88 & 40.68 & 12.71 & 55.92 & 10.818 & 4 & 0.029 \\
\hline & $\underline{f}$ & 14 & 14 & 27 & 48 & 15 & 118 & & & \\
\hline \multirow[t]{2}{*}{ I } & 8 & 11.83 & 29.03 & 18.28 & 27.96 & 12.90 & 44.08 & & & \\
\hline & $\underline{f}$ & 11 & 27 & 17 & 26 & 12 & 93 & & & \\
\hline \multirow[t]{2}{*}{ Total } & $\%$ & 11.85 & 19.43 & 20.85 & 35.07 & 12.80 & & & & \\
\hline & $\underline{\mathbf{f}}$ & 25 & 41 & 44 & 74 & 27 & 211 & & & \\
\hline
\end{tabular}

$\mathrm{A}=$ American students; $\mathrm{I}=$ intemational students; $0=$ no response/not applicable; 1 = very unsatisfied; 2 = somewhat unsatisfied; 3 = somewhat satisfied; $4 \neq$ very satisfied; Chi-S = chisquare; $\underline{d f}=$ degrees of freedom; $\mathrm{p}=$ probability

NOTE: The no response category was deleted because of low expected frequencies. 
Table 36

\section{Distribution of Responses and Chi-Square Analyses of Significance Between American and International students Pertaining to Importance of Intercollegiate Athletic Programs}

\begin{tabular}{lllllllllll}
\hline Status & & 0 & 1 & 2 & 3 & 4 & Total & Chi-S & df & p \\
& & & & & & & & & & \\
A & $\%$ & 4.03 & 33.06 & 24.19 & 20.16 & 18.55 & 53.91 & 27.377 & 4 & .000 \\
& $\underline{f}$ & 5 & & 41 & 30 & 25 & 23 & 124 & & \\
I & $\%$ & 8.49 & 6.60 & 23.58 & 23.30 & 33.02 & 46.09 & & \\
& $\underline{f}$ & 9 & 7 & 25 & 0 & & 35 & 106 & \\
Total & $\%$ & 6.09 & 20.87 & 23.91 & 23.91 & 25.22 & 100.00 & & \\
& $\mathbf{f}$ & 14 & 48 & 55 & 55 & 58 & 230 & & \\
\end{tabular}

$\mathrm{A}=$ American students; $\mathrm{I}=$ international students; $0=$ no response/not applicable; $1=$ very unsatisfied; 2 = somewhat unsatisfied; $3=$ somewhat satisfied; $4=$ very satisfied; Chi-S $=$ chisquare; $\underline{\mathrm{df}}=$ degrees of freedom; $\mathbf{p}=$ probability

Table 37

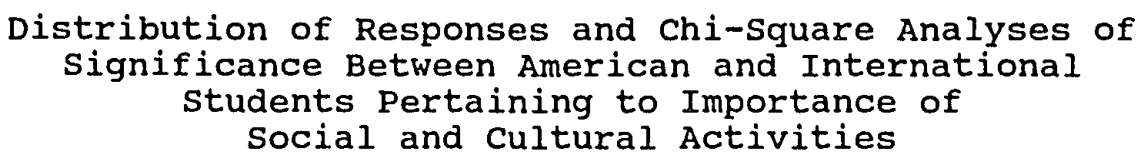

\begin{tabular}{|c|c|c|c|c|c|c|c|c|c|c|}
\hline \multicolumn{2}{|l|}{ Status } & 0 & 1 & 2 & 3 & 4 & Total & Chi-S & df & $\mathbf{p}$ \\
\hline \multirow[t]{2}{*}{ A } & $\%$ & 8.06 & 13.71 & 27.42 & 32.26 & 18.55 & 53.91 & 31.413 & 4 & .000 \\
\hline & $\underline{\mathbf{f}}$. & 10 & 17 & 34 & 40 & 23 & 124 & & & \\
\hline \multirow[t]{2}{*}{ I } & $\%$ & 6.60 & 1.89 & 9.43 & 39.62 & 42.45 & 46.09 & & & \\
\hline & $\underline{f}$ & 7 & 2 & 10 & 42 & 45 & 106 & & & \\
\hline \multirow[t]{2}{*}{ Total } & $\%$ & 7.39 & 8.26 & 19.13 & 35.65 & 29.57 & 100.00 & & & \\
\hline & $\underline{f}$ & 17 & 19 & 44 & 82 & 68 & 230 & & & \\
\hline
\end{tabular}

$\mathrm{A}=$ American students; $\mathrm{I}=$ international students; $0=$ no response/not applicable; $1=$ very unsatisfied; 2 = somewhat unsatisfied; 3 = somewhat satisfied; $4=$ very satisfied; Chi-S = chisquare; $\underline{\mathrm{d} f}=$ degrees of freedom; $\mathbf{p}=$ probability 
Table 38

\section{Distribution of Responses and Chi-Square Analyses of Significance Between American and International Stuclents Pertaining to Importance of Campus orientation Program}

\begin{tabular}{|c|c|c|c|c|c|c|c|c|c|c|}
\hline \multicolumn{2}{|c|}{ Status } & 0 & 1 & 2 & 3 & 4 & Total & Chi-S & $\underline{\mathrm{df}}$ & $\mathbf{p}$ \\
\hline A & $\%$ & 12.10 & 12.90 & 25.00 & 28.23 & 21.77 & 53.91 & 32.128 & 4 & .000 \\
\hline & $\underline{\mathbf{f}}$ & 15 & 15 & 31 & 35 & 27 & 124 & & & \\
\hline \multirow[t]{2}{*}{ I } & $\%$ & 6.60 & 0.00 & 10.38 & 42.45 & 40.57 & 46.09 & & & \\
\hline & $\underline{\mathbf{f}}$ & 0 & 11 & 45 & 43 & 106 & & & & \\
\hline \multirow[t]{2}{*}{ Total } & $\%$ & 9.57 & 6.96 & 18.26 & 34.78 & 30.43 & 100.00 & & & \\
\hline & $\underline{f}$ & 22 & 16 & 42 & 80 & 70 & 230 & & & \\
\hline
\end{tabular}

$\mathrm{A}=$ American students; $\mathrm{I}=$ international students; $0=$ no response/not applicable; 1 = very unsatisfied; 2 = somewhat unsatisfied; 3 = somewhat satisfied; 4 = very satisfied; Chi-S = chisquare; $\underline{\mathrm{df}}=$ degrees of freedom; $\mathbf{D}=$ probability

Table 39

$$
\begin{gathered}
\text { Distribution of Responses and Chi-Square Analyses of } \\
\text { Significance Between American and International } \\
\text { Students Pertaining to Importance of } \\
\text { Special student Services }
\end{gathered}
$$

\begin{tabular}{|c|c|c|c|c|c|c|c|c|c|c|}
\hline Status & & 0 & 1 & 2 & 3 & 4 & Total & Chi-S & df & p \\
\hline \multirow[t]{2}{*}{ A } & $\%$ & 14.52 & 25.00 & 21.77 & 16.94 & 21.77 & 53.91 & 32.448 & 4 & .000 \\
\hline & $\underline{f}$ & 18 & $3 \|$ & 27 & 21 & 27 & 124 & & & \\
\hline \multirow[t]{2}{*}{ I } & 80 & 11.32 & 3.77 & 12.26 & 32.08 & 40.57 & 46.09 & & & \\
\hline & $\underline{f}$ & 12 & 4 & 13 & 34 & 43 & i06 & & & \\
\hline \multirow[t]{2}{*}{ Total } & 96 & 13.04 & 15.22 & 17.39 & 23.91 & 30.43 & 100.00 & & & \\
\hline & f & 30 & 35 & 40 & 55 & 70 & 230 & & & \\
\hline
\end{tabular}

$\mathrm{A}=$ American students; $\mathrm{I}=$ international students; $0=$ no response/not applicable; $1=$ very unsatisfied; 2 = somewhat unsatisfied; $3=$ somewhat satisfied; $4=$ very satisfied; Chi-S = chisquare; $\underline{\mathrm{df}}=$ degrees of freedom; $\mathbf{p}=$ probability 
Table 40

Summary of the Probability Associated with All Chi-squares of Importance and Satisfaction of International and American Students for Instruction

\begin{tabular}{|c|c|c|}
\hline Instruction & IQ & SQ \\
\hline $\begin{array}{l}\text { Instructional quality } \\
\text { Accessibility of the faculty } \\
\text { Fairness of faculty treatment of students } \\
\text { Fairness of testing and grading } \\
\text { Intellectual stimulation from faculty } \\
\text { Contents of courses } \\
\text { Class size }\end{array}$ & $\begin{array}{l}.069 \\
.633 \\
.706 \\
.150 \\
.384 \\
.712 \\
.154\end{array}$ & $\begin{array}{l}.542 \\
.783 \\
.010 * \\
.043 * \\
.266 \\
.292 \\
.688\end{array}$ \\
\hline \multicolumn{3}{|c|}{$\begin{array}{l}Q=\text { Importance questionnaire; } S Q=\text { Satisfaction } \\
\text { Questionnaire; } *=\text { Significant }\end{array}$} \\
\hline \multicolumn{3}{|c|}{$\begin{array}{c}\text { Summary of the Probability Associated with All Chi-squares } \\
\text { of Importance and Satisfaction of International } \\
\text { and American Students for Academic Support }\end{array}$} \\
\hline Academic support & IQ & SQ \\
\hline $\begin{array}{l}\text { Library collections } \\
\text { Library services } \\
\text { Lab facilities } \\
\text { Computer facilities } \\
\text { Academic advising services on campus } \\
\text { Pre-college advising from high school } \\
\text { Pre-transfer advising from prev. college } \\
\text { Catalog (bulletin) \& schedule of classes } \\
\text { Tutoring/basic skills services } \\
\text { Variety of courses offered } \\
\text { Availability of courses to finish degree } \\
\text { on time } \\
\text { Convenience of class scheduling }\end{array}$ & $\begin{array}{l}.007 \star \\
.002 \star \\
.000 \star \\
.000 \star \\
.687 \\
.181 \\
.208 \\
.865 \\
.000^{\star} \\
.885 \\
.653 \\
.355\end{array}$ & $\begin{array}{l}.090 \\
.875 \\
.224 \\
.856 \\
.282 \\
.194 \\
.197 \\
.115 \\
.312 \\
.191 \\
.087 \\
.080\end{array}$ \\
\hline
\end{tabular}


Table 42

Summary of the Probability Associated with All Chi-Squares of Importance and Satisfaction of International and American students for student Services

\begin{tabular}{|c|c|c|}
\hline Student Service & IQ & SQ \\
\hline Reqistrar's office & .337 & .067 \\
\hline Campus housing & $.000 *$ & .516 \\
\hline Recreation programs/activities & $.000 *$ & .098 \\
\hline Student organizations & $.000 *$ & .906 \\
\hline Child care & $.000 *$ & .464 \\
\hline Parking & .061 & .720 \\
\hline student health services & $.001 *$ & .417 \\
\hline Psychological counseling & $.037 \star$ & .731 \\
\hline Financial aid office (not consider. amount) & .091 & .065 \\
\hline Religious services & $.006 *$ & .766 \\
\hline Job search services & .080 & .154 \\
\hline Campus food services & $.001 *$ & $.029 *$ \\
\hline Intercollegiate athletic programs & $.000 *$ & .748 \\
\hline Career guidance from faculty & .261 & .460 \\
\hline Career guidance fr. Career Plan office & .490 & .336 \\
\hline Social and cultural activities & $.000 *$ & .476 \\
\hline Campus orientation programs & $.000 *$ & .146 \\
\hline Special student services & $.000 *$ & .942 \\
\hline
\end{tabular}

Results for Research Question \#5

For each service quality statement, what is the relationship between the perceived importance and level of satisfaction for U.S. students? For each service quality statement, what is the relationship between the perceived importance and level of satisfaction for international students? 
For all need composites, importance scores were found to be significantly higher than satisfaction scores. The data on the difference between importance and satisfaction scores are found in Tables 43 to 45 .

For every need composite students indicated a level of satisfaction lower than that of importance except for thirteen items that had significantly higher satisfaction scores, which implied that American students were satisfied with these needs to more than the extent to which they regarded them as important. These items were "lab facilities," "tutoring/basic skills services," "campus housing," "recreation programs/activities," "student organizations," "child care," "student health services," "psychological counseling," "religious services," "intercollegiate athletic programs," social and cultural activities," "campus orientation programs," and "special students services."

For international students, when the individual need items were examined there were only three items that had significantly higher satisfaction scores. These items were "child care," "psychological counseling" and "religious services." 
Table 43

\section{Difference of Importance and Satisfaction Scores Between American and International Students for Instruction}

\begin{tabular}{|c|c|c|c|c|c|c|}
\hline \multirow[b]{2}{*}{ Instruction } & \multicolumn{3}{|c|}{ American } & \multicolumn{3}{|c|}{ International } \\
\hline & I & $\mathbf{S}$ & $\mathrm{D}$ & I & $S$ & $\mathrm{D}$ \\
\hline Instructional quality & 98 & 87 & 11 & 97 & 83 & 14 \\
\hline Accessibility of faculty & 92 & 82 & 10 & 94 & 83 & 11 \\
\hline Faimess of fac. treatment of students & 92 & 87 & 05 & 94 & 72 & 22 \\
\hline Faimess of testing \& grading & 99 & 84 & 15 & 95 & 81 & 14 \\
\hline Intellectual stimulation from faculty & 95 & 82 & 13 & 94 & 79 & 15 \\
\hline Contents of courses & 98 & 85 & 13 & 96 & 78 & 18 \\
\hline Class size & 79 & 74 & 05 & 89 & 75 & 14 \\
\hline
\end{tabular}

$\mathrm{I}=$ importance; $\mathrm{S}=$ satisfaction; $\mathrm{D}=$ difference

Table 44

Difference of Importance and Satisfaction Scores Between American and International students for Academic Support

\begin{tabular}{|c|c|c|c|c|c|c|}
\hline \multirow[b]{2}{*}{ Academic Support } & \multicolumn{3}{|c|}{ American } & \multicolumn{3}{|c|}{ International } \\
\hline & I & $S$ & $\mathrm{D}$ & I & $S$ & $\mathrm{D}$ \\
\hline Library collection & 89 & 85 & 04 & 97 & 70 & 27 \\
\hline Library service & 94 & 83 & 11 & 97 & 80 & 17 \\
\hline Lab facilities & 74 & 83 & $09+$ & 95 & 75 & 20 \\
\hline Computer facilities & 81 & 65 & 16 & 95 & 63 & 32 \\
\hline Acad advising serv. on campus & 90 & 44 & 46 & 93 & 57 & 36 \\
\hline Pre-college advising fr high school & 62 & 48 & 14 & 76 & 69 & 07 \\
\hline Pre-transfer advising fr.prev coll. & 77 & 55 & 22 & 86 & 73 & 13 \\
\hline Catalog (bulletin) \& sched.class & 92 & 89 & 03 & 95 & 77 & 18 \\
\hline Tutoring/basic skills services & 63 & 77 & $14+$ & 91 & 71 & 20 \\
\hline Variety of courses offered & 96 & 66 & 30 & 98 & 54 & 44 \\
\hline Avail. of courses to finish degree & 94 & 52 & 42 & 97 & 57 & 40 \\
\hline Convenience of class scheduling & 95 & 62 & 33 & 95 & 55 & 40 \\
\hline
\end{tabular}

$\mathrm{I}=$ importance; $\mathrm{S}=$ satisfaction; $\mathrm{D}=$ difference 
Table 45

Difference of Importance and Satisfaction Scores Between American and International students for student Services

\begin{tabular}{llllllllll}
\hline & & American & & \multicolumn{3}{l}{ International } \\
\cline { 2 - 6 } Student Services & I & S & D & I & S & D \\
\hline
\end{tabular}

Admission office

Registrar's office

Campus housing

Recreation programs/activities

Student organizations

Child care

Parking

Student health services

Psychological counseling

Financial aid office

Job search services

Campus food services

Intercollegiate ath. programs

Career guidance from faculty

Career guidance fr Career Pl.Office

Social \& cultural activities

Campus orientation programs

Special student services $\begin{array}{llllll}83 & 75 & 08 & 99 & 51 & 48\end{array}$

$\begin{array}{llllll}89 & 79 & 10 & 95 & 63 & 32\end{array}$

$\begin{array}{lllll}41 & 69 & 28+89 & 64 & 25\end{array}$

$\begin{array}{lllll}42 & 81 & 39+86 & 75 & 11\end{array}$

$\begin{array}{lllll}47 & 76 & 29+80 & 77 & 03\end{array}$

$\begin{array}{lllll}38 & 64 & 26+67 & 76 & 09+\end{array}$

$\begin{array}{llllll}72 & 67 & 05 & 84 & 50 & 34\end{array}$

$\begin{array}{lllll}74 & 84 & 10+92 & 75 & 17\end{array}$

$\begin{array}{lllll}58 & 88 & 30+73 & 90 & 17+\end{array}$

$\begin{array}{llllll}79 & 60 & 19 & 80 & 73 & 07\end{array}$

$\begin{array}{llllll}85 & 80 & 05 & 86 & 64 & 22\end{array}$

$\begin{array}{llllll}72 & 60 & 12 & 89 & 46 & 43\end{array}$

$\begin{array}{lllll}40 & 71 & 31+67 & 66 & 01\end{array}$

$\begin{array}{llllll}85 & 57 & 28 & 93 & 62 & 31\end{array}$

$\begin{array}{llllll}80 & 64 & 16 & 86 & 54 & 32\end{array}$

$\begin{array}{lllll}55 & 80 & 25+88 & 69 & 19\end{array}$

$\begin{array}{lllll}57 & 67 & 10+89 & 80 & 09\end{array}$

$\begin{array}{lllll}45 & 73 & 28+82 & 77 & 05\end{array}$

$\mathrm{I}=$ importance; $\mathrm{S}=$ satisfaction; $\mathrm{D}=$ difference

For every need composite for which students indicated a

level of satisfaction lower than that of importance, the

disparity indicated that needs were not being met at a level approaching their importance. This researcher regarded this gap between importance and satisfaction of needs to be a potential or actual source of frustration among students, especially where the gap is great and high importance was placed. The following composites were the needs least met, with the widest gaps between the importance and satisfaction 


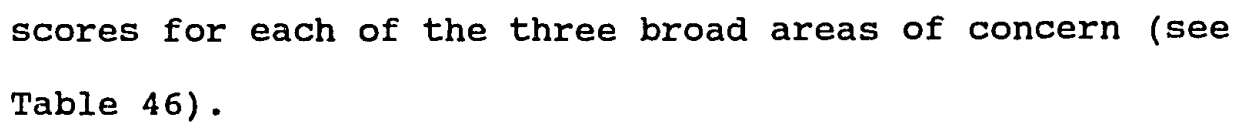

Instruction

1. Faimess of testing and grading

2. Intellectual stimulation from faculty

3. Content of courses

4. Instructional quality

5. Accessibility of faculty

Academic Support

1. Academic advising services on campus

2. Availability of courses to finish degree

3. Convenience of class scheduling

4. Variety of courses offered

5. Pre-transfer advising from previous college

Student Services

1. Career guidance from faculty

2. Financial aid office

3. Career guidance from Career Planning Office

4. Campus food services

5. Registrar's office
1. Faimess of faculty treatment of stud.

2. Content of courses

3. Intellectual stimulation from faculty

4. Fairness of testing and grading

5. Instructional quality

6. Class size

1. Variety of courses offered

2. Availability of courses to finish deg.

3. Convenience of class scheduling

4. Acad. advising services on campus

5. Library collection

1. Admission office

2. Campus food services

3. Parking

4. Career guid. fr. Career Plan Office

5. Registrar's office

The need for "academic advising services on campus" was the least met of all for American students. This item ranked the eleventh highest in importance and the lowest in satisfaction. The highest ranked in importance was

"fairness of testing and grading." The second widest gap exhibited was "availability of courses to finish degree," followed by "convenience of class scheduling," "variety of 
courses offered" and "pre-transfer advising from previous college."

For international students, the least-met need was "admission office" which ranked the highest in importance and judged lowest in satisfaction. The second least met was "variety of courses offered," followed by "campus food services," "availability of courses to finish degree," "convenience of class scheduling" and "academic advising services on campus."

The following five composites had the narrowest gap among American students between importance and satisfaction scores (listed in ascending order):

1. Catalog (Bulletin) \& Schedule of classes

2. Library collection

3. Parking

4. Job search services

5. Class size

The following composite items had exceeded the importance over satisfaction scores (listed in ascending order):

1. Recreation programs/activities

2. Religious services

3. Intercollegiate athletic programs

4. Student organizations

5. Psychological counseling 
For international students, the following composite items had the narrowest gap between importance and satisfaction scores (listed in ascending order):

1. Intercollegiate athletic program

2. Student organizations

3. Special student services

4. Financial aid office

5. Pre-college advising from high school

The only three composite items where satisfaction

scores exceeded the importance scores for international

students were (listed in ascending order):

1. Religious services

2. Psychological counseling

3. Child care

Question 28 of the survey questionnaire asked students

to rate $P S U$ in general according to its faculty and

instructional quality, academic support, student services, and student experience as a whole. Participants rated each of these areas on a five-point scale: very poor, poor, fair, good, and excellent. A plurality of the international students rated as fair each of the following: faculty and instructional quality (47\%); academic support (58\%); student services (50\%), and student experience as a whole (47\%). A plurality of the American students also rated as fair academic support (43\%), student services (48\%), and student 
plurality rated faculty and instructional quality as good $(44 \%)$.

\section{Conclusion}

It is evident from the similarity of international and American students' ratings of various PSU services that in many ways both groups of students have very similar needs. Academic concerns come first for both groups, and although some measures of academic quality take on different a different level of importance for one group or another, their "top 5" are markedly alike. The same can be said of academic support services, although American students were more likely to have concerns about effecting smooth college transfers.

It is in the area of non-academic student services that the greatest disparities appear to exist, both in terms of ranking items by importance and in the level of satisfaction with these services. That Admissions office sexvices were a particular sore point with the international student population comes as no surprise to any administrator who has worked with this group, for example, as admissions errors can cause visa and financial problems out of proportion with the consequences of similar mistakes for American students. 
CHAPTER V

RESULTS OF THE FOCUS GROUP

INTERVIEWS

Focus group interviews were conducted primarily to validate, in a less formal and--in lawyerly--less "leading" way, the results of the survey, particularly regarding areas of student dissatisfaction at PSU. It was of special interest whether the focus group interviews would indicate the same relative agreement and disparity between American and international student levels of (dis)satisfaction in those categories of instruction, academic support, and students services that the surveys tested. This chapter presents in detail the protocol used and the results of the focus group interviews.

\section{Protocol of the Focus}

Group Interviews

Two focus groups were conducted for this study. One group was composed of American students; the other group was composed of international students. The selection of the members of the focus group was based on their responses to the survey questionnaire, with the intention of obtaining a group of participants likely to have dissatisfactions they might wish to give voice to in a more specific way than the 
survey questionnaire allowed. Thus focus group participants were chosen in the basis of the high degree of dissatisfaction their survey responses indicated. However, these did not always turn out to be the most highly dissatisfied from the survey, because when a number of those declined to participate in the focus groups, they were replaced by the seemingly most dissatisfied of the remaining survey respondents. Both interviews were conducted on the Portland State University campus in September 1993. Each participant signed a consent letter before the interview took place. Both interviews were tape-recorded with the consent of all the participants. The tape-recorded materials were transcribed into written form for use.

\section{Interviewees}

There were eight U.S. students in the first group, four males and four females. For international students, there were six males, as the four female international students invited did not show up. Their reasons are not known by this researcher, although one of the female international students indicated when invited that she was unlikely to attend an evening meeting unaccompanied. Another indicated that she needed a ride to attend, and may not have obtained one. It is also possible that one or more of the female international "no-shows" were resisting contradicting the more modest, uncomplaining and relatively non-vocal role that their cultures impose upon females--a role that to 
their eyes focus group participation might seem to be asking or requiring them to discard or turn inside-out. It is possible that future researchers could compensate for potential cultural or personal conflicts that may have prevented female students from taking part in this study. Both groups of students included individuals engaged in various levels and fields of study. The interview procedure for each of the groups lasted approximately 1.5 hours. In the following summary, findings are discussed in greater detail and illustrated with typical quotes from focus group participants.

\section{Summary of Findings in the Focus Group Interviews: American students}

The interview went smoothly. Each participant seemed to be enthusiastic. The interview started at 7:10 p.m. and ended at $8: 30 \mathrm{p} . \mathrm{m}$. The meeting was held in a classroom in the school of Education building. The table was placed in the middle of the room, and was properly sized for the eight participants and the moderator. Two microphones were placed carefully to catch each speaker's words.

The moderator explained the purpose of the focus group meeting. He encouraged all participants to take an active part in the proceedings and to express their feelings, attitudes, perceptions and other thoughts as honestly as possible. He assured all participants that their comments would be held in strict confidence as they signed the letter 
of consent of participation. Participants included students majoring in mechanical engineering, marketing, art, history, accounting, music and theater arts.

The moderator started by asking the participants to introduce themselves individually. Instructional Quality was the group's first focus. The group members generally agreed that the majority of professors are really great, except for a few with whom lack of preparation for the class is a major concern.

\section{Instruction}

class preparation by teaching staff is an issue that a majority of the participants are concerned about.

There are so many times that professors walk into the class and aren't prepared. They don't even know what they are lecturing on that day. They ask [us] to bring in the books and start from there.. . they just don't really seem to take some time out of class to prepare, and that's what I am disappointed in.

My complaint is with a couple of the math professors I've had. I just got done taking one active class during the summer. It was algebra and that teacher in particular asked [us to work from] a book--and he didn't know what was in that book. I was really disappointed with that class, so I kept on questioning it in my mind. In engineering courses I've had good and bad, but mostly lots of good, professors here.

I know in engineering, the professors have outside research that they do on the side with the corporations in their area. That's their first priority, second priority is research projects for the graduate students that they are working with, and third priority is teaching us--but if they have no time to prepare a lesson or lecture and they come in .. . I am making a lot of generalizations. I guess most of my professors 
are really good, but I've had one or two that aren't.

I am glad that they do have ties with the corporate [world], you know, and they are getting experience outside, because it makes the class more interesting to know how things work in the real world rather than just [textbook examples.] And I don't expect real structure, just at least for them to know where to start, rather than asking the students "what were we talking about last time?" Sometimes I hear that and think, "gee, you know, he is here and doesn't know what we are going to talk about."

Generally, I've been pretty satisfied with the quality of instructors here. I have problems with some TAs who teach labs. They think that it's the only class you have and occupies most of your time. I did a lab last summer session which was 1 hour credit, but I spent 25 hours a week working on it.

One participant who had the opportunity to attend

another university for a two-year exchange program

commented:

I started here at PSU and [then] I went for a two-year exchange program at the University of Massachusetts in Boston. Well, one thing I would say is that when I was in Boston, the professors were really educated. They went to Harvard and all the great schools back east, and so I think "these are great professors!" And I came back here [afterwards], and the comparison was very good. The professors I had here are just as welleducated, and they'd been to fine schools . . . that would be a good mark for the professors here that I have had contact with.

The majority of the participants seemed to agree that

the university in general should cater more to non-

traditional students:

The biggest concern I have about the universitty is I think it's trying hard to be a traditional out-in-the-middle-of-nowhere college that caters to the traditional four-year college student of 
university, and it's not going to work that way. This is an urban university, and most of the students that we have here are non traditional students. I think the focus should be on them rather than the one-third of the students who fit the traditional college-student profile.

It seems like the business schools do work well with nontraditional students, [at least] in my experience, because I work at various jobs on and off. During the last year whenever I had problems and had to work, I've always been able to reschedule. Everybody's been very, very flexible and understanding, at least in the business school. It seems like everybody, [even some] professors, they all work too, and they all seem to understand. If I can't make it to the exam because I had to work, they say "when can you make it?" so I found it very accommodating. I have really taken the time out of classes outside of the school of business. I don't know how the other departments are.

Professors seem to be avaflable for advising outside:

the classroom, according to most of the participants.

My experience is that my professors are always available, and lots of them sit in/their office for hours and no one ever talks to them. I think they are available, but a lot of people don't go out of their way.

other classes I'd taken, they always made their office really clean and tried to be available and let the students know. I think because this is a commuter campus most people work, and a lot of people are busy and they don't spend all day around there for the class, they just go home. But professors are trying| to be available.

Fairness is always an important issue when it comes to grading, assistance and support from teaching staff, and । general attitude toward students. For international students, fairness issues are sometimes part of a larger problem of perceived bias based on race, nationality or citizenship status. 
As far as fairness, I have found only one instructor I felt was unfair, and that I put a lot of effort in my papers and I couldn't get half on the grades. And one guy who wrote a major paper the morning that it was due did far better than I did . . . It was one experience where I felt that I was cheated and that the instructor made a vendetta against me.

Participants were asked for any suggestions to improve the quality of instruction, or to correct at least some of the problems students perceive regarding instructional quality. Instructor evaluations, which students complete each semester at PSU, were a subject that came quickly into the discussion.

I know that they fill out the teachers' evaluations at the end of every term, and I've always done that. I don't know what they do with those. . . That is really a good idea to do that, and then if they see a recurring problem with certain professors, they should address those problems. But it seems this one math professor I had two years ago is still the same now. It seems like it's the same recurring problems, and they don't address those problems. I know I put in an evaluation back then about some of the concerns I have with this particular professor. I wonder if those get addressed. Somehow there should be a way to departmentalize and to check on it after they've given the professors a talk, and to check back and have somebody sit through class period or something. Even that would change the professors. Get a "spy" in each class. Ask a couple of students to come to the meeting and talk and basically follow up on the feedback.

There's one professor in the physics department who has been a problem every single year, and every time he teaches the same class. Everybody complains about him, and he has no idea why twothirds of his class is missing for three weeks each term: it's because he has a boring class. Everybody explains it on their evaluation forms and nothing ever gets done about it. Perhaps if that's true, it requires that the Dean's pressure 
should not only be on the professors, but on the departments.

There should be something that can be done. Maybe something needs to be instituted [within] the tenure system. Some kind of feedback.

I took political science this summer, and this instructor was retired and he was like a "loose cannon" [type]. He didn't assign any text of any kind, and everything was strictly subjective. His questions ranged through everything. He based a lot of his little lessons on questions like "what did you get out of George Bernard Shaw?"

\section{Academic Support Services}

Academic support services, like the library and computer facilities drew mixed feedback from the participants.

I think we have a pretty good library, and I like the computers and their services.

I've used better library and computer systems than I have here. Here, it is very basic, very slow, and very tedious.

The downtown library is much better than PSU's. It is easier to find the information there than at this one. In PSU, I can barely get the things when I know what I am doing. It is not very "smart" at all, and it's very slow--it's very, very old. I work at the library so... you have to have very, very much nailed exactly on the head what you are looking for, or else you are not going to find it.

Participants understood the problem quite well:

funding.

I hear they are pretty discontented with the system that is in the library. It's got to be updated, there's no question about it. It's something that's batted around back and forth, that I know of from the library administration. The biggest concern they have is the cost of running it--they don't even have the expenses 
covered to keep the fourth floor open anymore, so I don't think they are going to be too concerned about putting in a new system.

I think a lot of instructors are so concerned about whether or not they are going to keep their jobs within the next three years, that's where their focus goes to and it strays away from their actual job of teaching.

one participant aired his frustrations about the

computer facilities:

A friend of mine who is majoring in computer science said that they have big macro computers. He said that his desktop has more power than this thing, and he is not kidding, it is absolutely ridiculous and antiquated beyond usefulness. If you are working with something you have to wait 30 seconds to a minute before the character comes up to the screen .. . I guess it's full, they won't let people on it because it is so full, I heard people say it takes half an hour to compile things, that it's very busy.

I went to PCC, and their computer room is all a bunch of microcomputers that are connected. Basically, their local area networks are all tied into the same thing, and one could access it together when processing from your own microcomputer, and it works great. PCC is a junior college, for God's sake, and their computer systems are 50 thousand times better than Portland state's. It is ridiculous. Here in PSU we have 10-to-15-year-old "monster bits."

Comments about the library computers were not all

negative, but understaffing did come in for criticism.

one good thing about the PSU library's computer systems [is that] you can call in from home.

It seems to me that we need to have more workstudy positions available at the library, because as an evening student, I work and there's never anyone at the desk on any of the floors to ask for help, and every time I need help, there's no one there--[everything is] closed. 
I think their library people [and] sometimes all of the academic support people, they are pretty bureaucratic. I talk with my roommate a lot about the academic support system, and he had a problem with just wanting to go in and check out a book at the beginning of the term. He had been away studying in Spain in an exchange program for a year, so he did not a have a sticker from last term. He had a letter showing he was studying abroad, but they would not check that book out to him because he did not have that sticker and had to prove that basically he was more or less attending PSU, but not here in Portland.

There's a lot of red tape...

The students understood how and why understaffing

happens. It is a matter of funding that affects other

aspects of the university, including how many classes can be

offered. Because some classes are rarely offered, students

expressed their frustrations.

My main problem is getting classes. I am glad you can call in now because [otherwise] you have to wait long lines. My high school had better ways to register for classes. I am taking like 200 level classes right now because I want to start early, but I can't get into it, because everyone is taking those and I couldn't get into. I've gone to classes and the teacher says, "it's full, but if you have to graduate this year I can do it," and that's for a 200 level class and for that [students] are waiting for years.

There's a big, big college in Utah and they have three pages [of listings] just about Writing 101, but here they have half a page. There are some classes that I am trying to get into, there's like one after one--there is no way you can have one class offered for everybody. It's gotten lots worse with the economics classes, and there are a lot less sections of everything.

Things are actually getting worse with some of the general classes and the entry-level classes in a lot of departments, for example, Biology 101, because of the funding. They had to cut some faculty, which means they had to condense Biology 
101. They just had three sections of it, and they condensed that into just one section, and it is now being held in Lincoln Hall 175, which is nevertheless a performing arts facility. First of all it means that you can't write anything and they can't hang lights--this isn't the only class where they're doing it. I think there's a couple more introductory classes [like that now]. They're doing this because they are getting rid of the faculty and they can pack in as many people as possible at one time, during which no one will be able to ask questions, because they are going to have 150 to 200 persons in the class. It's going to be one professor that has no idea what is going on with the class, does not know who is in his class. Probably one TA (Teaching Assistant) that is probably just confused, and that is not a good sign.

Is there any way the university can do to alleviate

this problem of funding? students have some suggestions.

Well, I want to be able to recognize the problem. I mean, [classes must] run in a certain time. I have a class that I have to take to graduate, and I have to take prerequisites for it. So now they have to double up my final term here with prerequisites for the class. It was only offered one time, and this term I could not take it and another class.

Not all students are having problems with getting into

class.

I've never had any problem getting another class, because even if you don't get in it, you can go for the first two times at least, if you hang tough, three times. I can't remember the last time that I've been turned away from class, because there are so many people who give up or drop out, or the people [who decide] by the second class that this is not a class for them.

I've never had a problem getting into class. There has only been one class that I have not gotten into during that first trial period. And with the business school too: up until this term I wasn't in the School of Business. I couldn't pre-register and I still got in. There is only 
one class that I have not be able to get into, and I could have been "wait-listed" on that.

\section{Student Support: Services}

When it came to the all-important student services and Financial Aid offices. students had a lot to say about bureaucratic red tape and unwillingness to give information.

The financial aid office [workers] are probably the people who hurt me the most. They must be bureaucratic people, and they are unwilling to give information to students. For example, I wanted to know how much my award would be affected if I reduced my credit hours. I must stand there at the window maneuvering around to get the answer that I wanted, and I was about to give up and say, "well, this is all that they are going to give me." I wouldn't have gotten the answer that really is important to me, and that would mean some drastic changes to my financial aid. The other thing is the attendance form we have to fill out for financial aid.

\section{Summary of Finding on the Focus Group} Interview: International students

Like the American students' focus group, the interview for international students went smoothly. Each participant seemed to be enthusiastic as well. The interview started at 7:15 p.m. and ended at 8:25 p.m. The meeting was held in a classroom in the school of Education building. The table was placed in the middle of the room, and was properly sized for the six participants and the moderator. Two microphones were placed carefully to catch each speaker's words. Only six male participants showed up, although every effort was made to include six female international 
students. The moderator explained the purpose of the focus group meeting. He encouraged each participant to take an active part in the proceedings and to express his or her feelings, attitudes, perceptions and other thoughts as honestly as possible. He assured each participant that their comments would be held in strict confidence as they signed the letter of consent of participation. Participants were comprised of students majoring in engineering, business, computer science, and liberal arts.

The moderator started by asking the participants to introduce themselves individually. Students expressed their concerns. Some students were worried about their ability to finish their degree in a timely fashion at pSU. cutbacks in class offerings can mean drastic setbacks to international students, who sometimes are given only so much time to be in this country on a student visa, and may have to leave if government or family resources cannot support an extra quarter or year.

I am not satisfied at PSU. It is very difficult because the classes are getting fewer and fewer and some of the requirements for my degree have closed or canceled. I can't finish it. I only took 101. I can't take the 102 or 103 classes, which are a requirement to graduate.

Most international students decide to put out the extra effort to finish their studies here, however, despite the setbacks. Their reasons include financial, educational and cultural concerns. To do so can mean running a frustrating 
gauntlet of bureaucracy, with the added difficulty of

language and cultural barriers.

I need to (finish my study at PSU) because I have already started. If I transfer to another school, maybe some of my credit hours will be gone.

To get a job in Japan, I have to graduate before I am 25 years old. I am 23, so I have 2 more years. Also, [parents] know that [students] are having fun. So if you spend too much time in college, whether you really had too much fun or not, it depends on your parents: [if they feel you are] sucking up their money without working, and then spend too much time for the fun, it means that these guys have been wasting their time.

I just want to graduate fast. If I stay in the University two more years, maybe next year the tuition will be $\$ 1300$ per term [Note: that was a 1994 prediction. In actuality, 1994 tuition was set at close to $\$ 2,000$ per term for international students]. I cannot supply it, and we have to pay a minimum of $\$ 100$ for Applied Engineering courses.

I am a senior and a transfer student from Indiana University. I transferred last fall so I will be here for one more year. I regret coming here, When I decided to transfer, I looked at the PSU application form. It sounded like a nice idea, so I came here. When I arrived, I was upset at the inefficiency of the [admission] office. It took four to five months before I found out that I was accepted. I came here three times to check on my admission. I went to the admission office a lot of times because I was doing a transfer credit evaluation. It took more than one year. I went there, they said "come back after a month." I went back after a month, they said "we lost your file, you must go to..." There are no certain rules that we can follow. I think it all depends on who you talk to and what you say. If you speak loud, or are impolite, then they will work faster. That's my experience. 
Instruction

Here are some of what the international students have

to say about instructional quality.

It depends. The evaluation forms that they have for professors are not working. Why? I had a couple of classes where the teachers were so bad, incredibly bad. Everybody turned in their forms. When you turn it in, nothing happens to this guy. He will stay for the next couple of years. What's the use of the evaluation then?

The evaluation forms are distributed and collected at the end of the class. I don't hear any results from those.

There's got to be a way to see how the evaluations are working. The students should be able to see how each professor is going to be evaluated by the other students. The professor should be aware about that.

Suggestions were offered to alleviate the problem of evaluation.

We have a school newspaper. We could put down the five best professors of this department or something. There should be a competition so the students can see it.

The Biology Dept., they are only working for their own stuff. They don't give a damn about their lectures. They come to lecture late just because they are lacking research. They won't prepare for your class. You pay the same tuition even if you have a bad professor.

Everybody complains all the time, but nothing happens. It is all habit. There are professors who have been teaching for a long time, the reason is that they did research. They published books, therefore they have power and have control of the department, they won't be kicked out. They could say that this person has a very good reputation. students can choose the classes by if a professor is known to the students to be good, the other students will choose this guy. 
If I were a professor, instead of buying a new book for students, I would compare the new edition and the old one, just add the new addition, instead of changing to a whole new book. It is so expensive. You spend $\$ 200+$. If you change professors for the same class, you will have to buy another book. Nobody will buy your old book which you used only once. Why is it that the PSU bookstore doesn't want to sell books three days before school starts? There are the three days that they are buying back the books. By the time they buy them back and re-shelve them in the bookstore and make them available, it is already the third day of school and some professors already want you to start reading. I assume that PSU is cooperating with the PSU bookstore. If that's the case, then they should be able to buy these books back all summer. Why can't they do that?

Participants were asked about the attitude of

instructors towards international students.

I don't feel much discrimination. I like the social sciences classes.

Sciences classes had narrow-minded professors. They don't care if you had surgery, personal problems.

I know one professor has racial discrimination. He gave one student 0 points because, he said, "Your grammar is incorrect." [This was computer science], not a grammar class. I talked to this instructor several times and I can tell.

\section{Students Support Services}

Lack of adequate support services can be a very

difficult problem for international students, who are

unlikely to know about other local resources for research or computer work.

I am not satisfied with the academic computer science program. There are [only] two microcomputer labs. They hire less experienced people for assistants. 
The lab is too small for the number of students and the system breaks down too often--at least six times this summer they shut down the place.

The place is too small too. The number of computers we have is really small and most of the classes require that we type on computers.

\begin{abstract}
First I was so polite, "OK, OK--whatever you say - . " Later, I spoke louder. I am also not satisfied with the library resources. With my major, I really couldn't find new books, new information. Most of the books are old. I really had a hard time finding the right information. I don't like my department because I don't think they provide the newest technology. They emphasize the old system, voice information, while now windows is so popular and if you look you couldn't find the cost. The network I think is very important in the future. I don't think they provide [what we need]. It seems to me I couldn't learn what I want. What I am trying to do is save my money.
\end{abstract}

International students rankle at the extra costs they incur at PSU, as well as the higher tuition they must pay, regardless of actual resources. Many feel that these high costs do not bring them as many benefits as they expect, especially when compared to college fees in Europe or Canada.

American students here are also facing these problems somewhat. For example, if [an international student] pays $\$ 100$ extra for each credit as an engineering student, then an American student pays $\$ 30$.

In the textbooks at the end of the chapter, they say "read more materials." They don't have them at PSU. You go to Powell's Bookstore or a technical library, you'll find them there. These books are available and they mention it in the library, but you don't find them there. So they are charging us, and a lot of things we need [aren't available.] 
Concerning ischool, it's [German] law that they will [not] charge you extra: everybody pays the same tuition. For example, when I was there in 1985, I paid|16 marks for a semester, which was 17 weeks longer/than here, and that will cover your health insurance also. The 16 marks you pay actually is for services, paper. Sixteen marks is $\$ 45$ [today's rate]. That gives you a lot. Since I started at PSU I've worked as a student. When you work [in Germany] there is no tax taken out of your paycheck, but here they take out tax.

To me the cafeteria is a money-making business [at PSU], but in Germany when you go to the cafeteria you go by this food cart every time you get food, and there is another window over there where you can get extra, but that extra is free. There is a standard-size meal for one person, but if one person eats more than another, he doesn't have to spend more money, just go that other window and get extra food. That is what I call student service. They care. They know students have limited/resources. They know that the school years are miserable and a hard life and if you don't get a job, it is the same way. This is not an easy way to live. That's how their system works. I wish it was like that here. Probably the best we can do is hope that this sales tax passes, but unfortunately people are ignorant about this outside. They don't know that this sales tax doesn't include your food. If you don't buy a luxurious car, furniture, brand new, you don't have to pay sales tax. Me, if I buy milk and bread ancl some food, I don't have to pay sales tax, I hope i.t passes.

\section{Academic Support Services}

Students responded to questions about the library, tutoring and other: student services, and talked about their strategies for getting the most out the school.

I wish the library was open 24 hours. I work until 2:30 AM and I need a place to study.

I don't have any. You can read a book with someone. We have books in the library to read. 
Get together, elect six people, have some authority. If I go by myself to some office and they don't buy what I was saying, then they can come back and talk to you and that's my problem and nobody is taking care of it. Because the staff thinks that international students are not very daring persons, [they are] not going to talk to the president, not going to write something in the paper, school of outside, and other publications. They treat you like this, but if we have an organization, we are going to fight against American students. That gives ourselves some kind of strength.

People aren't very supportive [of the current: international student organization]. We have to make an election. Here they do it for American students. We have one for school for American and non-American students. I don't see international students come and do elections.

There is a program. I've been running this office. The student government in this campus is an "inside job" actually. You know what's going on, you have a huge project and you know your brother, sister, etc.-you have connections, on a friendly basis. They just put it in the paper instead of doing an election. Actualiy, the people voting for you are your friends. That's what's going on at PSU:

There is not much participation. Fifteen days before it starts, "OK, / this day we are going ta get together. These are previous members, new people who are volunteers, or who are being nominated." We talk about this. If it is published in the Vanquard, people will come.

We need more participation from our staff. There is a big percentage of international students at PSU.

Has the office of International students, which was originally instituted to address many of these concerns, been a factor in helping international students with their problems? The answers to this question were mixed, as / were 
feelings about the relevance of student government in general.

Since I came here, I haven't been there.

Traditionally, we have problems with this office. We have a lot of international students on this campus, [but] we have only two permanent staff in this office, so they are pretty busy. All the papers, stupid papers, they have to deal with for students, and also graduate and doctorate programs, exchange studies and all this stuff, everything that has to do with visa status, they come to this office. There are only two people working, they don't get paid too well, and they're frustrated. If students go up there for help, they don't move that fast. It's a tense situation. One time the Pakistani students felt discriminated against, so they signed papers and sent them to the President of the University, saying they would like to see something happen in this [ISS] office.

The problem was they don't give you the same services as the other students get. A student went to get a piece of paper signed so that he could go home, they gave him a 30-minute lecture about his class record, "you didn't do well in this class..." But all I want is your signature right here, that's your job, and then I can go home for the summer vacation, that's all I need, but they . . . they can keep you as long as they want, if they are in a bad mood. That's been happening. This [staff member], I personally like him, but he could be worse to some. Because most students believe that he has authority to kick you out from school. Students feel that they have all the records, they hold your visa status, etc., in their office, that they might be able to kick you out from the school, which is not correct. If they do that, that's illegal. Especially, Asian students think that way.

That's what happened to one of my friends. He has a lot of problems. He is taking advantage sometimes. They don't know him, he went there, they gave him a hard time. They told him, if he is not happy, leave.

We told this office a couple of times, "that's your job. That's your job to do this service, if 
you have difficulty giving this service to the students without making the students feel bad about coming to the office, then get out and we can hire somebody else because we are the ones paying your salary, from our tuition. We don't have to pay the tuition if we get this bad service." We argued about this.

It is more of an attitude problem [with certain workers in ISS].

It is not only because he is a bad person, it is about the school system, a highly stressful situation. Why do 800 international students pay out-of-state tuition as long as they are in the United States and are getting minimal service, compared to the American students? At least they should have 4 to 5 full-time paid officers to help us, then we could have a much better time. If one person gets sick, then go to another person who also knows what he is doing. If this person gets sick, you can go to someone else. [Mrs. Curtis] is one who knows about status and stuff, she is the only one who knows what's going on about it. She is actually the advisor of the place. She knows more about ISS stuff but she doesn't have much authority in the university. She gets sick so often, she had a heart operation, so she has to go home. What can you do about it? We don't have anybody else to take care of it. It's pathetic.

They are understaffed. If there was more staff, we could minimize their stress.

[PSU should] pay more attention to the international students. They should hire more people to deal with us. Because the international students on campus are benefits to the school, tuition-wise and cultural-wise. It is interesting when there are discussions among themselves, the professors like that.

They actually try to recruit students, because of Measure 5. You can apply at PSU once a year. You can come to PSU, full term, one year right now. If you apply for the ESL class, you can come in anytime, so one of the cheating [methods] is to apply at PSU as an ESL student, and once you come to the United States, and pass it, you can get into the regular classes. Otherwise, you have to wait for one year to get to PSU. That's another 
problem that the PSU has--the paperwork is too slow.

The student government is a different issue. It is still through the Greek system. More minority groups have joined. This year for some reason the election didn't go too well and most of the people chosen for the student government are through the Greek system, they've never been involved in student activities before so they don't know what's going on. Nothing has happened so far.

The student government is getting worse right now.

How do they deal with those in the front offices, like the Admissions' office, when international students have contact with people in the various student services and academic departments? Some staffers got positive marks for helpfulness, others did not.

[Some are] pretty good, but you must be pushy to get help. [Like saying,] "Get your supervisor right now, otherwise I will write a letter to the president's office because I don't like your service." I don't think we should have to go this far to get help.

Registrars, OK. Cashiers, OK.

[This year the] staff has been cut and financial aid cut, but not much. There are the same number of students.

They cut the most important people. They kept the ones who have the big title but don't do anything. That's the major problem of the school. Doing nothing. [For example, one individual was] just dealing with student government and he was getting so much money, $\$ 60,000$ a year? I think this person still works the exactly the same as the person who is getting [one-third his salary].

In the audio-visual department, I don't know why the head of the department is even there. I don't exactly know what he is doing, everything in audio visual is done by Larry sawyer. If I will get day off or work more hours, overtime, I talk to $\mathrm{Mr}$. 
Sawyer. What does [the head of the department] do? He never talks to people. Unless he is doing some technical things over there, doing the design part, assembly part, nothing like that. He has a computer over there. He leaves at 3:30. He comes in at 90 . clock.

He probably gets paid two times what Larry makes. Probably 100 times of what I make. I think it wouldn't make any difference [if he wasn't there].

Several students had specific comments, impressions or suggestions regarding the student services offices and procedures. About admissions, for instance.

International students have to fill out I-20 forms before they can start. When I was in Japan I tried to call the Admissions office. It takes only three minutes to type and sign your name.

First you have to go to Admissions, check all your records, your financial status. Actually, it doesn't take that long, they just look at it, and if it is satisfactory they send [the $I-20$ form] to the Iss office, type it out, sign it, then send it to your place. Once it gets to the Iss office, it is pretty fast. The place where it takes a long time is Admissions. I guess it takes a couple of months to open it. May be cutting the paper like this way . . I don't know, I think it is too long but that's what's going on.

It is probably important to look at that one too. An interview with one of the staff members about how really long it takes for the Admissions office to process forms and then from the ISS how long it takes.

They just cut the person who has been dealing with international status, and that's why they accept only once a year. It takes a special task to look at the following transcripts from the old high school. In Germany, they go to high school for four years, so therefore they can transfer one year's credit [as entry-level college credit]. Most Asian schools are exactly the same. The Eastern European system is a little different. So they have to look at them carefully, whether they can trust them or not. They ask for your GPA, recommendation letters, how much money you have in 
a bank. If they are really calling back to the country or sending letters back to the school for signatures and waiting for references, I would say it takes a long time, but I don't think they have done that. If they just look at the paper, if they think they are believable, I think they just issue the stuff. I don't know why we have to wait half a year to get the I-20 form.

It took me quite a while, a year probably from the time I started. I have a connection here, my host family, she always follows my $I-20$ here because I cannot make a long distance call all the time and it costs a lot of money. I wrote letters to my host family and she followed it up here.

on-campus work experience is of great importance to international students, as most are not legally allowed to hold off-campus jobs. Several students complained that the jobs that might provide career-felated experience rarely go to international students.

The university hires work-study students because they cost less for the school. They don't hire international students although they have skills, especially computer science and engineering.

I don't know, for some reason most international students are in computer engineering, still they don't get a job.

In the food service department it is very noticeable that there are a lot of international students working.

Yeah. Like in audiovisual, there is only one American student and all others are international students. Americans don't need money, they pay less tuition, parents are here, they have funds, trusts, have providers, like families, friends, other resources.

I think one other reasons is, there are not many American students who applied in this position, that's why most of them are international students. Another observation of mine: international students work harder. In the chemistry department, I scraped the lab things. 
[My American co-workers] don't really work hard, they just talk, they just think of how they can cheat, they just come late and then leave, and they put down the same amount of time. I didn't want to say anything but I think they are obligated to do their job as much as they can and do the best they can. Actually, [this makes some campus employers] like to hire the international students, although sometimes we have difficulty in communication.

\section{Suggestions were offered.}

You have all the rights, you can complain to the President, you can complain to the student services or to the department heads, but as I said, the more organized you are, the more you are stronger. Hopefully, with this study, [PSU] will be able to look at it and see what the students are saying. So it is up to them. [This study] is for their benefit. They should have at least have support in/some ways and normally, when there is a study going, they are supplemented with fellowships, just to study a particular thing. So, in the long run they are saving money for this study. This study should list the "most unsatisfied" items and the "most satisfied" ones so the administration can look at it and do something about it.

Comments about other services included talking about

the difficulties international students experience in

finding housing in a new country where they may not know anyone.

About housing: when you apply for school, you should be guaranteed a place to stay for at least two months.

I applied for housing. I didn't have a place to stay the first couple of days so I had to find a host family, and then they let me stay for the first couple of months while I am looking for an apartment. They need proof that you are a student. They put your name on the computer waiting list. The PSS [?] should be mentioned by PSU as a help for housing service. 
If you wish to have a place on campus, if you say "yes," you can mail it back with all the applications. [Unfortunately,] they sent me my I20 , but not the form for a place to stay.

I thanked the international students as well as the American students for their active participation and honest opinions. I told them that I hope that this study will be able to help students by letting the administration know about their frustrations while attending Portland state University, providing them with the information they need to improve the university's services.

\section{Conclusion}

Although the interviewees did not address all the issues from the questionnaire, the focus group interviews generated remarks from American and international students at PSU that tend to corroborate the concerns within, and the agreements and disparities between, their respective groups from the survey. Therefore, the comments in the interviewees' own words help enrich a portrait of student thoughts and feelings in relation to the university, lending it credibility. In effect, the interviews complement the survey results by more directly suggesting that was in a representative sample of students' "own minds" rather|than, simply, how students reacted to what was in this researcher's mind. The generally high degree of relationships between the survey and interview results, then, place the university on firmer ground from which they 
can, if they so desire, ponder and (in whatever ways they deem appropriate) act upon these results.

The insightful comments of the international focusgroup participants reveal a great deal about their experience at PSU and, I believe, indicate many areas in which even minor changes would improve the university's standing in their eyes. The idea that their suggestions and complaints would be heard by the administration seemed to have a positive effect for these students. Most of their comments conveyed the simple idea that if administrators understood the problems and challenges they face during their stay in the U.S., they would be able to tailor service-delivery systems that more closely meet their needs. 
CHAPTER VI

DISCUSSIONS, CONCLUSIONS AND

RECOMMENDATIONS

This chapter discusses and analyzes the survey results and the focus group interview data and interprets these results with reference to related literature. The discussion is organized to focus on the research questions. The conclusion offers some recommendations based on the findings of the study, which are targeted to assist administrators and personnel of the institution.

\section{Responses to Open-Ended Survey Questions Compared with Survey Results}

Comments made by survey participants in response to the open-ended questions generally support the survey questionnaire results. Four representative areas, of special concern to international students, may be used to demonstrate this: "Fairness of Faculty Treatment of Students," "Tutoring/Basic Skills Services," "Admissions Office," and "Campus Housing." The first of these examples relates to "Instructional Quality," the second, to "Academic Support," and the third and fourth to "Student Services." This study, in its survey phase, has found international 
students expressing a substantial degree of dissatisfaction in each of these four areas.

"Faculty fairness" is important to international students, who may feel that the disadvantage of studying in a second language in a foreign country is compounded if instructors are insensitive to this situation or are even biased against them on racial, ethnic or related grounds. It may even be true that for some international students being treated "fairly" is code for their desire to be treated "unequally"--that is, with greater tact and, academically, with greater leniency than American students. Regardless, international students perceive this issue as real and pressing.

Indeed, both the survey questionnaire and the open ended question results bear this out. In the survey, international as well as American students overwhelmingly ranked as important--that is to say, "somewhat important" or "very important"--faculty fairness. (The difference between the American and international students is negligible: 928 and 948 , respectively.) However, the American participants were far more convinced of being treated fairly than were their international counterparts. Whereas the satisfaction score for the American students--indicating their being either "somewhat satisfied" or "very satisfied"--was $87 \%$, for the international students it was $72 \%$; in turn, this meant a gap or "difference" of 22 percentage points between 
the importance and satisfaction scores for international students--more than four times that (5 percentage points) for American students. Similarly, the open-ended question part of the questionnaire generated from international students five comments about the need for greater faculty fairness, but only one such comment from American students. "Some instructors are not fair," is a typically unambiguous comment in this regard from an international student. International students see "tutoring/basic skills services" as a means to narrowing the academic gap between themselves and their American counterparts, who enjoy the "home court advantage" of learning and studying in their own language in their own country. Not surprisingly, therefore, such services draw in the survey questionnaire as a much higher importance score (918) from international students than from American students (63\%). Indeed, the gap is wider yet; for American students the satisfaction score is 14 percentage points higher than the importance score, while for international students the satisfaction score is 20 percentage points lower than the importance score--a difference of 34 percentage points. Correspondingly, the open-ended questions drew three responses from international students that these services should be improved or enhanced, but no such comment from American students. "Tutoring services should be offered more for international students," remarked one of the international students. 
The perceived inefficiency and lack of organization of the Admissions office seemed to compound and frustrate international students even more than they do American students. The importance score of "Admission Office" is high for both groups of participants: 83\%, for American students; but a whopping 998 for international students. Although for both groups of students the satisfaction scores fall below the importance scores, the American students' 8 percentage-point difference pales beside the international students' 51 percentage-point average. Again, the openended question responses support the survey questionnaire results. International students made four comments suggesting the Admissions office be improved, while only one American student made such a comment.

It is not surprising, surely, that at a largely community-based urban university "Campus Housing" should be a more pressing issue for international visitors than for the local students in attendance. The questionnaire results reflect this: for international and American students, the importance scores are 898 and $41 \%$, respectively--a huge difference. This gap widens further into a 53 percentage point gap in the difference scores of both groups of students, even though their satisfaction scores--64\% and 698--are not so far apart. 


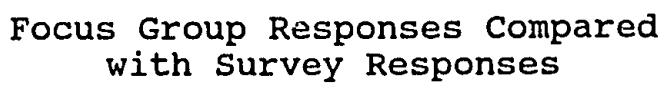

The focus group interviews generated responses which support the responses from both aspects--questionnaire and open-ended questions--of the survey. The four areas of concern just examined again demonstrate this. In the case of faculty fairness, only one American student mentioned the issue--and only to say how "fair" PSU professors are. One of the international participants, however, cites "racial discrimination" in one professor; another participant refers to "narrow-minded" science professors. similarly, no American interviewee expressed any need for better tutoring services at PSU, but two international interviewees did. While the American interviewees saved all their ire for the Financial Aid office, the international interviewees found tremendous need for improvement in the Admissions office as well. Finally the issue of Campus Housing proved an exception: neither the American nor the international focus group participants mentioned it. In general, however, the survey questionnaire responses, the survey open-ended question responses, and the focus group interview responses al1 reflected one another. 
Discussion

The following discussion is focused on the five research questions, and based on the results of the questionnaire and the focus group interviews.

Question 1: What is the demographic profile of students at Portland State University?

The student-body samples used reflect in all but one respect the general characteristics of the total population of the university, this one deviation being that business administration, not liberal arts, was the most popular major of the participating students. Otherwise, the student-body samples coincided with the university profile: female students were in the majority and the average age of the students in the sample was 25 years old for Americans and 24 years old for international respondents. This last characteristic is due to PSU being a commuter institution, where the majority of the students are working for a living at the same time as trying to finish a degree, getting a second degree, or returning to postsecondary education after a long absence from school.

As expected, the majority of the American students are self-supporting for their college education, whereas international students rely mostly on money sent by their families from their home countries. In this way, international students more closely resemble the "traditional" college student of years gone by: they 
generally cannot work off-campus, and they are more likely to use the university's food and housing services. They are also less likely to use services aimed at non-traditional students, such as child care or special re-entry programs for returning students, displaced workers and the like.

The understanding level for written English is not a problem for most international students. However, financial burden is still the major concern, just as it is for American students. There is one important difference: more than half of the international students are not working at all; while the majority of Americans work more than 20 hours a week.

Location is the most important factor in why American respondents chose Portland State University; for international students, however, it is because they knew someone at the university, which is the same way they learned about Portland State University.

Question 2: What is the importance of the various [need] service quality statements to international students at Portland State University? What is the current level of satisfaction of international students in regard to these [need] service quality statements?

In every category of needs identified and examined via the questionnaire and focus groups, some needs were not satisfied to a degree that met the level of students' expectations. Nevertheless, students reported some degree 
of satisfaction regarding most needs. With respect to academic support, for instance, at least $50 \%$ of the participating international students described themselves as being at least "somewhat satisfied" in 1 of the 12 items, and in two of the remaining three--pre-college advising from high school and pre-transfer advising from previous college --the percentage of "no responses" were unusually high (52\% and $44 \%$, respectively), a reflection of the fact that these items did not impinge on them as visitors from other countries.

Among the categories of needs listed under Instruction: instructional quality, intellectual stimulation from faculty, fairness of testing and grading, fairness of faculty treatment of students, accessibility of faculty and contents of courses were best met, with more than $50 \%$ of respondents declaring that they were "somewhat satisfied" with the university's offerirgs in these areas. Students said their needs regarding class size were the least-met, with 418 responding "somewhat satisfied."

Under Academic Support, library service needs were best met, with the largest of the respondents (41\%) very satisfied," and another $35 q$ "somewhat satisfied," for a combined score of $76 \%$-all those at least "somewhat satisfied." Library service needs were followed by library collection, with 388 "very satisfied," and a total of $68 \%$ who were at least "somewhat satisfied." More than half of 
the respondents (65\%) were at least "somewhat satisfied" with PSU laboratory facilities, although less than one-third of this (18\%) described themselves as "very satisfied." Close behind, $60 \%$ were at least "somewhat satisfied" with the tutoring/basic skills services PSU makes available-although, again, a relatively small number (16\%) were "very satisfied." At least half the students also were at least "somewhat satisfied" regarding the course catalog (718), computer facilities ( $58 \%$ ), variety of courses offered (51\%), convenience of class scheduling (51\%), and academic advising on campus $(50 \%)$.

Under the needs category of student Services, students declared themselves "somewhat satisfied" with student organizations (50\%), recreation programs/activities (47\%), campus orientation programs $(44 \%)$, student health services (398), social and cultural activities (38\%), Registrar's office (37\%), career guidance from faculty (36\%), campus housing (36\%), job services (348), intercollegiate athletic programs (33\%), psychological counseling (33\%), special student services (32\%), Admissions office (31\%), and career guidance from Career Planning office (30\%). Least satisfied categories under were "somewhat satisfied" include: financial aid office (28\%), religious services (28\%), campus food services (25\%), child care (248), and parking (23\%). Even though most needs were satisfied to a certain extent rather than entirely unsatisfied, it is clear that 
this partial satisfaction did not meet the level of students' expectations, as shown by the comments elicited in the focus group interviews.

Question 3. What is the importance of the various [need] service quality statements to U.S. students at Portland State University? What is the current level of satisfaction of U.S. students in regard to these [need] service quality statements?

This study, as well as other studies undertaken at different campuses (particularly Daigle's 1981, 1989 California state University system survey), has shown that the level of student satisfaction depends on several variables. At PSU, U.S. students said the most important variables in their educational experience are instructional quality, fairness of testing and grading, fairness of faculty treatment of istudents, course content, intellectual stimulation, and faculty accessibility. At most, only $60 \%$ of U.S. students said they were somewhat satisfied with how well the university's offerings in these "most important" service areas met their expectations of quality. They expressed lesser degrees of satisfaction with many items judged to be of high importance--and in no case did the majority express a high degree of satisfaction.

In the Academic Support category, availability of required courses, variety of courses offered, convenient class scheduling, on-campus academic advising, 
catalog/schedule of classes, library collections, library services, computer facilities, lab facilities, pre-college advising from high school, pre-transfer advising from previous college and tutoring/basic skills services were called most important. Less than half of the respondents said they were "very satisfied" with any of these services, although over half expressed some degree of satisfaction. Notably, more than a quarter of U.S. students said their need for academic advising services was very unsatisfied and also more than a quarter said somewhat unsatisfied.

In Student Services, the registrar's office, student health services, career guidance from faculty, parking, financial aid office, job search services and career guidance from career planning office were judged most important. U.S. students expressed a surprisingly low degree of satisfaction with student services, with fewer than half saying they were even "somewhat satisfied" with the services listed, and many expressing a great deal of dissatisfaction.

Question 4. Do U.S. and international students at Portland State University differ in the importance they assign to the [need] service quality statements? Do U.S. and international students differ in their level of satisfaction with the [need] service quality at portland state University? 
International students judged instructional quality, fairness of faculty treatment of students, fairness of testing and grading, course content, intellectual stimulation and faculty accessibility to be the most important instructional service offerings at PSU. As this list shows, these choices are identical to those of the US. students, although the percentage of students judging each item to be "most important" differed by up to $10 \%$. These differences, while not huge, may be significant enough to necessitate some differentiation in how service offerings are structured and presented to these two groups of students by policy makers.

In general, it is clear that all PSU students share a high degree of concern about the quality for the classroom educational experience at this university, and that they measure that quality in very similar ways. [In the academic support category, availability of required courses, variety of courses offered, convenient class scheduling, on-campus academic advising, catalog/schedule of classes, library collections, library services, computer facilities, lab facilities, pre-college advising from high school, pretransfer advising from previous college and tutoring/basic skills services were called most important. Less than half of the respondents said they were "very satisfied" with any of these services, although over half expressed some degree of satisfaction. Notably, a quarter of US. students said 
their need for academic advising services was somewhat unsatisfied.]

In the Academic Support category, availability of required courses, convenient class scheduling, computer facilities, variety of courses offered, library collections, library service, on-campus academic advising services, lab facilities, catalog/schedule of classes, tutoring/basic skills services and pre-transfer advising from previous college were judged to be most important.

International students were less than totally positive about the degree to which these needs are being satisfied at PSU. Nearly half| were "very satisfied" with library services, library collections and the catalog/schedule of classes; for the other items less than half were "somewhat satisfied," with the remainder expressing varying degrees of dissatisfaction. Although U.S. and international students were not dissimilar in the importance they assigned to various services, international students found computer facilities to be significantly more important, and pretransfer counseling from high school less so.

Among Student Services, the admissions office, Registrar's office, student health services, career guidance from faculty, campus housing, job search services, career guidance from career planning office, parking, food services, social and cultural activities, financial aid office, recreation programs/activities, special students 
services and the intercollegiate athletic program were deemed "most important" by international respondents. There are some significant differences in the importance given each area between U.S. and international students: as noted earlier, the international student population in many ways more closely resembles the "traditional" student population of the 1950s and 1960s. International students are more likely to live, eat and work on campus, and to expect their social and recreational needs to be met in the context of university programs as well.

These student services also were the target of gripes from international students, with half or less declaring themselves "somewhat satisfied," and campus food services coming under particular criticism, with a quarter responding that they were "very unsatisfied." Such a strong statement by a significant portion of this population bears further examination: is it price, quality, type, amount or variety of foods offered, or scheduling of meals, that elicited such negative opinions? Food service is one area in which applying customer-satisfaction research should improve the perception of quality, particularly since it is an area in which the university directly competes with for-profit businesses.

Question 5: For each service quality statement, what is the relationship between the perceived importance and level of satisfaction for U.S. students? For each service 
statement, what is the relationship between the perceived importance and level of satisfaction for international students?

As shown in Tables 43-45, there are a number of categories in which considerable differences were found between needs given high priority by students and the level of satisfaction of those needs. Among the areas in which international students perceived a particularly low degree of satisfaction of important needs were fairness of faculty treatment of students, computer facilities, the admissions office and campus food services. Both groups of students were extremely disappointed in the areas of academic advising services on campus, with U.S. students being less satisfied; and with the availability of courses to finish their degree.

Some items indicated a positive relationship between importance and satisfaction. In many cases, however, this researcher feels this may be misleading: it appears that students were more likely to give a service they are not familiar with or do not use a positive rating. For example, international students probably are more likely to use PSU food service than are U.S. students because they tend to live on or close to campus in campus housing, while u.s. students can go home to eat or often are better able financially to eat out at area restaurants. U.S. students tend to rate food services favorably, while international 
students tended to be more dissatisfied. This "I don't know so it must be ok" effect can also be observed in relation to psychological services, child care, religious services, campus housing and several other areas. Future instruments could be designed to compensate for this assumed factor; focus group studies should also be able to determine if it is in fact in play.

significantly negative scores are also open to interpretation. For example, international students from some countries may have different expectations of professors, and when these are not met they express dissatisfaction. This type of issue can best be addressed in the focus-group interview process, with the knowledge gained perhaps applied to creating materials for international students that provide them with a different base for their expectations. If a student has never been graded on a curve, for example, such grading could be interpreted as "unfair."

Question 6: What are the perceived reasons for dissatisfaction concerning the service quality of U.S. and international students? What suggestions do these students have for improving the quality of services?

When these issues were explored in the focus groups, the students were extremely articulate in expressing coherent reasons for their discontent. Although reasons for any subjective feeling always have an element of the 
personal within them, patterns emerged that professionals can certainly learn from as they design or redesign university programs.

In the current financial climate, it is no surprise that both U.S. and international students feel a great deal of pressure over any issue that costs them money. Student fees, tuition, food and housing costs are only the easiest of these to see. The main reason that students express a high degree of dissatisfaction when they cannot get into classes required to complete their major program is that staying in school for extra semesters or years is a financial burden. For international students, this burden can mean expensive visa problems as well. Many of the needs items that received negative evaluations from students can in some way be tied to the lack of satisfaction of that need having a direct impact on the students' pocketbook.

Cultural conflicts are also present. Differing expectations about the educational experience, college life and support services can be addressed through revising programs or revising expectations, but this process will not be identical for U.S. and international students. Many international students have experienced college life in Japan, Europe, or European-style systems in the nations of Africa or Latin America, where students enjoy a higher social status, receive many special privileges and discounts on campus and in the larger community, and participate 
heavily in campus activities that can be very different from those found on an American campus. orienting students can help them understand these differences and narrow the gap between expectations and reality--and foreign universities may have found ways to enhance the university experience that American colleges can emulate. Both groups of students presented themselves as serious, academically oriented and sincere about wanting to get the best education their time and money could buy. Policy makers can use this enthusiasm to their advantage by including students in the decision-making process, either by eliciting their opinions through surveys and other research instruments, or by involving them directly through some more-formal mechanism.

From the results of this study certain themes and broader patterns can be discerned or extrapolated. These often take the form of outlining divergent portraits of the two groups of PSU students under consideration, American and international. By extension, this divergence suggests certain generalizations about one group vis-a-vis the other, at PSU or elsewhere. As with any such broad characterizations or generalizations, a researcher should retain a margin of skepticism; but they do suggest, however roughly, directions in which the data seem to be moving. one such theme is the greater intrinsic importance that international students seem to place on higher education. 
Historically, such education in the U.S. presumably helps enact the promise of equal opportunity for those born into a social or sociological disadvantage; education in general, and higher education in particular, help make the U.S. "the land of opportunity." Nevertheless, this rich historical association seems to have lost some of its potency and momentousness for American students, whose criticisms of aspects of the university experience tend to be based more often than in the case of their international counterparts on personal prerogatives rather than on the depth of their learning experience or the projected fulfillment of specific career goals. In short, international students more often seem to be "at work" in school, while American students more often seem to be "passing through." Perhaps where American students want "better" and "fairer" teachers because they want the time they spend in class to be better occupied, international students want "better" and "fairer" teachers--and express themselves with greater concern on the matter--because they feel the absence of such instructors jeopardizes their goals. Whereas American students tend to look to the moment, international students more often look to the future. They may feel their college experience is more directly connected to the "future" than do their American counterparts.

It is not surprising that American students, "at home" --relatively speaking--and in their own culture, should 
conceive of their college education more of as a cultural rite of passage than do international students, who may be more concerned with the "education" itself. For international students, then, the educational experience assumes to a greater degree the aspect of a repository of their hopes and anxieties. In the international student focus group, one Japanese student expressed worry about completing his education in time to be employable back home because past his 25 th birthday would be too late. In an extreme (and perhaps exaggerated) way, this student may have been expressing an intensity of concern about the university experience that he shares with other international students--a sense of being "under the clock." In a quite a literal way, international students must worry about the expiration of their student visas, while many American students can "string out" their higher education to their hearts' content. In an even more profound way, however, international students find their American education to be a more "pressurized" experience than do their American counterparts. Accurately or not, they feel that much more is "riding on" their successful completion of their education. Both groups of students may feel "family pressure" to succeed (and in the case of American students, "the family" is closer at hand); but international students are additionally burdened with the sense of their representing their nations, and in any case they feel 
obliged to justify their decision to leave home in order to get an American education. This sharpens the point of their need to extract as much from that experience as possible. American students are under a comparable obligation only in those relatively rare instances where great family sacrifices have been made so that they may get a college education.

It is not impossible that this "pressurized" sense shared by international students even leads them to overstate the case of their concerns about and dissatisfactions with PSU. Every shortcoming they confront may become magnified into a potential obstacle to achieving their goal of a successfully conpleted and beneficial education. Unlike their American counterparts, they are as much "under the gun" as "under the clock."

Because international students tend to be more efficiently organized than their American counterparts in their effort to achieve their more urgent and more focused goals, they may expect greater efficiency, organization and purpose from the university's instructional, support and administrative staffs. They believe themselves to be so much "at work" at school they find it particularly hard to understand why those literally "at work" there seem so unwilling to do what presumably they are supposed to do. Whereas American students may confront the same casual attitude they see (or prefer not to see) in themselves, the 
relatively "unlaid back" international students want staff members and others in authority at the University to reflect their own conscientiousness. Therefore, where American students may feel annoyed with certain kinds of inattention and unresponsiveness, international students may feel violated. They may feel they are making such a concerted effort to do their best that those working at the University, with whom they must interact, should make more of an effort to do their best.

Cultural differences also play a significant role.

"Hard work" may be a part of American sociocultural mythology, but the reality may be somewhat different, especially in the West (and even more especially, the closer one gets to California), where even bank clerks dress in jeans, and where people (as they themselves so cleverly put it) "work to live, not live to work." There is a very casual attitude toward work in Portland, oregon, that PSU inevitably reflects; and this runs counter to the high priority placed on hard work and industriousness by some (though not all) foreign cultures, particularly eastern and southeastern Asian cultures, from which a majority of PSU's international students come. Many international students see PSU staff as individuals unwilling to take the time or make the effort to do their jobs.

Furthermore, these foreign cultures often attach a mythology of their own to this "hard work" and 
"industriousness" that they so highly prize. As a result, international students may be even more inclined than American students (especially given the additional time they must commit to their studies just to cope with English) to find in their own commitment and conscientiousness an entitlement to academic success. Again, this sense of entitlement intersects with their dxamatic sense of what the absence of such success might mean for them. Americans mythologize terrific failure as part of the spectacular success stories they love; they love to see failure as spurring success. Most non-western cultures have no such comparable notion or myth. They see failure as failure, not as a bump in the road to triumph; they see it as a dead-end in itself, and associate it with irretrievably lost opportunity and a ruined life. Hence, these individuals bring to their life experiences, including their education, this sense of definitiveness. It colors everything. International students are apt to expect more from professors in the classroom setting than do their American counterparts. U.S. education gives students a far more active role than international students are used to. Whereas international students have been accustomed to the role of being relatively passive recipients of a carefilly planned presentation of material they are required to learn, American students are more familiar with the informal "class discussions" which occupy much American class time 
and in which students are encouraged to participate actively--something international students may be additionally prone to avoid because of self-consciousness over language problems. As a result, whereas American students might find worthwhile a class meeting that gives them an opportunity to "speak out," international students may see such situation as an evasion of pedagogical responsibility on the professor's part. "Learning" seems to mean something different to Americans, who bring even to the educational setting their fervor for individualistic expression. International students may be frustrated by what appear to them to be "teachers not teaching" but turning over their responsibilities to the students. International students, then, may feel more reliant on teachers for their education; and when teachers lead class discussions, these students may feel more frustrated and dissatisfied than their American counterparts, who are more familiar with these often unfocused and often tangential exchanges. Add to this one more thing: professors almost invariably speak better, clearer and more grammatical English than do their American students, whose contributions to class discussions, as a result, more burdensomely tax an international student's comprehension of what is being said.

In conclusion, inside the classroom and out, international students are more apt than their American counterparts to feel "on the edge," resulting in a more 
problematic reception of the whole educational experience at PSU.

\section{Conclusions and Recommendations}

This study was intended primarily for a policy-making audience; and accordingly, the questions it raises and the conclusions drawn have significant policy implications. It also provides important comparisons to other surveys. The basic question addressed is whether PSU's institutional policies and practices are in line with students' needs and expectations. It is clear that in many areas they are not, while in others room for improvement remains.

The general findings of this study provide information that will be useful to those who wish to link institutional policies more closely with student goals, interests and needs, thus increasing congruencies between the administration and students' needs in general.

The second set of questions, which address more specifically the needs and satisfaction of students, helps to assess the administrative performance of the institution. For instance, is the institution doing a good job in meeting the ever-changing needs of international and American students? An ongoing assessment process can heip administrators to address the all-important issues of 
recruitment and retention, which hinge squarely on the level of student satisfaction.

It is evident from the survey results and comments collected in the focus-group interview process that both U.S. and international students have strong opinions about the quality of their educational experience at PSU and wish to make these opinions known. If this desire to address the issues that affect their on-campus lives can be harnessed, students themselves could be a powerful force in the ongoing attempt to reinvent higher education. The changing student demographics of the 1980 s and 1990s, coupled with financial pressures, have put many educational institutions in the uncomfortable position of trying to balance between traditional services and offerings, continuing their commitment to faculty research programs and new alliances with the business community, and restructuring themselves to meet the needs of the new majority that is often still called the "non-traditional" student. An ongoing process of assessment, suggestion and experimentation could help make this period of transition easier to navigate. Because of the disparity between needs and their satisfaction that the instruments used in this research uncovered among both U.S. and international students, administrators would be wise to look at these categories of students separately as well as at the student body as a whole. There may be other categories of students that 
should be broken out for needs-assessment purposes (student parents, married students, part-time students, undergraduate and graduate scudents, etc.) in order to more closely tailor programs to meet their needs. Within larger institutions, disparities may be found--and addressed--at the departmental level. As institutions increasingly rely on international as well as part-time U.S. students, for revenue, addressing the different needs of these groups will become ever more essential.

As the results gained from the focus group sessions show, the methodologies used by business to improve customer satisfaction may hold great potential for academic institutions that wish to improve student satisfaction. There are essentially two reasons why universities need to pursue a business model of customer satisfaction. One, is that such a model assists students in developing the business mentality or mindset that will in fact best serve the vast majority of them, who will be looking to the business world for employment in the business world. Those who are satisfied students today, for example, will take from that experience a better appreciation of what it means to satisfy customers and clients. In effect, their experience as customers of higher education will better sensitize them toward their own business customers later on. Moreover, businesses, knowing that schools are inculcating students with just this sensitivity, will place greater 
confidence in those schools and, as a result, will

themselves better support those schools. The other reason why universities need to pursue a model of customer satisfaction is an extension of this. Once students know that this is the deliberate aim of a university, to the degree that those students will desire to find employment in the business community they will also select just such a university to educate them and thus best make them "employment ready." Therefore, it will accrue to the benefit of a given school, in increased enrollments and increased funds eithex privately or legislatively accorded it, that it develops a reputation as being "business friendly"-tas being but a step in the process by which students become better, and more attractively, employable. Surely, this will be no easy pill for a university to swallow. Such a perspective must do battle with encrusted notions of ivory-tower elitism and intellectualism. Nevertheless, the salvation of higher education in America resides in just such a pragmatic approach--as indeed the salvation of everything American is equally pragmatically determined.

This researcher recommends continuing to explore and use tools developed by business to make delivery systems more flexible and effect the needed change. Students may be even more motivated than mere "consumers" to be part of this process and more than willing to assume the central position 
in the re-creation of educational institutions that they should occupy. 


\section{REFERENCES}

Altscher, D. C. (1976, April 11-14). A rationale for a counseling program designed uniquely for international students. Paper presented at the Annual Convention of the American Personnel and Guidance Association, Chicago, IL.

AMIDEAST. (1983). Orientation handbook: An Introduction to living and studying in the United states. Washington, DC: American-Mideast Educational and Training Services.

Arubayi, E. (1979). Identification of problems experienced by Nigerian students enrolled in Kansas state University (Doctoral dissertation, Kansas State University, 1979). Dissertation Abstracts International, 41, 0118A.

Astin, A. W. (1982, spring). Why not try some new ways of measuring quality? Educational Record, 63(2), 10-15.

Barker, R. (1968). Ecological psychology: Concepts for studying the environment of human behavior. Stanford, $\mathrm{CA}$ : Stanford University Press.

Barker, R. (1978). Habitats, environments, and human behavior: studies in ecological psychology and ecobehavioral science. San Francisco: Jossey-Bass.

Barrow, J. (1989, January). Student needs assessment surveys: Do they predict student use of services? Journal of College Student Development, 30(1), 77-82.

Advisory Council for International Educational Exchange. (1988). Educating for global competence. New York: Author. (ERIC Document Production Service No. ED 305 833)

Bassis, M., \& Guskin, A. (1986, July/August). Building quality: Research and regional institutions. Change, pp. 57-66.

Bellenger, D., Bernhardt, K., \& Goldstucker, J. (1989). Qualitative research in marketing. In $T$. Hayes \& $C$. Tatham (Eds.), Focus group interview: A reader (pp. 10-25). Chicago, IL: American Marketing Association. 
Berdie, R. F., Pilapil, B., \& Im, I. S. (1968). Graduating seniors' satisfaction with the university. Minneapolis: University of Minnesota, Bureau of Institutional Research.

Berk, R. (Ed.). (1981). Educational evaluation methodology: The state of the art. Baltimore: John Hopkins University.

Betz, E. L., Klingensmith, J. E., \& Menne, J. W. (1970). The measurement and analysis of college student satisfaction. Measurement and Evaluation in Guidance, $\underline{3}(2), 110-118$.

Bickman, L. (1987). The functions of program theory. In L. Bickman (Ed.), Using program theory in evaluation: New directions for program theory (pp. 5-17). San Francisco: Jossey-Bass.

Borich, G. (1985). Evaluating educational programs and products. Englewood Cliffs, NJ: Educational Technology Publication.

Bowen, E. (1989, January). Wanted: Fresh, homegrown talent; foreigners are swamping graduate science schools. Time, 131(1), 55 .

Boyer, S., \& Sedlacek, W. (1986). Attitudes and perceptions of incoming foreign students: A research report. College Park: Maryland University, College Park Counseling Center.

Brogowicz, A., Delene, L., \& Lyth, L. (1990). A synthesized service quality model with managerial implications. International Journal of Service Industry Management, $1(1), 27-45$.

Cannon, G. (1959). Foreign students in the United States. American Association of University Professors, $\underline{45}$, 539-542.

Canter, J. (1967). Our common challenge in international education. Junior College Journal, 37, 14-16.

Carnegie Foundation for the Advancement of Teaching. (1978). Mission of the college curriculum: $A$ contemporary review with suggestions. San Francisco: Jossey-Bass.

Chinapah, V., \& Miron, G. (1990). Evaluating educational programmes and projects: Holistic and practical considerations. Ducolot, Gembloux (Belgium): UNESCO. 
Conrad, K., \& Miller, T. (1987). Measuring and testing program philosophy. In L. Bickman (Ed.), Using program theory in evaluation: New directions for program theory (pp. 19-14). San Francisco: Jossey-Bass.

Coombs, P. H. (1961, september). International education exchange: A work for many hands. Higher Education, 18, $3-6$.

Culha, M. U. (1974). Needs and satisfactions of foreign students at the University of Minnesota (Docotral dissertation, University of Minnesota, 1974). Dissertation Abstracts International, 35, 4141.

Daigle, S. (1981, May). Student needs and priorities survey, 1981 summary of findings. Domingues Hills: California State University.

Daigle, S. (1989). Student needs and priorities survey. Fresno: California State University.

Dawis, R. V., England, G. W., \& Lofquist, L. H. (1964). 슬 theory of work adjustment. Minneapolis: Minneapolis University, Industrial Relation Center, (ERIC Document Production Service No. ED 018 590)

Delene, L., \& Bunda, M. A. (1991, July 16-79). The assessment of service quality in higher education. paper presented at the International Conference on Assessing Quality in Higher Education, Bath, England.

Deressa, B. , \& Beavers, I. (1988). Needs assessment of international students in a college of home economics. Educational Research Quarterly, 12(2), 51-55.

DeRoche, E. (1981). An administrator's guide for evaluation programs and personnel. Boston: Allyn \& Bacon.

De Weert, E. (1990). A macro-analysis of quality assessment in higher education. Higher Education, $19(1), 57-72$.

Dillman, D. (1978). Mail and telephone survey: A total design method. New York: John Wiley \& Sons.

Eberhard, w. (1970, Spring). Problems of students returning to Asia. International Education and Cultural Exchange, $\underline{5}, 41-50$. 
Eid, M. T., \& Jordan-Domschot, T. (1989). Needs assessment of international students at Eastern oregon state College: An evaluative report. LaGrande, OR: Eastern oregon state College. (ERIC Document Reproduction Service No. ED 326 098)

Ewell, P. (1988). Outcomes, assessment and academic improvement: In search of usable knowledge. In $\mathrm{J}$. Smart (Ed.), Higher education: Handbook of theory and research (pp. 53-108). New York: Agathon Press.

Farber, S. (1987, February 12-15). The diversity of student needs in higher education. Position paper presented at the annual meeting of the California Association for Counseling and Development, Los Angeles, CA.

Gilbert, S., \& Evers, F. (1989). Accessibility and quality in higher education. Service Industries Journal, $9(4)$, $44-62$.

Greenbaun, T. (1989). The practical handbook and quide to focus groups. Lexington, MA: Lexington Books.

Harcleroad, F. (1980). The context of academic program evaluation. New Directions for Institutional Research \#27, $2(3), 1-20$.

Hayes, T., \& Tatham, C. (1989). Focus group interview: A reader (2nd ed.). Chicago: AMA.

Hinchberger, B. (1990, July 11). Brazil's University of Sao Paulo strives to restore quality in undergraduate education. Chronicle of Hiqher Education, 36(43), A31.

Hoaglin, D. (1982). Data for decisions: Information strategies for policymakers. Cambridge, MA: Abt Books.

Holland, J. (1985). Making vocational choices: A theory of vocational personalities and work environments. Englewood cliffs, NJ: Prentice-Hall.

Iyake, M., \& Mendelsohn, D. (1986, November). Student needs: Cognitive as well as communicative. TESI Canada Journal, 1, 171-83.

James, E., Alsalam, N., Conaty, J., \& To, D. (1989, May). College quality and future earnings: Where should you send your child to college. AEA Papers and Proceedings, pp. 247-252. 
Jenkins, H. (1983). Educating students from other nations. San Francisco: Jossey-Bass.

Kincaid, H. V. (1951). A preliminary study of the goals and problems of the foreign students in the United States. Menlo Park, CA: Stanford Research Institute.

Kitabchi, G., \& Benjamin, K. (1984, October 24-26). Factor analysis of evening student needs: Implications for planning. A paper presented at the annual conference of the Southern Association for Institutional Research, Little Rock, AR.

Kotler, P., \& Armstrong, G. (1989). Principles of marketing ( 4 th ed). Englewood cliffs, NJ: Prentice Hall.

Langer, J. (1978, September 8). Clients, check qualitative researcher's personal traits to get more; quality researchers, enter entire marketing process to give more. Marketing News, 12, 10-11.

Lee, M., Abd-Ella, M., \& Burks, L. (1981). Needs of foreign students from developing nations at U.S. colleges and universities. Washington, DC: NAFSA.

Leslie, L., \& Conrad, C. (1986, winter). Higher education in the 1980s: Examining the conventional wisdom. College Board Review, (138), 12-17, 30-31.

Mackson, C. J. (1975, May). What do foreign graduates think about their U.S. degree programs? Engineering Education, 66, 830-831.

Madaus, G., Stufflebeam, D., \& Scriven, M. (1983). Program evaluation: A historical overview. Evaluation models, viewpoints on educational and human services evaluation. Boston: Kluwer-Nijhoff Publishing.

Masciocchi, J. (1990). Job satisfaction of classified employees in a public suburban school district. Ed.D. Dissertation. Portland State University.

McMillen, L. (1991, February 6). To boost quality and cut costs, oregon state University adopts a customeroriented approach to campus services. The chronicle of Higher Education, 37(21), A27-28. 
Molla, B., \& Sedlacek, W. (1989). International student self-appraisal and institutional exp ectations. College Park, Maryland University, MD: Maryland University, \#23-89. (ERIC Document Reproduction Service No. ED 323 881)

Moock, P., \& Jamison, D. (1988, March). Educational development in sub-saharan Africa. Finance and Development, pp. 22-24.

Moore, F. G. (1965). The collegiate environment: The experience and relations of foreign students, government-sponsored and self sponsored. Preliminary draft for Bureau of Social Science Research Meeting of oct. $13-17$.

Munitz, B., \& Wright, D. (1980). Institutional approaches to academic program evaluation. New Direction for Institutional Research \#27, $\underline{7}(3), 21-42$.

Pascarelle, E., \& Terenzini, P. (1991). How college affects students, findings and insights from twenty years of research. San Francisco: Jossey-Bass.

Patton, M (1975). Alternative evaluation research paradigm. North Dakota Study Group on Evaluation. Grand Forks, NY: Rockefeller Bros. Fund. (ERIC Document Reproduction Service No. ED 127 275)

Popham, J. (1988). Educational evaluation. Englewood cliffs, NJ: Prentice Hall.

Press, I., \& Garvey, K. (1991, February). Satisfied patients can spell financial well-being. Healthcare Financial Management, $\underline{45}(2), 34-42$.

Raizen, S., \& Rossi, P. (Eds.) (1981). Program evaluation in education: When? How? To what ends? Washington, DC: National Academy Press.

Rising, M. N., \& Copp, B. M. (1968). Adjustment experiences of non-immigrant foreign stirdents at the University of Rochester: 1967-68. Rochester, NY: Rochester University. (ERIC Document Reproduction Service No. ED 062 902)

Rossi, P., \& Wright, R. (1976). Evaluation research: An assessment theory, practice and politics. Evaluation ouarterly, 1(1), 5-52.

Sanders, I. T., \& Ward, J. G. (1970). Bridges to understanding. New York: McGraw-Hill. 
Schliessmann, M. (1986, November 13-16). The ethics of western rhetoric as a basis for teaching foreign students. A paper presented at the annual meeting of the Speech Communication Association, 72nd, Chicago, IL.

Schlossberg, H. (1991, February 4). U.S. firms: Quality is the way to satisfy. Marketing News, $\underline{25}(3), 1,8$.

Scriven, M (1967). Methodology of evaluation. In R. Tylex \& R. Gagne (Eds.), Perspective of curriculum evaluation (pp. 39-83). Chicago, IL: Rand McNally.

Spaulding, S., \& Flack, M. J., Tate, S., Mahon, P., \& Marshall, c. (1976). The world's students in the united states: A review and evaluation of research of foreign students. New York: Praeger.

Stewart, D. (1990). Focus groups: Theory and practice. Newberry Park, CA: Sage Publications.

Stufflebeam, D. (1983). The CIPP Model for program evaluation. Evaluation models, viewpoints on educational and human services evaluation. Boston: Kluwer-Nijhoff Publishing.

SYSTAT. (1992). System for Statistics computer software package. Ivanston, IL: SYSTAT, Inc.

Taynan, C., \& Drayton, J. (1988). Conducting focus groups, a guide for first-time users. In $T$. Hayes \& $C$. Tathum (Eds.), Focus groups: A reader (pp. 30-34). Chicago, IL: AMA.

Walter, J. H. (1978). Counseling appropriateness: An exploration from a cross-cultural perspective. A paper presented at the speech Communication Association Summer Conference on Intercultural communication, Tampa, FL. (ERIC Document Reproduction Service No. ED 159751 )

Wang, C. (1993). Friendship patterns of Chinese students and their adjustment in the United States (Doctoral dissertation, Portland State University, 1993). Dissertation Abstracts International, 54, 0846 .

Weiler, H. (1984, May). The political dilemmas of foreign studies. Comparative Education Review, 28, (2), 168-79.

Weisberg, H., Krosnick, J., \& Bowen, B. (1989). An introduction to survey research and data analysis. Boston: Scott, Foresman and company. 
Worthen, B., \& Sanders, J. (1987). Educational evaluation: Alternative approaches and practical guidelines. White Plains, NY: Longman.

Zeithaml, V., Parasuraman, A., \& Berry, L. (1990). Delivering quality service: Balancing customer perceptions and expectations. New York: Free Press. 
APPENDIX A

SURVEY INSTRUMENTS 


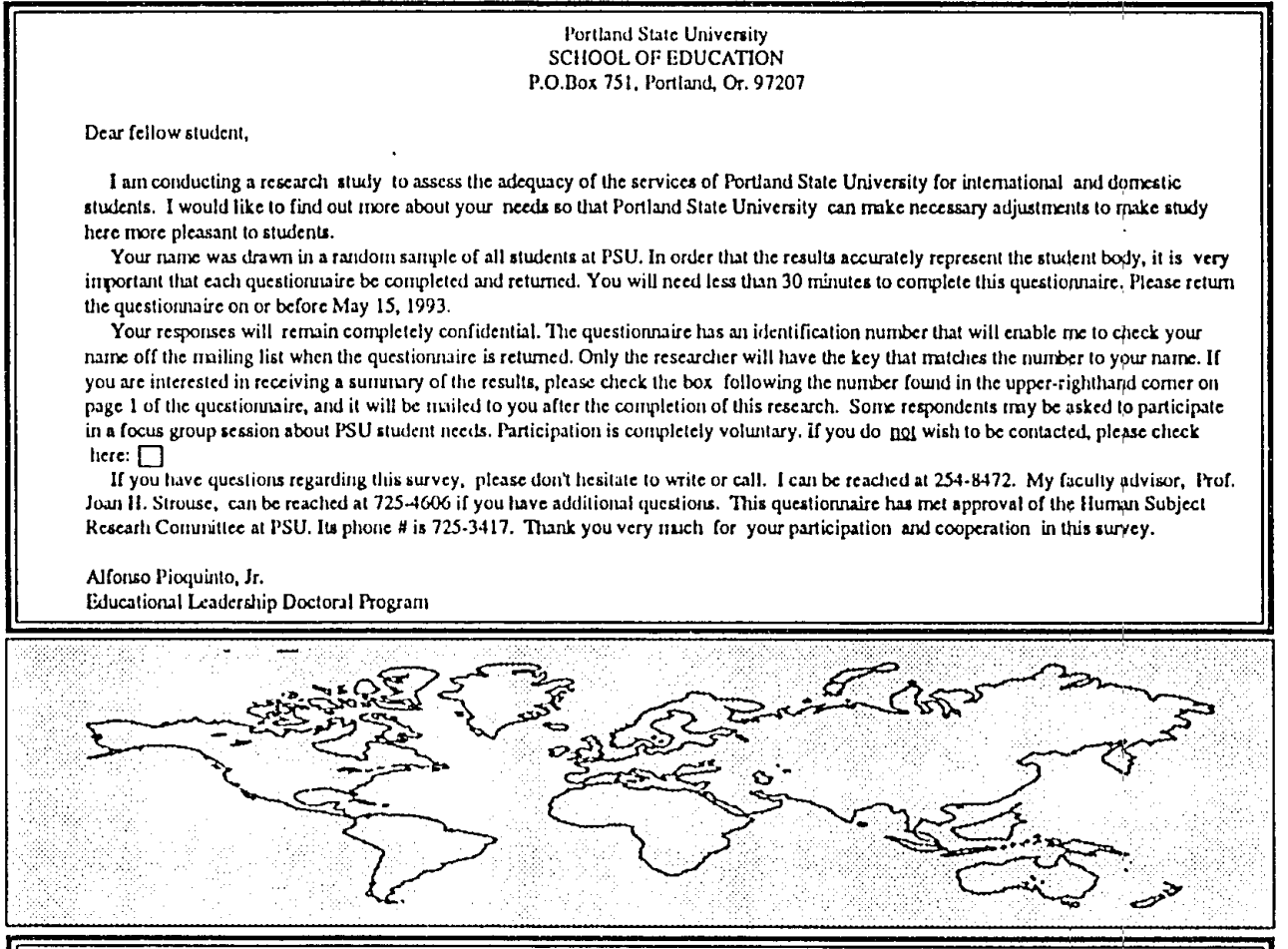

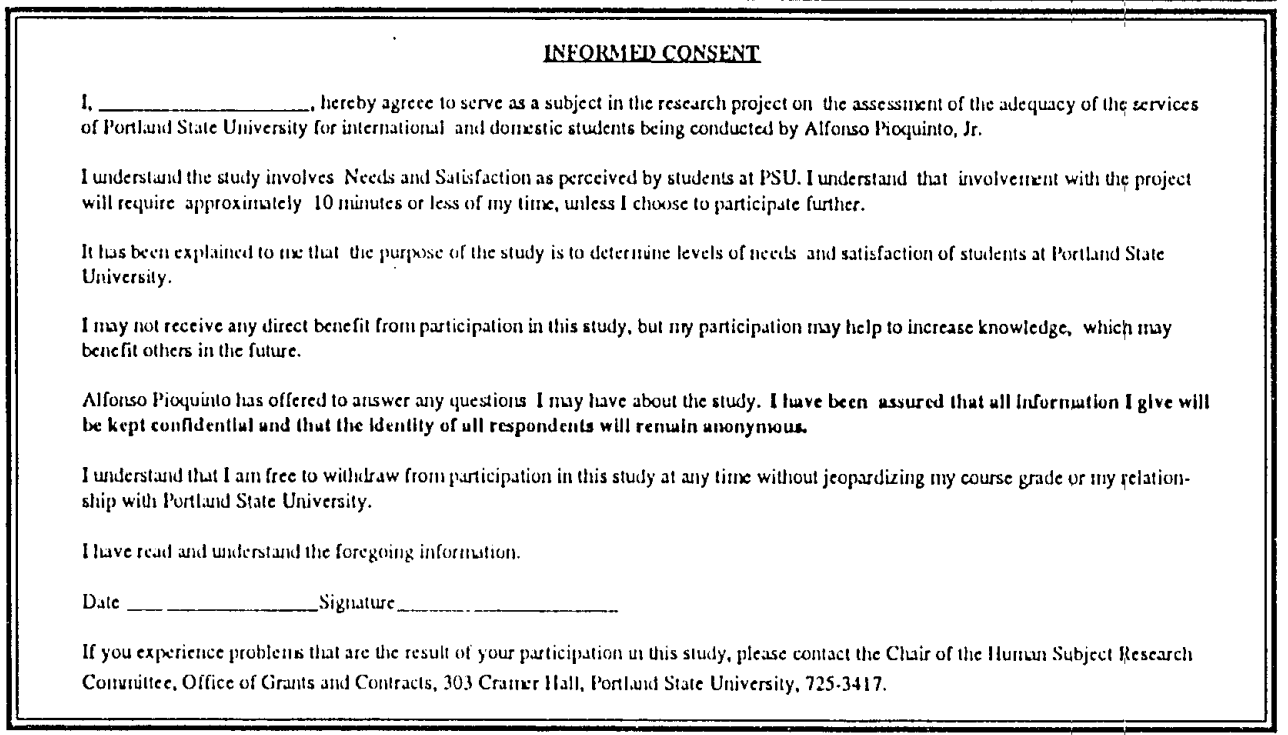


Backyround Information No.

1. Please indicate if you are a

Q1 U.S. citizen or permanent resident

Q2 foreign student, comhtry

2. Your sex (gender)

$$
\text { al inale an itrale }
$$

3. Your field of study

al Business Administration

an rivation

O3 Engineering \& Applied Sciences

of Fine \& Performing Atts

at Healuh \& Physical Education

OG Litxral Arts i Sciendes

Q7 Sucial Work

Qs Urban \& P'ublic AIfairs

Des Ollers, specify

4. How long you've been:

4.1 in the 1.5

4.2 At PSU

years _monthu

_years _ month

5. Your age al your last birthday

$$
\text { -years }
$$

6. Your academic leve

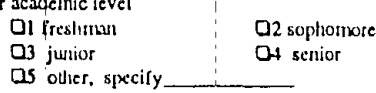

7. Your unrital status

Ql uingle

Q2 nurried (spouse not with you)

03 married (spouse withyou)

at other, specify

8. Your maipl source of funancial support for colle ge education (select the qource that provides you with the Inost support)

O pelf supporting

Q2 funily assistance

Q3 joan

Ot scholarship

as other, please specify

9. While altending PSU, are you tiving
DI by yoursel?
Q2 with friends?

Q3 wilh your fantuly?

QH otber, specify

10. Your living quarters

OI dom (stutetil housing) 02 house

$\mathrm{O}$ apartixent

Q4 oller, specify.

11. Your peseeption of your parenit's status

$$
\text { Ol wealthyclass | } 02 \text { lower class }
$$

al wealthy class

Q2 lowerclass

How do you go to seliool?

Ol bycis

Q2 walk

Q3 by bus

마 other, specify

13. Do you oнn a car?

$$
\text { al yes }
$$

14. How well do you understand written English?

O1 very well 02 good $a$ fair

다 poor

15. Your present G.P.A

16. How many hours (average) per week do you spend studying?

Q1 less ulan 5 hours of 5-12 hre. D3 over 12 hrs.

17. How nany hours (average) a week do you work if you are currenily enployed?

O1 less than 10 hrs. Q2 10.20 hrs Q3 over 20 hrs.

18. What is your religion at home?

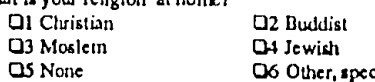

as None 060 Other, specify

19. Have your religious beliefs and/or practices changed sjgnificantly since coming to PSU

Oino

$$
\text { Q2yes }
$$

If yes, to what?

20. Did you altend the Student Orientation at Portland Stale University?

Ql yes

Q2 no

21. Did you allend olter U.S. higher education institutions before allending P.S.U.?

Ol yes

Q2 no

22. Do you plan to stay permanenlly in the United States?

Ol yes, I plan to $\quad \mathrm{Q} 2$ no

a) yes, but I cant of other

23. Which of the following is the most inportant reason why you selected the U.S as the place to study. Check one only. (skip if you ase NOT a foreign studert)

Dl repulation or prestige of the United Stales

Q2 plan of staying perninnenlly in the U.S.

Q3 leam more about the United States

Of learn nore about the U.S. system of education

as gain specialized skills and knowledge of ny field

Do inproving my English language skills

Q7 Other reasons, specify

24. Why did you choose Portland State University the place 10 study. Geck only one.

OI Ive been here before 02 I know a person here

03 good facilities

OS location

Of reputation

Oo degrec offerings

How did you learn about Portland Stale University? Cueck one.

O1 from fastily nectubers Q2 from printed naterials

Q3 froml frieriós Of fromteschers/counselon

as educational agencies $\quad 06$ other, specify

26. What is the biggest problem you'e having now? Check one

Ol l'm not having any problens $\mathrm{O} 2$ (inaseial problerm

Q3 language or comsuntication $\quad$ Of loneliness

$\begin{array}{ll}\text { Q3 language or corrunanication } & \text { OA loneliness } \\ 05 \text { cultural differences } & 06 \text { acale nuic }\end{array}$

07 ollier, specify__ difliculty 


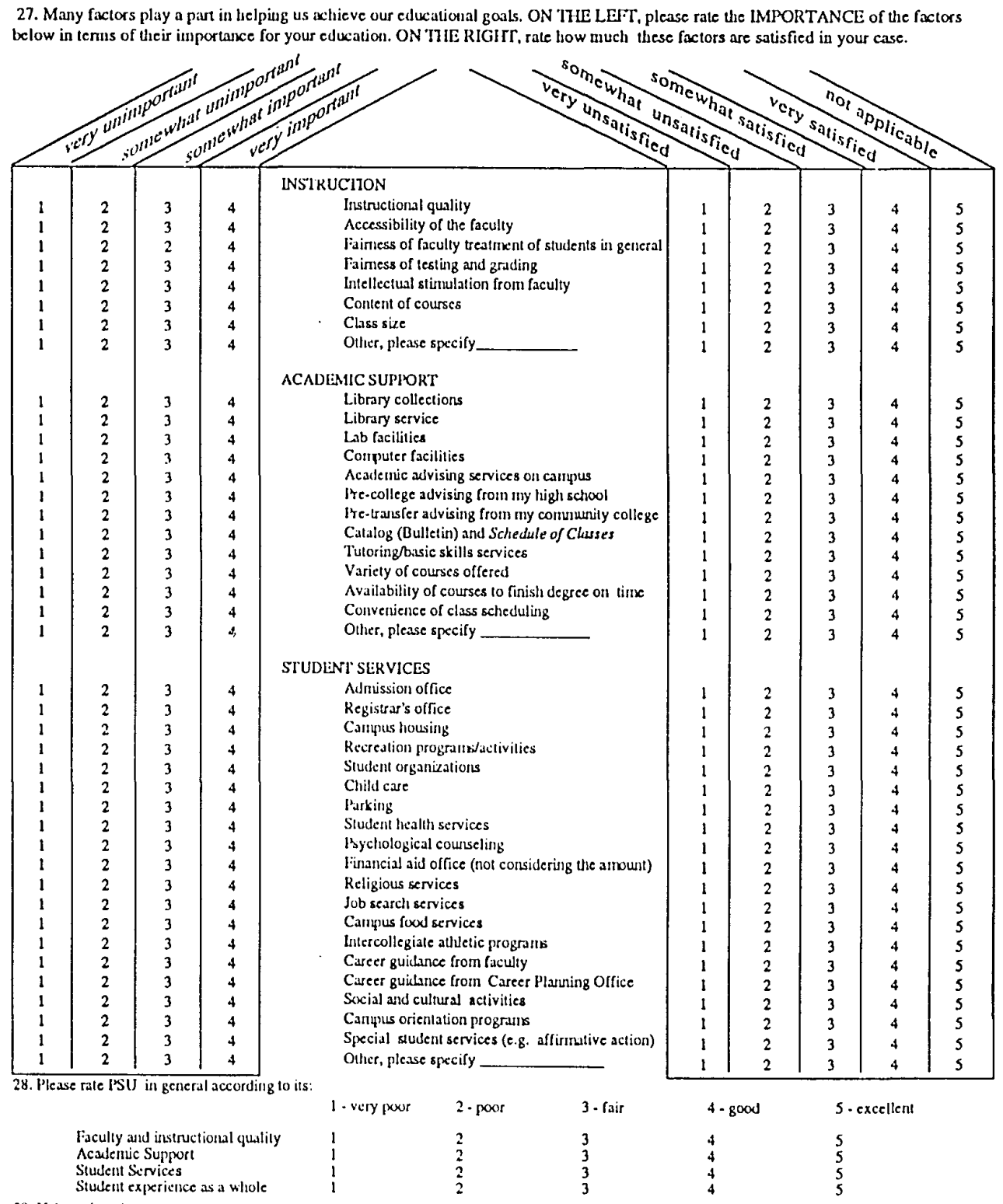

29. If the university could chunge two things that would introve the quality of your life as a student at HSU, what would those be?

30. Is there anything else you would like to say about your stay at P'ortland Stale University? 


\title{
$\therefore \quad$ Focus Group Participation \\ in Assessment of the Adequacy of the Services of an Urban University \\ for International and U.S. Students: A Comparative Study
}

\author{
Informed Consent Form \\ September 21, 1993
}

\section{I} , agree to take part in this research project on "Assessment of the Adequacy of the Services of an Urban University for International and U.S. Students: A Comparative Study" at Portland State University.

I understand that the study involves a focus group interview session, during which I will participate in a discussion of the quality services at Portland State University.

I understand that because of this study, I will have to come to Portland State University during a week night and take time away from other activities to participate in the group discussion.

Alfonso Pioquinto, Jr. has told me that the purpose of this study is to collect and analyze student impressions, experiences, and degree of satisfactions about services at PSU and that this information will be used as part of the university's on-going effort to find out more about its students and how best to serve their needs.

I may not receive any direct benefit from taking pat in this study. But, the study may help to increase knowledge that will help others in the future.

Alfonso Pioquinto, Jr. has agreed to ariswer any questions I may have about the study and what I am expected to do.

He promised that all the information I give will be kept confidential to the extent permitted by law, and that the names of all persons included in the study will remain confidential.

I understand that I do not have to participate in this study, and that my willingness or unwillingness to participate will not affect my relationship with Portland State University, as a student or an employee.

I have read and understood the above information and agree to take part in the study.

Date: Signature:

If you have concerns or questions about this study, please contact the Chair of the Human Subjects Research Review Committee, Office of Research and Sponsored Profects, 105 Neuberger Hall, Portland State University, 503/725-3417. 
APPENDIX B

LETTERS 


\section{THE CALIFORNIA STATE UNIVERSITY}

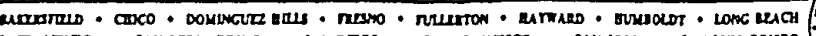

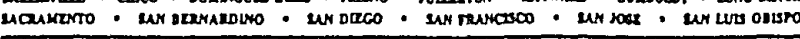

OTICE OF THE CHANCELLOR

Tustrone.

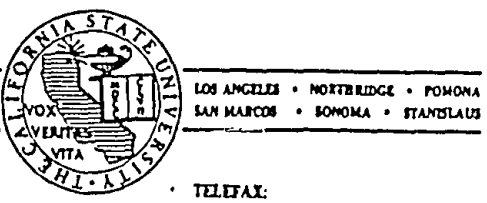

October 3I, 1991

Alfonso Pioquinto, Ir.

$4537 \mathrm{NE} 82 \mathrm{nd}$ Avenue

Portland, on 97220

Dear Mr. Pioquinto:

Thank you for your letter of October 22, 1991. You may use any of the items from the student Needs and Priority Survey

for your research. The only request that the CSU would make is that you acknowledge the source of the item either in the text of your final report and/or appropriate footnotes.

You may find that the book by Arnold Groveman, Urban State Universities useful, as well as the Urban University in America, by Maurice Berube. An article by Kinnick and Ricks in the Fall 1990 issue of Research and Higher Education helpful as well.

Good luck with your studies.

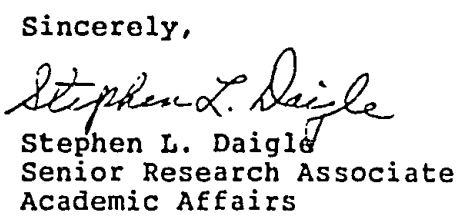

SLD $: \mathrm{dh}$ 


\section{OFFICE OF GRANTS AND CONTRACTS}

DATE: $\quad$ March 10,1993

TO: $\quad$ Alfonso Pioquinto 4537 NE 82nd Ave Portland, OR. 97220

FROM: Martha Balshem, Chair, HSRRC 92-93 Manthen Bulshem/Af

RE: $\quad$ The revised copy of your research questionnaire

Thank you for sending us a revised copy of the questionnaire for your study entitled: "An Assessment of the Adequacy of the Services of an Urban Public University for International and Domestic Students: A: Comparative Study".

The Committee is satisfied that your provisions for protecting the rights and welfare of all subjects participating in the research are adequate. 


\section{APPENDIX C}

COMMENTS FROM OPEN-ENDED QUESTIONS 


\author{
COMMENTS \\ (from open-ended questions) \\ INTERNATIONAL STUDENTS \\ (Instructional Quality)
}

Teaching assistants are helpful. Writing Lab is beneficial to all students. (Singapore)

Fair treatment for students, more classes. (Japan)

[Improve] the students' behavior and the teachers' behavior. (Jordan)

Hiring more qualified faculty members. Looks like the faculty isn't interested in quality of education.

(Permanent resident)

Sometimes I feel [PSU is] not fair to international students and residents. Also, we can't work off-campus. (Japan)

Better teaching staff/Less financial pressure on students. The big thing I missed being at PSU is not feeling the "campus" life. It's so much like city life. (Bangladesh) I transferred from a private school to PSU because of the variety of courses offered but I was disappointed with too many students in one class! Please raise tuition rates like private school and make class size smaller. It's important for the quality of education. "Education" should not be cheap.

\title{
Attitude of Instructors
}

Increase instructor (except professor) quality: TAs hired for lower-level classes have been incapable of performing their jobs.

Choose better instructors.

Improve the quality of instructors--change to a new way of teaching each term.

Please ask PSU's instructors to smile more often (all of them).

Choose good instructors. (Japan)

Take student complaints into consideration, treat students equally. PSU is a good university, but some instructors are not fair, therefore degrading the reputation of the school in general. 
Instructors should understand more about the difficulties of the foreign students!

Improve faculty quality

[Improve] ISS (International Student Services) - [do something about] the unkindness, and their ineffective work. I hate to go there, but sometimes I have to. (Korea)

Instructional quality and fairness of testing and grading [could be improved]. Instructors in my department are not very helpful in giving encouragement and guidance to students, such as career advising. ISome of them just want to get paid. They missed the whole purpose of teaching, they should not teach in school. Hire more history professors.

Faculty should take time to talk to us, [so should] advisers. PSU should encourage job search/placement. I enjoyed every minute of it! (Malaysia)

\section{AMERICAN STUDENTS}

(Instructional Quality)

Better faculty treatment of students, more time to spend in classrooms.

Smaller classes, somehow convince students to become more involved in college.

1) Clarify academic requirements.

2) Hire teachers who want to teach, not those who just want to do research!!! This school could be good, but I graduate with a bitter taste in my mouth. The administration is to blame for running students in circles about degree requirements, financial aid, academic and career advising, etc., and having questionable priorities.

[Change] the type of testing (exams) and senior audit. overall it was a good experience for me.

Some of the teachers are "out of control," in that they pick favorites. In a writing class I took, the teacher had already decided my grade before I handed in my portfolio. I enjoyed Portland state, since it's very liberal and I feel I can do what I want.

1) Somehow draw the focus [away] from the grade-earning emphasis. This detracts from the quality of learning. 
2) Increase use of the essay in all classes as this will be primary way of working when leaving the university within my major or department (anthropology).

Go back to straight $A-F$ grading, not +-

Make professors treat students as grown-up, experienced adults, no matter what age they are. Some SBA professors seem like they are simply there for the paycheck alone.

The majority of the instructors are liberal and convey their personal (misguided) ideas much too often during class time.

More instructors in the department.

More instructors for smaller classes, better instructorstudent relations.

I've had some wonderful instructors and a few not so great.

Restructuring of instructor evaluation [system].

Better instructors.

I will comment that I have also met and been involved with a number of very supportive and knowledgeable instructors and employees.

Overall, I enjoyed PSU and like my instructors.

The instructional quality and support to me as a student is exemplary. If all departments at PSU were of this caliber, the university would be top-notch, even in the face of large budget cuts.

Drop athletics and get more instructors.l

Younger faculty.

Do away with tenure.

There should be some sort of department review of teacher ability. Maybe sit in on classes. Some teachers are unable to express thoughts clearly.

Faculty is very bad.

Professors need to be able to say, "if you can't keep up in this class, I will talk to you outside of class, or maybe you need to take another class." Instead, they waste time and bring the whole class down. 


\section{INTERNATIONAL STUDENTS}

(Academic Support)

[Improve] lab facilities, especially electrical engineering lab.

24-hour library and computer lab service. No more budget cuts. There is little communication between international students and native people or students. It is very important to understand each other, different culture and society. (Japan)

Rationalize admissions and registration. Improve Arabic language section. I have enjoyed meeting and studying with the Middle East Studies faculty a lot. (Sweden)

[Improve] availability of classes. It is ok for now. (Malaysia)

Please do something with the Admission office! They are so slow and rude, so is the Iss office!! There's a big difference between different majors [for] students. Some departments are very bad, but some are good. Generally, faculty in the Linguistics department is excellent, but SP department is terrible! (Japan)

1) Extend open hours of the library.

2) Increase amount of recreation activities. I have very little feeling of belonging to PSU. I think there should be something done to unite the whole college closer together. (Hong Kong)

Academic Advising Services/Administration

[We need an] academic international student advisor (Oman)

1) Understanding challenges faced by international students, American students

2) Sensitivity classes for teachers. There is some bias among many teachers in things like expectations, values

(labs) and grading!!! (Saudi Arabia)

Have more classes available. (Malaysia)

1) More variety of classes.

1) Offer classes at different times.

The fact that the tuition increases every year is not a pleasant event for the student. (Greece)

Open the main gym more often, open the library longer. I like my dorm (West Hall). (Indonesia) 
Library collections should be completed more. Tutoring services should be offered more for international students. (Japan)

Longer library hours. (Japan)

Library should be open for a longer time, even in summer. Compare [it to the] library of other universities in oregon?

1) Try to make the calendar (bulletin) more readable, especially on degree requirements.

2) Have more people working in registration windows. The PSU faculty is extremely knowledgeable and people are friendly. (Hong Kong)

If the library becomes open for 24 hours, it might be better. (Japan)

More student activity and tutoring, library and computer room should be opened 24 hours. (Japan)

[Increased] availability of courses.

offer a variety of courses and more convenient class scheduling.

More experienced teachers and good lab assistants. In my field (Electrical Engineering) practical work is very important. Although we have labs with every EE course, I am not gaining anything from it. Right now $I$ feel that passing the course is more important than to learn something from the departments" perspective.

Academic advice/availability of courses. If I wasn't so far into my education here I would leave! The system as a whole for transferring classes from different schools is pathetic!

I think we need more courses in each department and a wider variety of courses.

[Improve] variety of courses, services and convenience of class scheduling.

1) Academic advising.

2) Tutoring, especially for international students.

[Improve] academic advising on campus. (Thailand)

1) Offer more classes ([especially in] Engineering).

2) Lower tuition. 
I like the school. However, PSU should restart its Persian studies [program], which was stopped in 1979. (Permanent resident).

AMERICAN STUDENTS

(Academic Support)

Simplify paperwork (not classwork): forms, applications, etc. Better student and academic advising. As a student I often feel that behind-the-scenes people (not faculty) forget that we are the reason they are there and that old procedures do not always work in the students' best interest. I often feel like there are many different agendas that each office and department are working toward but not necessarily to the same end goal. Observation--the old stereotypes about state workers hold very true to a number of employees at PSU: "that's not my department," "I cannot do that," "Proper procedures are . . ." and so on.

Greater variety of classes.

Not offer grades for Juniors/Seniors, but evaluations. A different computer system at the library. I have found the faculty quite accessible and supportive!

offer more classes in Arts and Letters and Ethnic studies.

I think they need to offer more help in choosing a career and helping you to take the classes necessary for a degree in that field. I do not feel as if the school has helped me get through any faster or easier. The thing that has helped me the most has been talking to people who have already been through it.

Reduce class sizes, have more lines available for registration. Paying more for less has made life miserable.

1) Better and easier advising.

2) Help foster social ties among students.

Smaller classes to encourage more working together, thus increasing interest and knowledge.

Parking is not fun, too expensive.

[Improve] academic advising, need to teach and match teacher's assistants more closely, especially Math TAs.

Academic advising [needs to improve] in accessibility and willingness to support its students; willingness to aid students in goals toward graduating. While I think most of 
the professors are from fair to good, I believe they would be better with more support from the management.

More teachers with smaller class sizes and more student housing of better quality. Try and make it a more socially interactive campus, [it's] too much a commuter campus.

More classes offered, especially those in a sequence. Tenure should be abolished. Most of my bad teachers had tenure. My professors in my major (Business Administration) were very knowledgeable and helpful.

[Improve] student advising, and [add] earlier and later library hours. Most classes are too easy, not enough work required.

Better academic advising/smaller classes. It is very impersonal.

More diversity of courses.

Good school, would hate to see it disappear from use.

Needs more money for more variety, options, of courses.

Offer more courses during the day, so that schedules are not so difficult to figure out. Offer classes more often, instead of just once a year as many courses are.

Better advising (not just affirming my course choices). More up-to-date library books. I am concerned about the quality of my education. If I am not being paranoid, I would like to know what to expect from PSU's financial cutbacks.

[Improve] availability of courses.

[Lengthen] library's open time.

More individual academic support, more student services, counseling when needed.

clarify admissions requirements--cut out excess programs unrelated to study. I don't enjoy trying to interpret the PSU handbook/catalog.

More night classes, especially upper division. Terrific "on-line" class registration system and parking permit system.

Standardize work required for classes and grading policies. cut athletic program and put that money in education. 
Remove admissions director and increase number of employees in Registrar's office. I think the upper administration is a farce. The choice of Provost after so many good and better-qualified candidates is a prime example of PSU's resistance to change. Grow up PSU!

Make it a requirement to see an advisor every term.

Classes fill up too fast.

Teach students to read, write and use computers for the 21st Century. overall, I feel that PSU is adequate for my needs, but for some students with less direction I think PSU could improve its efficiency in teaching the above subjects!

A more open academic advising services and more class times available.

Advising system, notification through mail of student services. I'm just glad it's almost over.

I can't think of anything except long lines. As an incoming freshman, I was overwhelmed at the class choices. No one actually helps you, you have to know what to take.

Better academic advising services ([more] accessible)

[Improve] academic support/advising

A little more flexibility in ways of finishing my degree program.

University requirement, grades removed, more professional advising.

1) Make it easier to find out needed information

2) More classes offered at various at various times, [improve] services.

More creative classes, i.e., photography, intro to painting, sculpting.

\section{INTERNATIONAL STUDENTS}

(Student Services)

More campus life and make study more enjoyable (Hong Kong)

Parking, class offerings, have more modem services at the computer service. 
[Improve] Admission, administration. Professors are great in some departments. (Taiwan)

More organized in Admission office! (France)

More extra-curricular activities, creativity in teaching. [ I am ] very happy. I think we should all have a better

attitude about the school as a whole. (Hong Kong)

Admissions office and Admissions office people and systems. All in all it's a good university.: (Japan)

Improve the Admissions service staff's efficiency, provide more accessibility to facilities. PSU does not really give me a sense of school.

[Improve] housing, student services. (Taiwan)

[Better] campus food services.

I am glad for the formation of a multicultural center. But

I am sad about the cafeteria food and its services.

Improve housing and food services.

Campus food services [need improvement].

[Improve] food service.

Food service, times. I couldn't see anything about PSU and I don't need to find that kind of thing about PSU because I want to finish my study as fast as/possible. (Korea)

[Improve] food. Classrooms that don't have windows are too bad. (Japan)

[Improve] cafeteria (menu) and quality of food. (Japan)

\section{AMERICAN STUDENTS}

(student services)

Creative computer use. I like the phone registration. overall I'm enjoying my experience।at PSU.

Have admissions, financial aid and /registrar communicate more with each other. If a student is unsure about a major it's hard to find an advisor.

More classes with variety, solution to parking problem. Cooperate with students instead of fighting against them. Fix the money situation. This school is annoyingly cheap. 
It's over . . . for now. I may endure a PSU graduate program.

Make services known so I don't have to search for them, i.e., child care.

1) More awareness that services are offered.

2) One week prior to final exam have no assignments due. For a school that has so much potential to network with other students (since many students work) there is not much cohesiveness in student organizations. The layout of the campus is divisive and doesn't promote blend of different students to be together.

Get more organized (i.e., financial aid, registrar). Parking - more available, more areas to sit and study, eat or meet friends, etc.

Create more parking, reorganize baseball program.

Offer financial aid as PSU, somewhat like the $U$ of $W$ gives its students. [Improve] parking.

It's too bad things are changing now - after I am finished (Summer 93). But I am out before the big Measure 5 cuts. Those poor new students!

The financial aid office should get its act together and profs should have more office hours.

More staff-student interaction.

1) Allow more living organization (try to get rid of commuter school attitude).

2) [Would like to see] the support staff acting as though they care about the students (service oriented)

I found myself very young compared to the average students. This leaves different priorities and incerests, which causes social inequality. I know school is for education, but I believe part of education is learning how to feel socially ept.

1) Better support from advisors

2) Better cafeteria food.

It is very impersonal.

More extensive career planning, a larger breadth of class scheduling.

[Improve] registration process.

Faculty [should] have longer office hours and the career center [should] more actively help students get a job after graduation. I had a child my junior year in school - there 
is no childcare, not even for an hour, for babies and toddlers.

1) Provide one place to go find out graduation requirements.

2) Drop athletics and get more instructors.

overall I am very happy with the academic side (History

major) but I am very resentful that part of my tuition goes to student groups I do not support.

I have enjoyed it very much thus far.

More attendance at PSU's functions and dances, etc. It was good overall, but maybe there;s a need for more of a "college life" instead of a commuter school. It's hard to get involved when no one attends games or dances as a school.

Make sure no one cheats on the exams. Campus food services are very expensive.

Healthier, better food.

Religious services should be religious, not political.

More cheaper parking, less requirements.

[PSU] really needs to take a look at the requirements, especially with concern to graduation. Not everyone is good at math, and that shouldn't prevent someone from graduation.

Parking is a joke - $\$ 108$ per term is bad!

The school's extremely slow with paperwork, Nobody can ever answer academic questions, you're always just sent somewhere else.

Clarify who counselors are. Financial aid at PSU is a total mess, cannot count on anything. Again, I have at least two or three problems per semester with financial aid at PSU. I have had my forms lost at the PSU financial aid office. In the spring of 193 it cost me my financial aid for the term.

cut back on incidental fees and unnecessary student organizations, as above, and lobby for a sales tax to fund state schools.

[Shorter] registration lines.

Cheaper parking and more social events. If I could afford to leave, I would. 
New registration lines.

Less money spent on special student groups.

The amount of advising could be much better. Many times students do not get any advising at all.

2) Many students do not know about half of the college's

organizations. student activities are not promoted.

[Improve] student union, social facilities,

[PSU should] have better training for international students for jobs on campus--better communications skills.

[Improve] the advising system and the admission process for the School of Education. Overall, I am very satisfied with my education. Thank you!

Better quality of job training for student jobs (CWSP). Better orientation for international students so they can understand English.

Drop health requirement.

\section{INTERNATIONAL STUDENTS}

(Others)

Lower the international tuition. (China)

1) Reduce tuition.

2) Improve the teaching quality.

Fairly good. (China)

[Lower] tuition and [improve] academic support. I strongly would like PSU to reconsider about non-residents' tuition. (Japan)

Increase student awareness of PSU's general expenses, how much and where the expenses come from. Students can participate in PSU cost-cutting due to Measure 5. (Hong Kong)

Raising of tuition, parking [are] problems. (Japan)

1) [Lower] tuition fee.

2) Extended library opening hours. (Hong|Kong)

1) Deduct the tuition fees 35-1 [??]. At least to offer better services. I sometimes think that the school is 
materialistic, example: $\$ 5$ [charge] for a transcript, the high prices of the bookstore. (Jordan)

If I had another choice of a state university in Portland I'd transfer to it.

PSU gives a change to foreigners to study here. (Thailand)

More funding/more student participation and departmental support. I think this is not a very suitable place for many foreign students. I think it lacks interest in them for the most part except for their money. (Brazil)

Lower the tuition fees, and [provide] more middle-class housing and apartments. Improve your quality. $ᄑ$ want to graduate as soon as possible. (Indonesia)

Lower tuition fees and make it easier for Freshmen to get a class. So far so good! (Indonesia)

First, tuition is killing me as a foreign student! second, I wish I did not have to wait a whole year to take certain classes. The international student services has been doing an excellent job. (Nigeria)

I know we international students don't pay tax, so that tuition is high. However, it's too high. I'm sure there are lots of people who can't help giving up on graduating because of tuition. Maybe it will happen to me the year after next. Some people may be wealthy, but not all the people. (Japan)

More funding, more funding, more funding. Very disappointing. (Norway)

Lower the tuition.

1) Lower the international student tuition.

2) Change the international student advisor. (Pakistan)

[Lower] tuition. (Japan)

I hope they do not increase tuition in near future. (Korea)

Cut the tuition fee for international students and decrease some requirements. Admissions office doesn't give clear guidance or explanation to the new student. (Indonesia)

International students' fee should be cheaper than it is.

Lower tuition for international|students. Budget cuts harm the quality of education. (Germany) 
[Better] organization and less change throughout the school year, I think. There is a lot of good at the institution but sometimes the frustration of dealing with the bad aspects makes things too difficult to deal with. (Bolivia)

More money for art department, less tuition. It seems to be a realistic cross-section of the Portland student population. I enjoy the diversity.

More availability in certain areas. PSU [needs] a tuition freeze. I met a lot of people who are fighting their way through school as an individual to improve themselves.

Quicker processing of tuition payments and send receipts ASAP .

Restore the cut programs.

\section{AMERICAN STUDENTS}

(Others)

Help the undergraduate students in choosing classes and rule out that mandatory 18 credits from three categories!

I've had a good experience so far, [but] it's not what I expected "college life" to be like--but that is because it's a commuter school. Unlike others, I have college life and my outside life as well.

Since I've been here a short period, I can't judge, but I don't feel the college is kept [up] enough.

Lower tuition.

[Improve?] The Vanguard, extra counseling for careers.

$+/$ - grading system removed, redirect money from athletics and student organizations to academics to compensate for Measure 5 losses.

Reverse Measure 5, lower tuition, less expensive textbooks.

[Increase] student loan amounts, tuition decrease, lowering textbook amounts.

Less money to special-interest organizations.

Provide a balanced political forum rather than a polarized liberal atmosphere. 
Measure 5 is a farce. Why does the legislature unnecessarily cut schools, police and fire departments when they know the people want them to cut limousines, administrators, fancy offices and all those social programs?

stop the bickering between faculty and administration. Repeal Measure 5. The honor program is great! so is the "Wei, Bitte" German program!

Lower costs, but [that's] wishful thinking. I have not been here very long, but so far I am satisfied.

Cheaper parking, tuition.

Stop releasing my class list and grades to my father throughout the term.

Switch to a semester system. Ban Greek and football cliques.

Tuition prices continue to rise.

Lower tuition.

I have found PSU to be very satisfactory, and I enjoyed my time here--no major problems so far.

Cheaper tuition.

It's been a wonderful experience. It's one I'll never forget!

Lower tuition. High amount of student financial aid that are not loans. 